\title{
Standard Systems Group (SSG) Technology Adoption Planning Workshop
}

Suzanne Garcia

Lorraine Nemeth-Adams

Jan Vargas

April 2004

SPECIAL REPORT

CMU/SEI-2004-SR-003 

= Carnegie Mellon

드 Software Engineering Institute

Pittsburgh, PA 15213-3890

\section{Standard Systems Group (SSG) Technology Adoption Planning Workshop}

CMU/SEI-2004-SR-003

Suzanne Garcia

Lorraine Nemeth-Adams

Jan Vargas

April 2004

Acquisition Support Program

Distribution limited by Standard Systems Group. 
This work is sponsored by the U.S. Department of Defense.

The Software Engineering Institute is a federally funded research and development center sponsored by the U.S. Department of Defense.

Copyright 2004 Carnegie Mellon University.

NO WARRANTY

THIS CARNEGIE MELLON UNIVERSITY AND SOFTWARE ENGINEERING INSTITUTE MATERIAL IS FURNISHED ON AN "AS-IS" BASIS. CARNEGIE MELLON UNIVERSITY MAKES NO WARRANTIES OF ANY KIND, EITHER EXPRESSED OR IMPLIED, AS TO ANY MATTER INCLUDING, BUT NOT LIMITED TO, WARRANTY OF FITNESS FOR PURPOSE OR MERCHANTABILITY, EXCLUSIVITY, OR RESULTS OBTAINED FROM USE OF THE MATERIAL. CARNEGIE MELLON UNIVERSITY DOES NOT MAKE ANY WARRANTY OF ANY KIND WITH RESPECT TO FREEDOM FROM PATENT, TRADEMARK, OR COPYRIGHT INFRINGEMENT.

Use of any trademarks in this report is not intended in any way to infringe on the rights of the trademark holder.

Internal use. Permission to reproduce this document and to prepare derivative works from this document for internal use is granted, provided the copyright and "No Warranty" statements are included with all reproductions and derivative works.

This work was created in the performance of Federal Government Contract Number F19628-00-C-0003 with Carnegie Mellon University for the operation of the Software Engineering Institute, a federally funded research and development center. The Government of the United States has a royalty-free government-purpose license to use, duplicate, or disclose the work, in whole or in part and in any manner, and to have or permit others to do so, for government purposes pursuant to the copyright license under the clause at 252.227-7013. 


\section{Table of Contents}

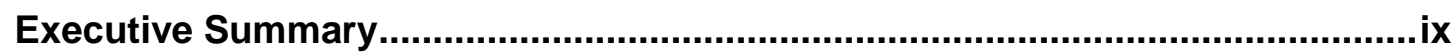

Abstract

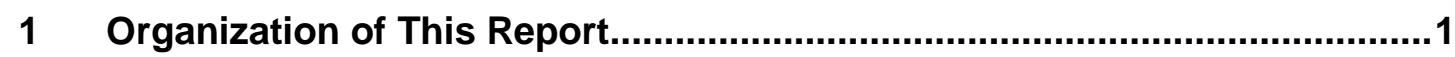

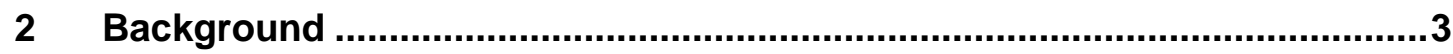

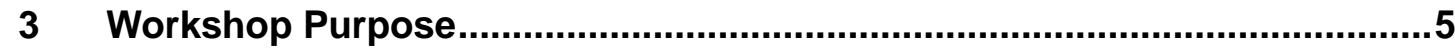

$4 \quad$ Workshop Goals and Desired Outcomes.....................................................

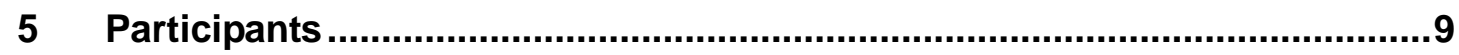

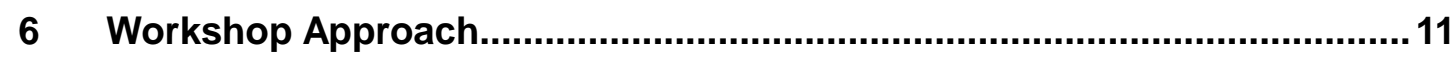

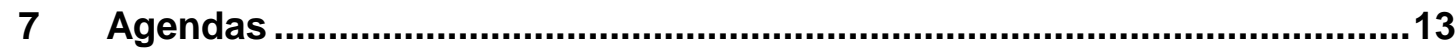

7.1.1 Rationale for Agenda Changes ..............................................17

8 Agenda Items for Day 1, October 27, 2003............................................19

8.1 Welcome and why the SEl is here ..................................................... 19

8.1.1 Desired Outcomes ............................................................... 19

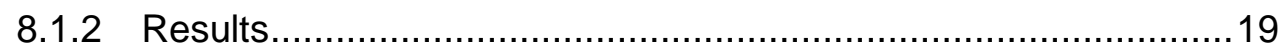

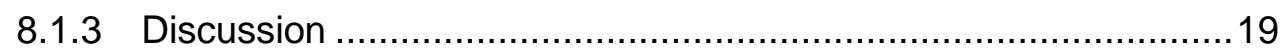

8.2 Agenda item "Introductions" ............................................................ 19

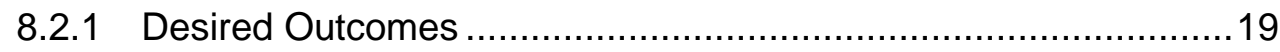

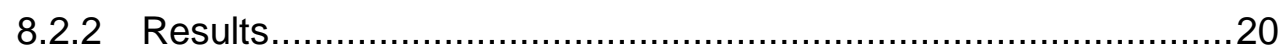

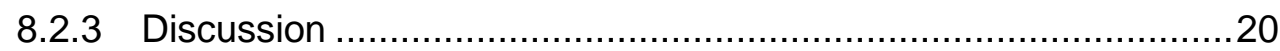

8.3 Agenda item "Review/Agree on workshop objectives" Summary .............20

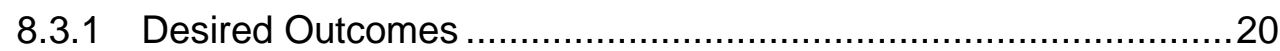

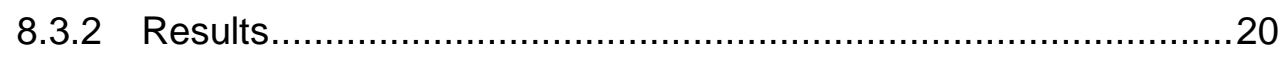

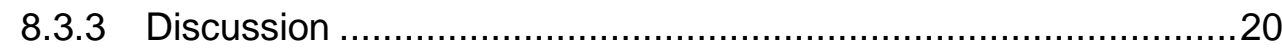

8.4 Gunter to provide review of SSG's strategic objectives .............................

8.4.1 Desired Outcomes ................................................................21

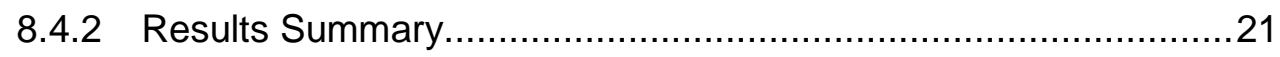




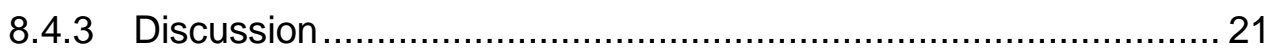

8.5 Review SEI work plan/connect to SSG objectives ................................. 21

8.5.1 Desired Outcomes............................................................... 21

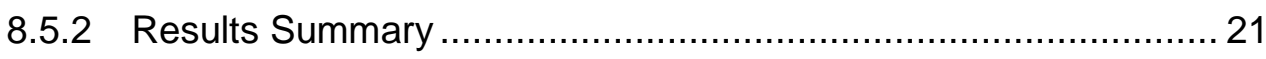

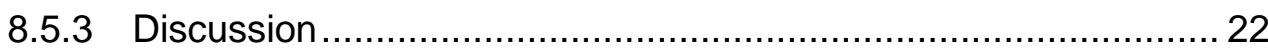

8.6 Create map of SSG's objectives/SEl connections ................................. 22

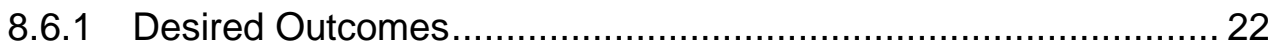

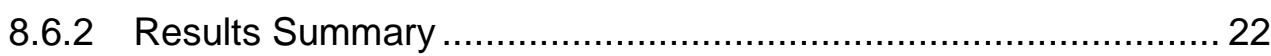

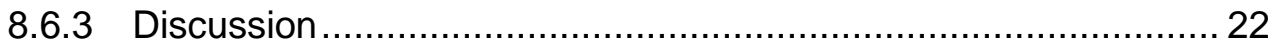

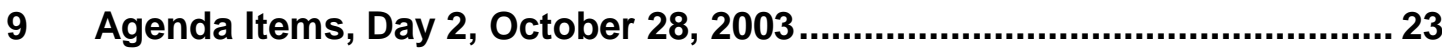

9.1 Review Day 1 work; revise as necessary ………….............................. 23

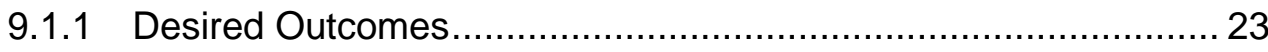

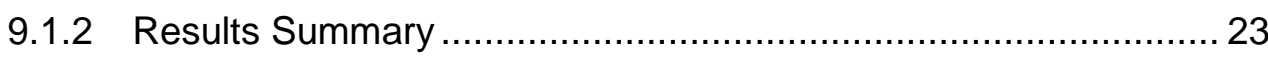

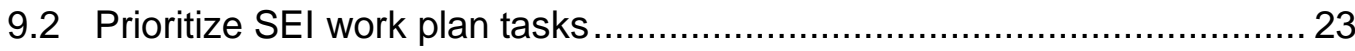

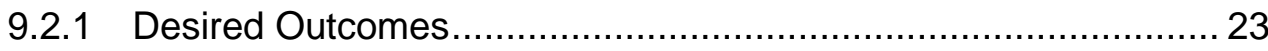

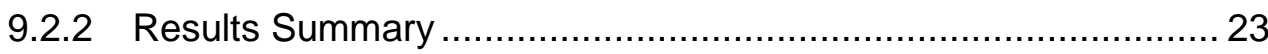

9.3 Perform readiness/fit analysis for top 3 tasks ……….......................... 24

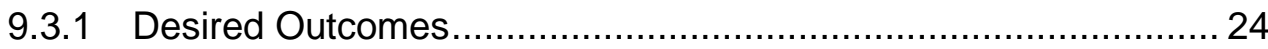

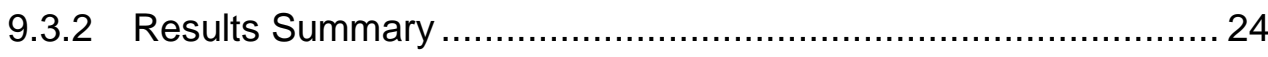

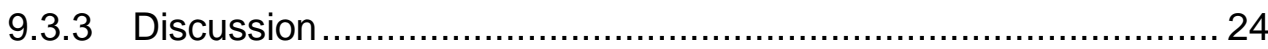

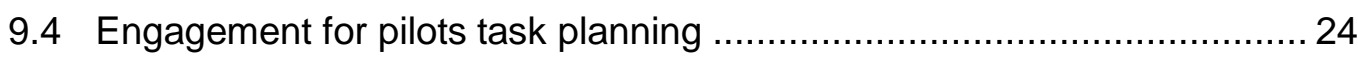

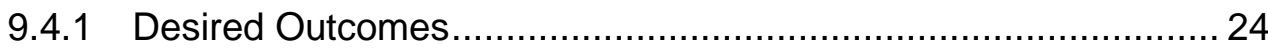

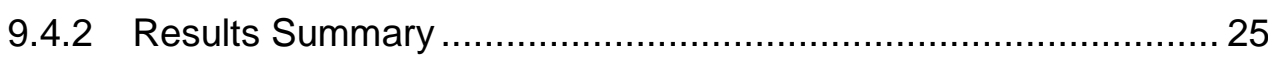

9.5 Close up main part of workshop ........................................................ 25

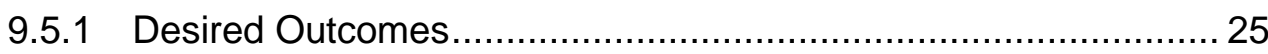

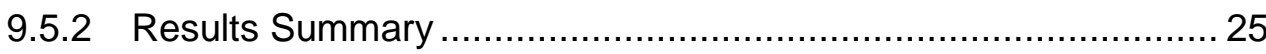

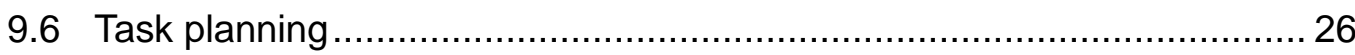

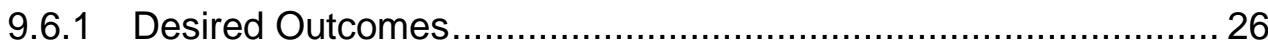

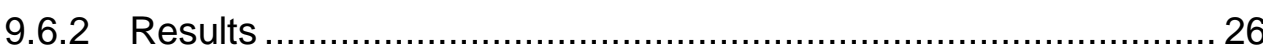

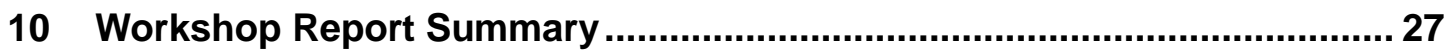

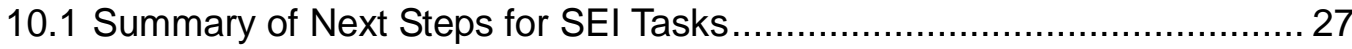

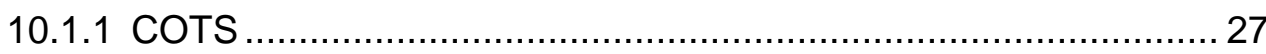

10.1.2 People Capability Maturity Model (P-CMM) ………................... 27

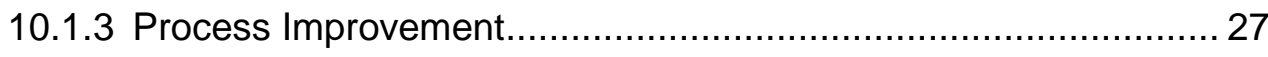

Appendix A Presentation: Col Jevsevar's HQ Standards Systems Group..... 29

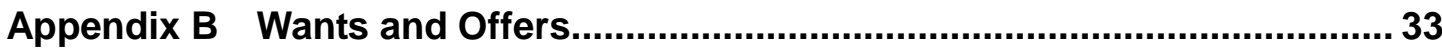

Appendix C: Issues and Comments................................................................... 
Appendix D: SSG's Strategic Objectives

Appendix E: SEI Work Plan ....................................................................51

Appendix F: People Capability Maturity Model (P-CMM) ...............................61

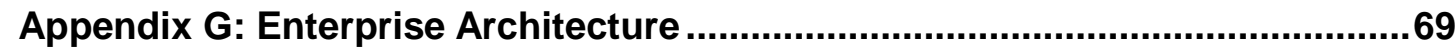

Appendix H: Software Sustainment and Modernizing Legacy Systems .............75

Appendix I: Capability Maturity Model - Integrated (CMMI) .............................85

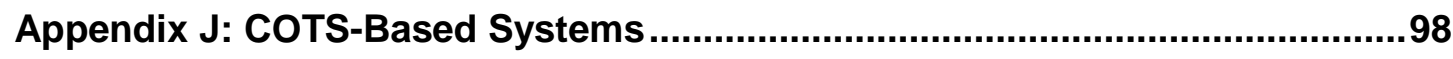

Appendix K: The Mind Maps .................................................................. 107

Appendix L: COTS-Based Systems Enablers and Barriers .............................113

Appendix M: People Capability Maturity Model Enablers and Barriers ............115

Appendix N: Capability Maturity Model-Integrated Enablers and Barriers......117 


\section{List of Figures}

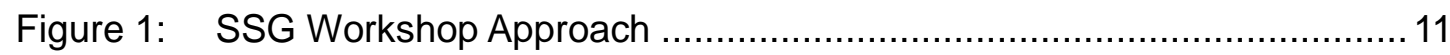

Figure 2: Map of SEI Technologies Against SSG (Cluster Focused on Customer

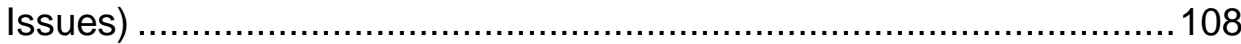

Figure 3: Map of SEI Technologies Against SSG (Cluster Focused on Innovation

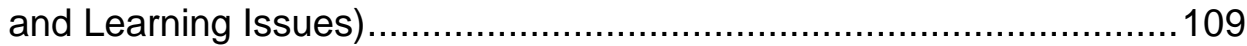

Figure 4: Map of SEI Technologies Against SSG (Cluster Focused on Internal

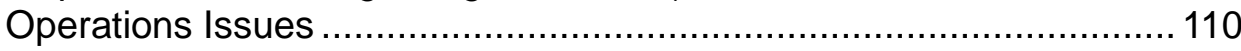

Figure 5: Map of SSG Issues to CMMI Content............................................ 111

Figure 6: Map of SSG Issues Against P-CMM Content ................................... 112 


\section{List of Tables}

Table 1: Standard Systems Group Participants Involved in the Workshop ..........10

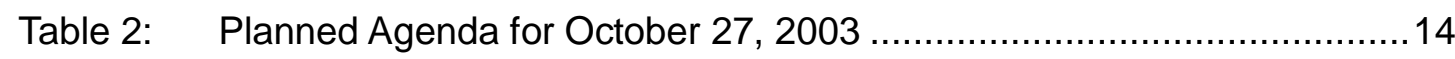

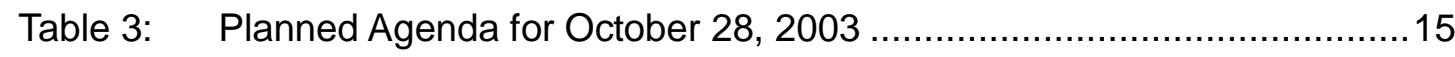

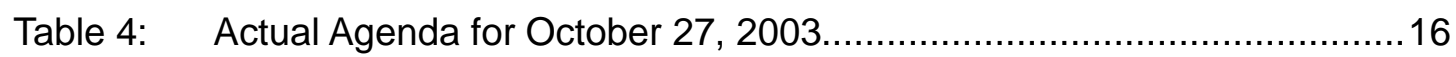

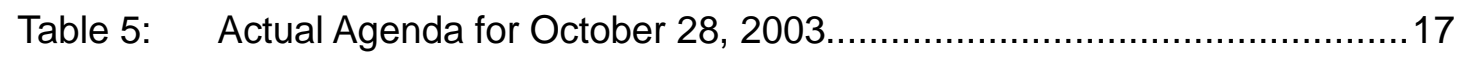

Table 6: $\quad$ Workshop Report Summary - Pluses and Deltas .................................25 


\section{Executive Summary}

The Software Engineering Institute (SEI) facilitated a two-day Technology Adoption Planning workshop for the SSG Transformation Team (vice director and the directors of the 2-letter organizations) on October 27 and 28, 2003 at the Alabama TechnaCenter in Montgomery, Alabama. The workshop was also attended by SSG personnel who were responsible for partnering with the SEI on the tasks in the FY03-04 SEI/SSG work plan.

The purpose of the workshop was to initiate the planning for phase 2 of the SSG/SEI partnership. (Phase 1, the "Enterprise Assessment," was conducted in Jan 03 and an out brief was delivered in May 03). The workshop focused on producing a tactical plan for incorporating the recommended SEI technical solutions (based on SSG-expressed needs during Phase 1) into the ongoing SSG transformation activities.

Workshop participants began by reviewing the SSG FY03-08 Strategic Objectives and the Balanced Score Card (BSC) objectives to verify that they were still relevant and supportive of the SSG Strategic Goals. After reviewing the list of 21 objectives, the SSG

Transformation Team confirmed that all of the objectives are still relevant, although it was noted that a few of them could be consolidated.

The objectives were grouped into three categories (customer focused, internal operations, and innovation \& learning). During the remainder of the workshop, SSG personnel participated in group activities where key technical challenges facing SSG were identified. SEI personnel identified those where SEI could provide expertise/support. A mapping exercise of SSG needs to SEI expertise was conducted. SSG personnel then "dot voted" on the top three areas they thought were the most important for SSG to pursue in the near term. The top three are COTS-Based Systems (CBS) support/integration, People-CMM (P-CMM) support, and Process Improvement support. Interested SSG 2-letter organizations were identified as partners for each task and then individuals from these organizations volunteered to be the primary POC. They are:

- COTS systems support/integration - Steve Wright (EN)

- P-CMM - Lt Col Ingenloff (DP)

- Process Improvement - Tom Speakman (XPJ)

Next step is for the SEI to draft another version of the FY04 work plan with more detailed task descriptions including specific deliverables, a schedule, and a revised cost estimate. 


\section{Abstract}

The Software Engineering Institute (SEI) facilitated a two-day Technology Adoption Planning workshop for the Standard Systems Group (SSG) Transformation Team (Vice Director and the Directors of the 2-letter organizations) on October 27 and 28, 2003 at the Alabama TechnaCenter in Montgomery, Alabama. Other pertinent SSG personnel, with responsibility for partnering with the SEI on the tasks in the FY03-04 SEI/SSG work plan, also were invited and attended.

The purpose of the workshop was to initiate the planning for phase 2 of the SSG/SEI partnership. (Phase 1 was the "Enterprise Assessment" conducted in January 2003 and out briefed in May 03). The workshop was focused on producing a tactical plan for incorporating the recommended SEI technical solutions (based on SSG-expressed needs during Phase 1) into the ongoing SSG transformation activities. 


\section{Organization of This Report}

This report is organized into the following sections:

Background: This section provides information as to why the workshop was held and other relevant background information expected to be needed to understand the workshop report.

Workshop Purpose: This section elaborates on the purpose of holding the workshop.

Workshop Goals/Desired Outcomes: This section elaborates on the deliverables of the workshop and provides details on the goals that supported the purpose of the workshop.

Participants: This section describes the SSG and the SEI participants of the workshop.

Workshop Approach: This section describes the rationale for the workshop activities and agenda items.

Nominal Agenda: This section contains the planned agenda for the workshop as well as the actual agenda that was followed.

Agenda Items Summary: This section outlines the desired outcomes, results summary, and discussion of each agenda item.

Appendices A - N: The appendices at the end of this report contain the raw data produced in the workshop (such as flip charts and other notes) as well as artifacts from the workshops (such as background information and presentations used during the workshop). 


\section{Background}

In late CY02, the SEI was asked by the new SSG director, Mr. Frank Weber, to perform an "enterprise assessment" of SSG. SSG's goal is to establish itself as a Center of Excellence (CoE) for Air Force combat support Information technology (IT) systems. Given that goal, SSG asked the SEI to provide initial, objective insights on core SSG processes/organizations that are critical to establishing this $\mathrm{CoE}$, to include:

- Roles/relationships between the Program Offices and Software Factory.

- Skills mix required to support future AF IT environment, to include best balance of blue suit vs. government civilian vs. contractors, considering legacy system requirements, modernization/technology evolution and training requirements/capabilities.

- Core competencies to promote an integrated combat support system domain.

- Basic organizational strategies.

Initial work culminated in a 17 Jan 03 briefing, which addressed areas of Apparent Strength and Areas of Apparent Concern toward the accomplishment of this goal.

Further investigation to include interviews and discussions with various Air Force leaders resulted in a more detailed presentation and a closeout of the "discovery phase" on 8 May 03.

The tasking in this work plan is the direct result of the aforementioned assessment outbriefs and ongoing discussion/direction from SSG leadership and is meant to be consistent with Mr. Weber's stated goals:

- Make SSG Easy to do business with ... a as deemed by our customers!

- Streamlined organization with agile processes

- Recognized expertise in exploring and exploiting leading IT technologies

- Enterprise-wide perspective

The Technology Adoption Planning workshop was part of the tasking statement of SEI's Fiscal Year 2003-04 Work Plan for the Standard Systems Group. This workshop was specifically focused on producing a working plan for incorporating technologies in the SEI work plan into the SSG transformation activities. The workshop began by reviewing the objectives and achievement strategies in the SSG FY03-08 Strategic Plan dated August 22, 
2002 to validate that they are still relevant in the context of recent organizational changes and priority changes. Working with the SSG leadership team, the SEI collaborated in planning and prioritizing the adoption of the technologies proposed in the FY03-04 work plan. These will be explicitly connected to the SSG strategic objectives in order to provide maximum benefit to SSG in achieving said objectives.

The SEI worked with SSG prior to the workshop to establish the agenda and identify appropriate participants. Attendees at the workshop included the Vice Director of SSG, his direct reports, and staff members who will be responsible for implementing, monitoring, and controlling the transformation effort. 


\section{Workshop Purpose}

The purpose of the SSG Technology Adoption Planning Workshop was to come up with a prioritized list of SSG's strategic objectives tied to specific tasks in the SEI work plan. In addition to creating the prioritized list of tasks, sequencing (i.e., education/training, consulting, etc.) of the subtasks were to be discussed and documented.

A technology adoption workshop approach was considered an appropriate method to come up with the primary list of activities. In addition, the workshop helped to facilitate communication among and between the SSG's departments involved in the two-day event. 


\section{Workshop Goals and Desired Outcomes}

The goals of the workshop included the following:

- Provide a communication forum between SSG and the SEI

- Establish a common understanding between SEI and SSG's objectives/plan

- Establish a common understanding of SEI's portfolio of "SSG appropriate" products

- Create a map of SEI technologies showing explicit connections to various SSG strategic objectives

The desired outcomes (deliverables) from the workshop included the following:

- A prioritized list of SSG's strategic objectives tied to specific tasks in the SEI work plan

- Sequencing of the subtasks discussed and documented

- Set of steps and dates with SEI and SSG resources

- Workshop report (this document) 


\section{Participants}

Participants for this workshop came from the SEI and from SSG. The SEI provided facilitators and subject matter experts for the workshop.

The following list includes SEI staff members and their respective roles in the workshop:

- Grady Campbell, Enterprise Architecture lead

- John Foreman, COTS-Based Systems lead

- Suzanne Garcia, Facilitator

- Kristi Keeler, Capability Maturity Model Integration (CMMI) lead

- Lisa Masciantonio, Business Manager

- Lorraine Nemeth, Facilitator

- Daniel Plakosh, Software Sustainment and Modernizing Legacy Systems leads

- Jan Vargas, SEI tech lead

- Gian Wemyss, People Capability Maturity Model (P-CMM) lead

The following table lists the Standard Systems Group participants involved in the workshop:

\begin{tabular}{|l|l|}
\hline Name & Area Represented \\
\hline Col Dave McKinney & AQ \\
\hline Stephen Stewart & BI \\
\hline LtCol Peter Ingenloff & DP/DAG \\
CMSGT Thomas Kirksey & EDX (DAG) \\
Willie Miller & DP/CCQ \\
\hline Kenneth Heitkamp & EA \\
\hline Eugene Wright & EN \\
\hline Col Victor Jevsevar & EV \\
\hline John Lucas & FM \\
Tommy Pope & \\
\hline Roger Herndon & FN \\
\hline
\end{tabular}




\begin{tabular}{|l|l|}
\hline Diane Suchan & ILS \\
\hline Maj John Hartsell & JA \\
\hline Maj Pat Reader & MI \\
\hline Tom Bayless & PI \\
\hline Trish Meadows & SEPG Lead \\
\hline David Boulian & ST \\
Col John Courtney & \\
\hline Col. Larry Wilson & XO \\
\hline John Macker & XP \\
Bloise Stubblefield & XP \\
Richard Plaskett & XP “Contractor" \\
Jim Hoffman & XPHC \\
Harold Speakman & XPJ \\
\hline
\end{tabular}

Table 1: $\quad$ Standard Systems Group Participants Involved in the Workshop 


\section{Workshop Approach}

The facilitators of this workshop utilized agenda items and activities that created a flow of information for shared understanding among all participants, as well as allowing a forum for open communications. The following diagram depicts the flow of the workshop.

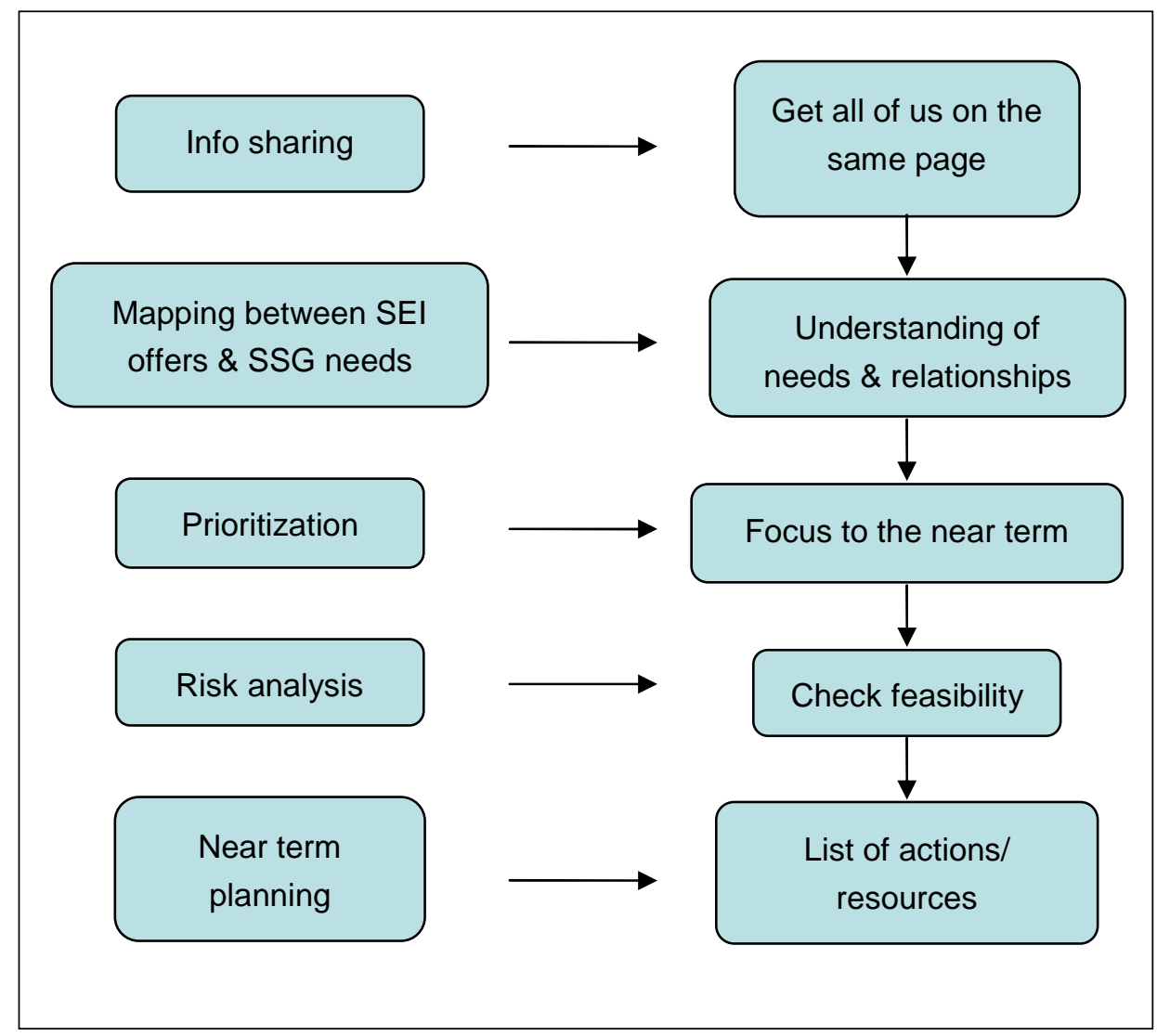

Figure 1: SSG Workshop Approach 


\section{Agendas}

The planned agendas shown in Table 2 and Table 3 were created and sent to all workshop attendees before the workshop. The actual agendas shown in Table 4 and Table 5 were revised throughout the workshop to meet the changing needs of the workshop and evolved into the "Worked Agendas."

The actual agendas in Table 4 and Table 5 were created during the workshop on October 27 and 28, 2003. The workshop facilitators worked with the actual agenda and fine-tuned it as each day progressed to meet the needs of the audience. 
Table 2: $\quad$ Planned Agenda for October 27, 2003

\begin{tabular}{|c|c|c|c|}
\hline \multicolumn{4}{|l|}{ October 27, 2003} \\
\hline Time & Agenda Topic & Lead/Participants & Desired Outcome \\
\hline $8: 00-8: 15$ am & $\begin{array}{l}\text { Welcome \& Why the SEI is } \\
\text { here }\end{array}$ & Jevsevar & $\begin{array}{l}\text { Common understanding among all } \\
\text { participants. }\end{array}$ \\
\hline $8: 15-9: 15$ am & Introductions & $\begin{array}{l}\text { Garcia \& Nemeth / } \\
\text { All }\end{array}$ & $\begin{array}{l}\text { Each participant has an opportunity to } \\
\text { introduce themselves, and state their } \\
\text { "wants/offers." }\end{array}$ \\
\hline $9: 15-9: 45$ am & $\begin{array}{l}\text { Review/Agree on Workshop } \\
\text { Objectives }\end{array}$ & $\begin{array}{l}\text { Garcia \& Nemeth / } \\
\text { All }\end{array}$ & $\begin{array}{l}\text { Agreement on agenda and understanding of } \\
\text { objectives. }\end{array}$ \\
\hline $9: 45-10: 00 \mathrm{am}$ & Break & All & Refresh. \\
\hline $10: 00-11: 45 \mathrm{am}$ & $\begin{array}{l}\text { Gunter to provide review of } \\
\text { SSG's Strategic Objectives }\end{array}$ & Rick Plaskett & $\begin{array}{l}\text { Common understanding of SSG's } \\
\text { objectives/plan. }\end{array}$ \\
\hline $\begin{array}{l}11: 45 \text { am }-1: 00 \\
\text { pm }\end{array}$ & Lunch & All & \\
\hline $1: 00-3: 00 \mathrm{pm}$ & $\begin{array}{l}\text { Review SEI Work } \\
\text { Plan/Connect to SSG } \\
\text { Objectives }\end{array}$ & SEI Tech Leads & $\begin{array}{l}\text { Common understanding on how SEI's } \\
\text { ideas map to SSG's objectives. }\end{array}$ \\
\hline 1:00 - 1:05 pm & Overview of Workplan & Jan Vargas & \\
\hline $1: 05-1: 20 \mathrm{pm}$ & $\begin{array}{l}\text { People Capability Maturity } \\
\text { Model (P-CMM) }\end{array}$ & Gian Wemyss & \\
\hline $1: 20-1: 35 \mathrm{pm}$ & Software Sustainment & Dan Plakosh & \\
\hline $1: 35-1: 50 \mathrm{pm}$ & Modernizing Legacy Systems & Dan Plakosh & \\
\hline $1: 50-2: 05 \mathrm{pm}$ & $\begin{array}{l}\text { Portfolio Management and } \\
\text { Integration }\end{array}$ & Dan Plakosh & \\
\hline $2: 05-2: 20 \mathrm{pm}$ & CMMI & Kristi Keeler & \\
\hline $2: 20-2: 35 \mathrm{pm}$ & COTS-Based Systems & John Foreman & \\
\hline $2: 35-2: 50 \mathrm{pm}$ & Enterprise Architecture & Grady Campbell & \\
\hline $2: 50-3: 00 \mathrm{pm}$ & (over run time) & & \\
\hline $3: 00-3: 30 \mathrm{pm}$ & Break & All & Refresh. \\
\hline $3: 30-4: 30 \mathrm{pm}$ & $\begin{array}{l}\text { Create map of Objectives/SEI } \\
\text { connections }\end{array}$ & Garcia / All & $\begin{array}{l}\text { Map of SEI technologies showing explicit } \\
\text { connections to various SSG strategic } \\
\text { objectives. }\end{array}$ \\
\hline $4: 30 \mathrm{pm}$ & Adjourn & & \\
\hline
\end{tabular}


Table 3: $\quad$ Planned Agenda for October 28, 2003

\begin{tabular}{|c|c|c|c|}
\hline $\begin{array}{l}\text { October } \mathbf{2 8 ,} \mathbf{2 0 0 3} \\
\text { Note: To accomm } \\
\text { Time }\end{array}$ & $\begin{array}{l}\text { the needs of SSG, this agend } \\
\text { Agenda Topic }\end{array}$ & $\begin{array}{l}\text { vas modified based o } \\
\text { Lead/Participants }\end{array}$ & $\begin{array}{l}\text { e results of the October } 27 \text { agenda. } \\
\text { Desired Outcome }\end{array}$ \\
\hline $8: 00-8: 30$ am & $\begin{array}{l}\text { Review Day } 1 \text { Work; Revise } \\
\text { as Necessary }\end{array}$ & $\begin{array}{l}\text { Garcia \& Nemeth / } \\
\text { All }\end{array}$ & Reset on where we are. \\
\hline $8: 30-10: 00$ am & $\begin{array}{l}\text { Prioritize SEI Work Plan } \\
\text { Tasks }\end{array}$ & $\begin{array}{l}\text { Garcia \& Nemeth / } \\
\text { All }\end{array}$ & SEI's tasks in prioritized order. \\
\hline $10: 00-10: 15$ am & Break & All & Refresh. \\
\hline $10: 15-11: 45$ am & $\begin{array}{l}\text { Perform Readiness/Fit } \\
\text { Analysis for Top } 3 \text { Tasks }\end{array}$ & $\begin{array}{l}\text { Garcia \& Nemeth / } \\
\text { All }\end{array}$ & $\begin{array}{l}\text { Transition risk list related to top three SEI } \\
\text { tasks and transition risk profiles. }\end{array}$ \\
\hline $\begin{array}{l}\text { 11:45 am - 1:00 } \\
\text { pm }\end{array}$ & Lunch & All & \\
\hline $1: 00-3: 00 \mathrm{pm}$ & Next Steps & $\begin{array}{l}\text { Garcia \& Nemeth / } \\
\text { All }\end{array}$ & $\begin{array}{l}\text { Set of steps with dates with SEI and SSG } \\
\text { resources. }\end{array}$ \\
\hline $3: 00-3: 30 \mathrm{pm}$ & Evaluate "Want" Satisfaction & Nemeth / All & $\begin{array}{l}\text { Understanding of what's been done and } \\
\text { what needs to be done. }\end{array}$ \\
\hline $3: 30 \mathrm{pm}$ & $\begin{array}{l}\text { Concluding Remarks and } \\
\text { Adjourn }\end{array}$ & Jevsevar & \\
\hline
\end{tabular}


Table 4: $\quad$ Actual Agenda for October 27, 2003

\begin{tabular}{|c|c|c|c|}
\hline \multicolumn{4}{|l|}{ October 27} \\
\hline Time & Agenda Topic & Lead/Participants & Desired Outcome \\
\hline $8: 00-8: 15$ am & $\begin{array}{l}\text { Welcome \& Why the SEI is } \\
\text { here }\end{array}$ & Jevsevar & $\begin{array}{l}\text { Common understanding among all } \\
\text { participants. }\end{array}$ \\
\hline $8: 15-8: 30 \mathrm{am}$ & Introductions & $\begin{array}{l}\text { Garcia \& Nemeth / } \\
\text { All }\end{array}$ & $\begin{array}{l}\text { Each participant has an opportunity to } \\
\text { introduce themselves, and state their } \\
\text { "wants/offers." }\end{array}$ \\
\hline $8: 30-8: 45$ am & $\begin{array}{l}\text { Review/Agree on Workshop } \\
\text { Objectives }\end{array}$ & $\begin{array}{l}\text { Garcia \& Nemeth / } \\
\text { All }\end{array}$ & $\begin{array}{l}\text { Agreement on agenda and understanding } \\
\text { of objectives. }\end{array}$ \\
\hline $8: 45-10: 40 \mathrm{am}$ & $\begin{array}{l}\text { Gunter to provide review of } \\
\text { SSG's Strategic Objectives }\end{array}$ & Rick Plaskett & $\begin{array}{l}\text { Common understanding of SSG's } \\
\text { objectives/plan. }\end{array}$ \\
\hline$(9: 20-9: 45)$ & Break & All & Refresh \\
\hline $10: 40-10: 45 \mathrm{am}$ & Overview of Workplan & Jan Vargas & \\
\hline $10: 45-11: 10$ & $\begin{array}{l}\text { People Capability Maturity } \\
\text { Model (P-CMM) }\end{array}$ & Gian Wemyss & \\
\hline $11: 10-11: 35 \mathrm{am}$ & Enterprise Architecture & Grady Campbell & \\
\hline$(11: 35 \mathrm{am}-1: 00 \mathrm{pm})$ & Lunch & All & \\
\hline $1: 00-1: 25$ & Software Sustainment & Dan Plakosh & \\
\hline $1: 25-2: 00 \mathrm{pm}$ & Modernizing Legacy Systems & Dan Plakosh & \\
\hline $2: 42-3: 07 \mathrm{pm}$ & COTS-Based Systems & John Foreman & \\
\hline$(3: 07-3: 30 \mathrm{pm})$ & Break & All & \\
\hline $3: 30-4: 30 \mathrm{pm}$ & $\begin{array}{l}\text { Create map of objectives/SEI } \\
\text { connections }\end{array}$ & Garcia/All & $\begin{array}{l}\text { Map of SEI technologies showing explicit } \\
\text { connections to various SSG strategic } \\
\text { objectives. }\end{array}$ \\
\hline $4: 30 \mathrm{pm}$ & Adjourn & & \\
\hline
\end{tabular}


Table 5: $\quad$ Actual Agenda for October 28, 2003

\begin{tabular}{|c|c|c|c|}
\hline \multicolumn{4}{|c|}{$\begin{array}{l}\text { October } \mathbf{2 8 ,} \mathbf{2 0 0 3} \\
\text { Note: To accommodate the needs of SSG, this agenda was modified based on the results of the October } 27 \text { agenda. }\end{array}$} \\
\hline $8: 00-8: 05$ am & $\begin{array}{l}\text { Review Day } 1 \text { Work; Revise } \\
\text { as Necessary }\end{array}$ & $\begin{array}{l}\text { Garcia \& Nemeth / } \\
\text { All }\end{array}$ & Reset on where we are \\
\hline $8: 05-9: 00 \mathrm{am}$ & $\begin{array}{l}\text { Prioritize SEI Work Plan } \\
\text { Tasks }\end{array}$ & $\begin{array}{l}\text { Garcia \& Nemeth / } \\
\text { All }\end{array}$ & SEI's tasks in prioritized order \\
\hline $9: 00-10: 30 \mathrm{am}$ & $\begin{array}{l}\text { Perform Readiness/Fit } \\
\text { Analysis for Top } 3 \text { Tasks } \\
\text { +Break }\end{array}$ & All & $\begin{array}{l}\text { Transition risk list related to top three SEI } \\
\text { tasks and transition risk profiles } \\
\text { Refresh. }\end{array}$ \\
\hline $10: 30-10: 50 \mathrm{am}$ & $\begin{array}{l}\text { Engagement for pilots task } \\
\text { planning }\end{array}$ & $\begin{array}{l}\text { Garcia \& Nemeth / } \\
\text { All }\end{array}$ & \\
\hline 10:50 - 11:05 am & $\begin{array}{l}\text { Close up main part of } \\
\text { workshop } \\
\text { - Evaluate meeting (+ and } \\
\text { delta) } \\
\text { - Folks not directly involved } \\
\text { in the Pilot Tasks may leave }\end{array}$ & $\begin{array}{l}\text { Garcia \& Nemeth / } \\
\text { All }\end{array}$ & $\begin{array}{l}\text { Is there anything you liked about this } \\
\text { workshop? Is there anything the SEI can } \\
\text { improve upon? }\end{array}$ \\
\hline $\begin{array}{l}\text { 11:05 am - 12:30 } \\
\text { pm }\end{array}$ & Lunch & All & \\
\hline $12: 30-3: 00 \mathrm{pm}$ & Task planning & All & \\
\hline
\end{tabular}

\subsubsection{Rationale for Agenda Changes}

The major changes to the planned agenda and the actual agenda on day one were based on the fact that the workshop members worked through the morning section of the agenda faster than anticipated. The facilitators also allowed an hour and a half for lunch, as participants had a distance to drive to eating establishments. The schedule was shifted slightly during the "Review of SEI Work Plan/Connect to SSG Objectives" to accommodate the time needs of the attendees to discuss in more depth some of the topics covered by the SEI's subject matter experts. 
The major changes to the workshop's agenda during day two included the workshop participants working through the morning's portions more rapidly than predicted. The morning's sections afforded the attendees an opportunity to evaluate the meeting. The facilitators closed up the main part of the workshop so that attendees who were not directly involved in the Pilot Tasks could leave. Lunch was moved up earlier to leave a full two and a half hours to discuss Task Planning. 


\section{Agenda Items for Day 1, October 27, 2003}

\subsection{Welcome and why the SEI is here}

The first topic on the agenda for day one was a welcoming message from SEI's facilitators and a welcome and brief talk on why the SEI was there by Col Jevsevar.

\subsubsection{Desired Outcomes}

Col Jevsevar wanted all of workshop participants to have a common understanding why the SEI was there and what the SEI was planning to do during the two-day workshop.

\subsubsection{Results}

Col Jevsevar presented a slide presentation to outline the purpose and the objectives of the workshop. In addition, he called for full participation from everyone and open communications

\subsubsection{Discussion}

See Appendix A for Col Jevsevar's slide presentation.

\subsection{Agenda item "Introductions"}

The next topic was an introductions section.

\subsubsection{Desired Outcomes}

Each workshop participant had an opportunity to introduce themselves and state their "wants/offers." 


\subsubsection{Results}

The facilitators stated the roles and rules of the workshop. Participants introduced their name and their role in SSG or in the SEI. Then, each participant was given two, different colored, large-sized post-it notes. They were instructed to write their wants on one post-it and their offers on the other post-it. When they were done writing, they came to the front of the room and placed their wants on one of the easel pads and their offers on the other easel pad. The facilitators then read through all of the offers and lined them up against the workshop objectives. In general, the wants and offers provided were appropriate for the intended scope of the workshops.

\subsubsection{Discussion}

See Appendix B for raw data collected from this section.

\subsection{Agenda item "Review/Agree on workshop objectives" Summary}

Next on the agenda, participants reviewed/agreed upon the workshop's objectives.

\subsubsection{Desired Outcomes}

The desired outcome of this agenda topic was for all participants to come to agreement on the agenda and understanding of objectives.

\subsubsection{Results}

Participants reviewed the workshop objectives and refined the agenda. Key points were captured on a flip chart.

\subsubsection{Discussion}

The data collected from this agenda item is in Appendix $\mathrm{J}$. 


\subsection{Gunter to provide review of SSG's strategic objectives}

Next, SSG provided a review of their strategic objectives.

\subsubsection{Desired Outcomes}

All participants were to have a common understanding of SSG's objectives/plans.

\subsubsection{Results Summary}

Rick Plaskett, from SSG, provided a slide presentation that reviewed all of SSG's strategic objectives. The result of this review and discussion was that the strategic priorities had not changed much since the plan was produced. This provided a stable basis for moving forward.

\subsubsection{Discussion}

See Appendix C for Rick Plaskett's slide presentation.

\subsection{Review SEI work plan/connect to SSG objectives}

The next topic on the agenda was a review of the SEI work plan and how it connected to SSG's strategic objectives.

\subsubsection{Desired Outcomes}

The desired outcome from this section was a common understanding of how SEI's ideas map to SSG's objectives.

\subsubsection{Results Summary}

Jan Vargas, SEI Tech Lead, gave a brief overview of the SEI work plan. Then, each SEI technology lead talked for 15 minutes on their particular technologies, as outlined below.

- Gian Wemyss: People Capability Maturity Model (P-CMM)

- Grady Campbell: Enterprise Architecture

- Dan Plakosh: Software Sustainment and Modernizing Legacy Systems 
- $\quad$ Kristi Keeler: Capability Maturity Model - Integrated (CMMI)

- John Foreman: COTS-Based Systems

\subsubsection{Discussion}

SEI Work Plan Version 1.40 is in Appendix D, and each SEI technology lead's slide presentation is located in Appendix E through I.

\subsection{Create map of SSG's objectives/SEI connections}

Create map of SSG's objectives/SEI connections.

\subsubsection{Desired Outcomes}

Create a map of SEI technologies showing explicit connections to various SSG strategic objectives and the balanced scorecard. There were 21 SSG objectives. These objectives were grouped into three categories: customer focused, internal operations, and innovation and learning.

\subsubsection{Results Summary}

A mapping exercise of SSG needs to SEI expertise was conducted. First, the SSG issues related to three strategic goal clusters were gathered. The goal clusters were as follows:

- Customer-focused

- Internal operations

- Innovation and learning

Then SEI subject matter experts mapped SEI technologies that could help solve the issue where feasible. The first three maps in Appendix K reflect this perspective. Then the maps were reversed, with SEI technologies at the center and the associated SSG issues highlighted. These maps were used together to support the prioritization activities of day two.

\subsubsection{Discussion}

The Mind Map that was generated for this exercise can be found in Appendix K. 


\section{Agenda Items, Day 2, October 28, 2003}

\subsection{Review Day 1 work; revise as necessary}

The first topic on day two's agenda was a review of day one work.

\subsubsection{Desired Outcomes}

Participants were to reset on where we left off the previous day.

\subsubsection{Results Summary}

Workshop facilitators "walked the wall," reviewing day one results, and proposed day two's agenda. See Table 5 for the agenda used for day two.

\subsection{Prioritize SEI work plan tasks}

The next agenda topic on day two was to prioritize SEI work plan tasks.

\subsubsection{Desired Outcomes}

The workshop participants put SEI's tasks in prioritized order.

\subsubsection{Results Summary}

A mapping exercise of SSG needs to SEI expertise was carried out. SSG attendees "dot voted" on the major three areas they thought were most important for SSG to follow in the near term. The top three tasks that were chosen were COTS systems support/integration, PCMM, and Process Improvement. 


\subsection{Perform readiness/fit analysis for top 3 tasks}

The next item was to perform a readiness/fit analysis for the top three tasks.

\subsubsection{Desired Outcomes}

The desired outcome for this item was to develop a risk list related to the top three SEI tasks and create a risk profile for each.

\subsubsection{Results Summary}

This task was replaced by a task to elicit barriers and enablers for each of the top technologies. Readiness/fit analysis was deemed too detailed an approach for this workshop.

\subsubsection{Discussion}

The raw data collected from the easel paper is part of the Appendix.

- COTS systems support/integration, Appendix L

- P-CMM, Appendix M

- Process Improvement, Appendix N

\subsection{Engagement for pilots task planning}

Engagements for pilot task planning.

\subsubsection{Desired Outcomes}

Interested SSG 2-letter organizations were identified as partners for each task and then individuals from these organizations volunteered to be the primary points of contact. 


\subsubsection{Results Summary}

The following individuals are the primary points of contact:

- COTS systems support/integration - Steve Wright (EN)

- P-CMM - Lt Col Ingenloff (DP)

- Process Improvement - Tom Speakman (XPJ)

\subsection{Close up main part of workshop}

\subsubsection{Desired Outcomes}

Participants evaluated the meeting.

\subsubsection{Results Summary}

Facilitators asked the workshop participants if there was anything they liked about the workshop and is there anything that the SEI could improve upon. SSG attendees not directly involved in the pilot tasks could leave the workshop at this time.

In general, the reaction to the workshop was positive. Individual items for improvement were noted and will be incorporated into future technology adoption events as appropriate.

This table outlines what the workshop attendees liked about the workshop and what they would change about the workshop.

Table 6: Workshop Report Summary - Pluses and Deltas

\begin{tabular}{|l|l|}
\hline Pluses & Deltas (Changes) \\
\hline Validated issues we see in practice outside in our work & Explain purpose/better preparation ahead of time \\
\hline In-process artifacts & Strategic vision was 50K, not 500 ft view \\
\hline Got us thinking about things we need to do & How not to lose other important areas \\
\hline & $\begin{array}{l}\text { Clarify summation/traceability from possible final } \\
\text { choices }\end{array}$ \\
\hline
\end{tabular}




\subsection{Task planning}

The final agenda topic was task planning.

\subsubsection{Desired Outcomes}

The SSG primary points of contact and the SEI technology leads met and discussed how they were going to carry out the top three tasks.

- COTS systems support/integration

- $\quad \mathrm{P}-\mathrm{CMM}$

- Process Improvement

\subsubsection{Results}

Each of the three groups met for approximately two and a half hours to discuss the goals, picture of success, success criteria, tasks for the next three months, and ties to the balanced scorecard clusters: innovation/learning, internal operations, and customer focus.

Section 10 contains the next steps agreed on for each task. 


\section{Workshop Report Summary}

\subsection{Summary of Next Steps for SEI Tasks}

\subsubsection{COTS}

The SEI is an acknowledged expert in the techniques and practices necessary to develop and evolved software systems which are based on/extensively utilize COTS products, as opposed to building systems completely from scratch. Using COTS products requires new or alternate processes and practices throughout the system life cycle, to include but not limited to business case evaluation, requirements definition, vendor and supplier relationships/management, architecture, product evaluation, risk management, and more. Using COTS products also requires ongoing tradeoffs be made among the system context (requirements, cost, schedule, business processes), the system's architecture/design, and the product marketplace.

\subsubsection{People Capability Maturity Model (P-CMM)}

The P-CMM framework helps organizations successfully address their critical people issues. Based on the best current practices in fields such as human resources, knowledge management, and organizational development, the People CMM guides organizations in improving their processes for managing and developing their workforces. As such, the SEI will work with SSG to deliver the following: P-CMM workshop, P-CMM Gap Analysis Findings and Recommendations Report, Action Planning workshop and resulting improvement plan, Improvement Teams workshop, P-CMM coaching and assistance.

\subsubsection{Process Improvement}

The SSG Software Engineering Process (SEP) document contains a well written set of processes that can facilitate the transition from the SW-CMM to the CMMI-SE/SW V1.1. The outcome from the Technology Adoption Planning Workshop indicates that CMMI adoption is an appropriate step for SSG. 
The SEI will provide assistance in developing detailed SEP to CMMI-SE/SW V1.1 gap analysis, understanding and interpreting the CMMI reference model and in developing processes that are consistent with the practices contained therein. 


\section{Appendix A Presentation: Col Jevsevar's HQ Standards Systems Group}

This appendix contains the presentation "Col Jevsevar's HQ Standards Systems Group." These slides, presented on Monday, October 27, 2003, outlined why we were attending the workshop, the purpose of the workshop, and expected outcomes.

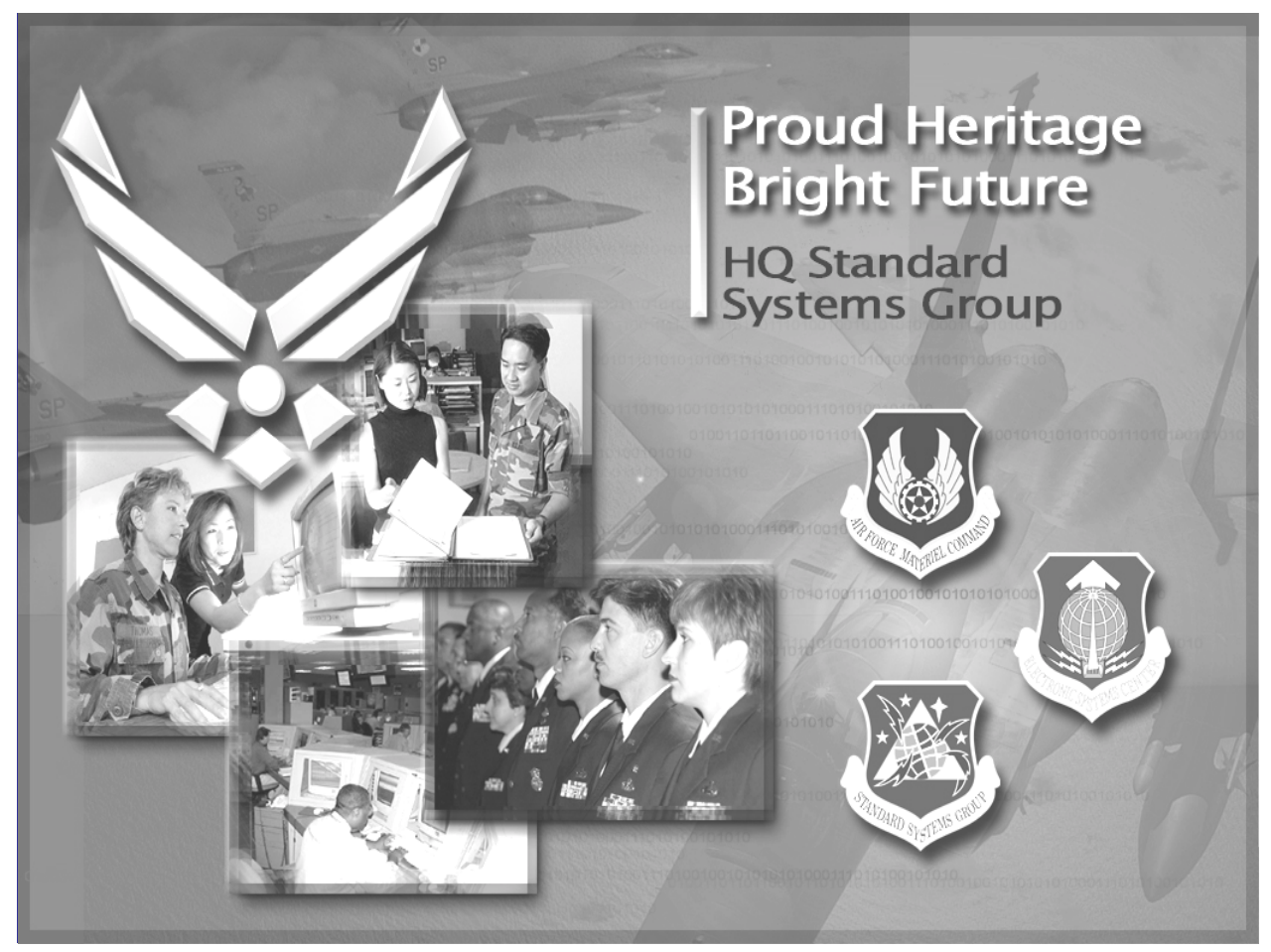




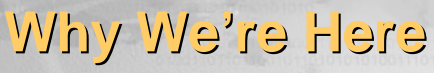

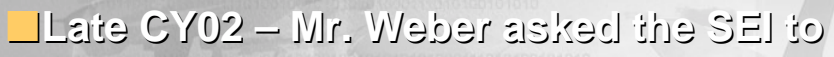

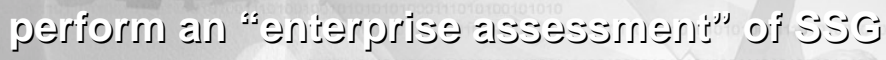

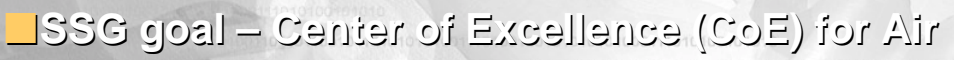

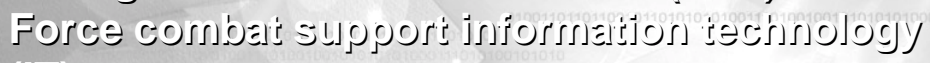
(J) systess

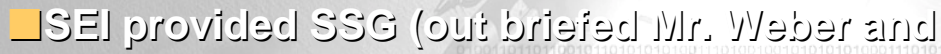

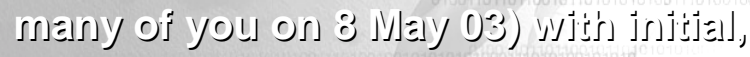

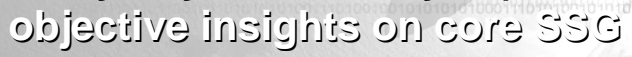

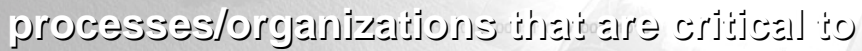
establishing inde CoE

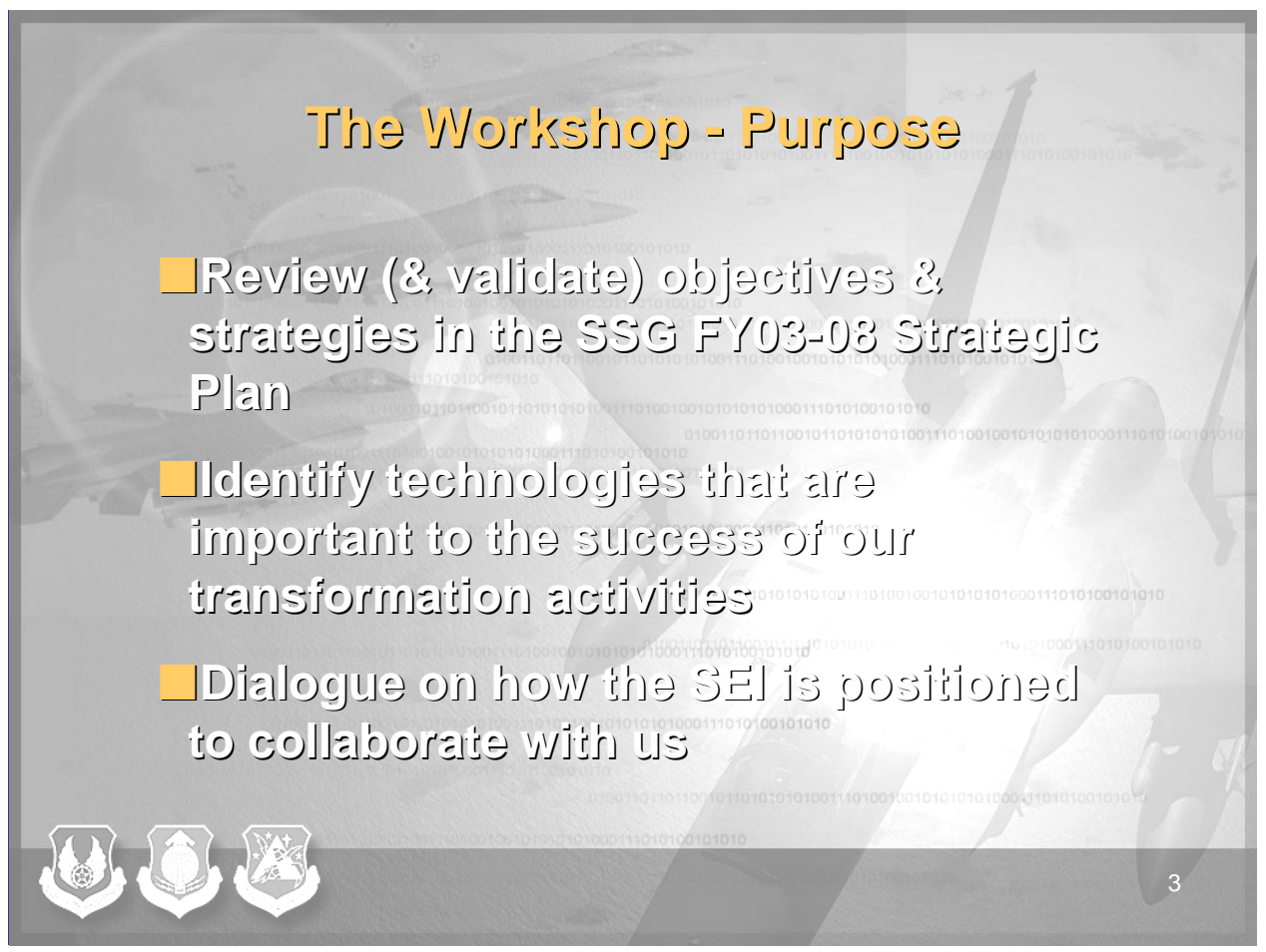




\section{Expected Onjeorses}

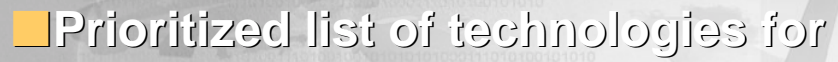

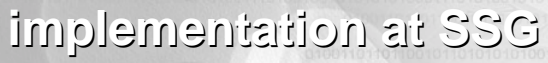

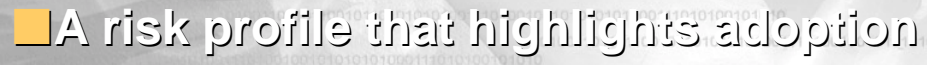

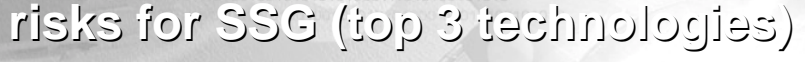

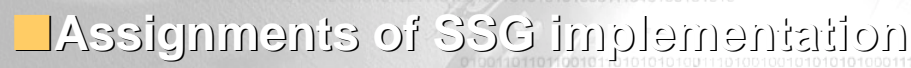

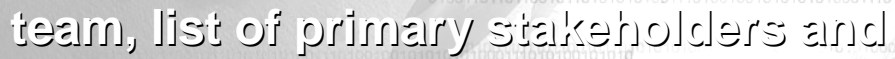

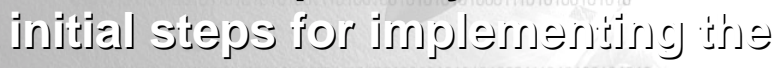
technology (iog) 3 tectusjologjest

\section{8}

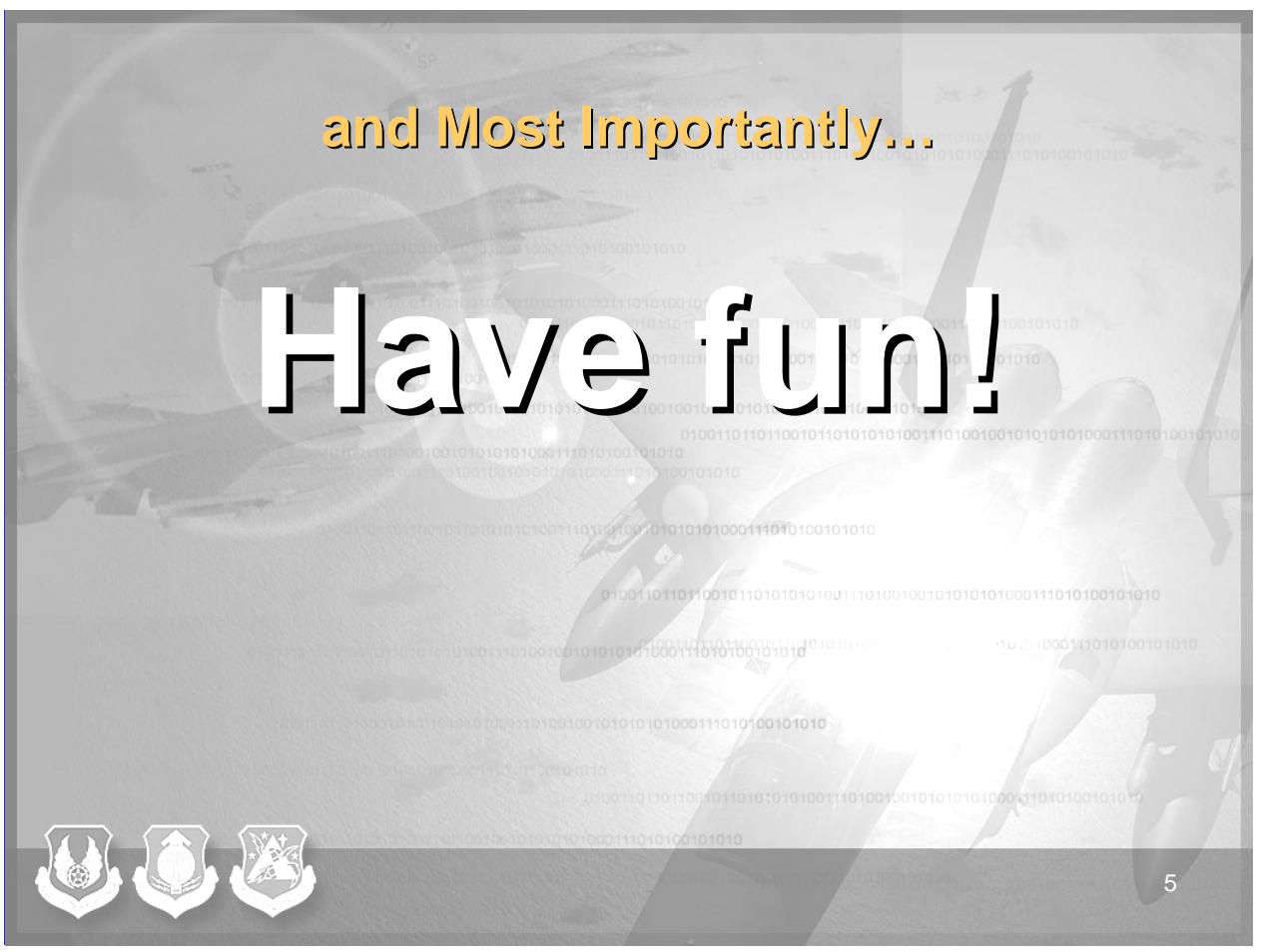




\section{Appendix B Wants and Offers}

This appendix contains the list of the workshop "wants" and "offers" from the second item on the Monday, October 27 agenda presented in Table 4.

\section{Offers}

- Technology adoption tools/techniques. Facilitation for workshop. (sg)

- Honesty, integrity, "can do" attitude. Vision for SSG workforce \& business goals. (Ingeloff)

- Gap analysis/fit determination with regard to CMMI \& other models. (klk)

- Contracting expertise. (wdm)

- Acquisition background. (tb)

- Strategic planning process skills. Understanding of metrics development. (rp)

- Background/skills in strategic planning \& program evaluation. (ln)

- 26 years in IT solutions. I have a good understanding of user needs. (dw)

- Insight into how organizations can unify business \& technology views of their organizational mission. (ghc)

- Facilitate communication. (jmv)

- An integrated view of SEI technologies $\&$ a promise to adapt $\&$ tailor as needed. (jtf)

- Offer financial expertise and outcomes obtained and processes reviewed during transformation initiatives. (tcp)

- Knowledge of DoD modernization plans.

- I will guarantee that the SSG needs are met through close internal SEI collaboration. (lm)

- Insight to customer concerns \& perceptions about SSG. Insight to the role/concerns of SSG's enlisted personnel.

- Robust legal advice to enhance mission and achieve SSG vision. (jeh)

- CM experience. (jhh)

- Personal experience with process implementation.

- Experience with P-CMM. Lessons learned from other organizations using PCMM, CMMI. Facilitation skills. (rgw) 
- Creative thinking.

- Sense of humor. Acquisition \& engineering experience. (vgj)

- Central point for all SSG business processes. (hs)

\section{Wants}

- Workshop results that support a productive relationship w/SSG. (suz)

- True strategic vision - capture essence of what each 2-ltr shall play... all in synch w/SSG's future, corporate goals. (pi)

- Meaningful, short strat plan which can be communicated easily to every person in SSG. Limited metrics. (tb)

- Understanding of what s new technology is so that a roadmap for execution can be built. (wdm)

- A prioritized list of SSG's strategic objectives tied to specific tasks in the SEI workplan (by end of workshop). (ln)

- SSG 2-ltr buy-in of technology priorities. SSG strategic plan. (vgj)

- Result - clear understanding of what the next steps are. (jmv)

- Insight into how SSG can transform itself into a software center of excellence. (jha)

- Everything we say we are going to do has a measurable method of determining success (or not). (rp)

- Co-workers thoughts on how to maximize support to our customers worldwide. (ldw)

- Understand SSG business objectives \& alignment/appropriateness fit of models \& technology. (klk)

- A productive workshop that helps clarify our strategic objectives. (jhl)

- Enhance SSG's ability to become the IT center of excellence for the war fighter. (jeh)

- Understand SSG status, goals \& needs for improvement. (ghc)

- Feedback from other SSG 2-ltrs on objectives/CMM, etc.

- Want to achieve an understanding of measurements we can use to gauge the success of transformation. (tcp)

- Results that helps transformation bring new business process into SEPG. (hs)

- Understand SSG's strategic objectives and the people issues (knowledge, skills, abilities) associated with these objectives. (rgw)

- To see a clear strategic plan that parallels the transformation activities within the organization, as well as meeting the AF's IT needs. 
- Agreement on at least one, but ideally three strategic objectives that we will jointly achieve together in 1-2 years.

- To ensure I have a clear understanding of the planned work activities for the SSG customer. (lm)

- Better understanding of how to mix technology advances into legacy sustainment.

- Some ideas about what not to measure as we adopt balanced scorecards. (jc)

- Ideas for ways to assess that SSG is "in the loop" on new technologies. (jc)

- Clearer vision of how to transition ST to better support the SSG strategic goals. (jc)

- Successful workshop in that a "roadmap" for upcoming work is defined \& we can proceed to more details \& implementation. (jtf) 


\section{Appendix C: Issues and Comments}

These issues and comments were generated during the workshop on Monday, October 27, 2003.

Spiral acquisition strategies

- Adding increments adds other overhead (e.g. AFCA) that is outside control of SSG

Develop technical expertise

- Place to add "portal skills" explicitly

CMMI Level 3

- How do people get refreshed

GCSS -AF compliance

- Update to include current ESC architecture requirements

$\underline{\text { SEP }}$

- Perception of SEP as "obstacle" wider spread than it should be based on results achieved with SEP

ID right mix of skills

- Remove overhires

- Merge this slide w/other 2 BSC slides related to skills

Missing?

- Charge back of DP/other staff ?? to 2-letters

$\circ$ How/when?

$\circ$ Where does it fit? 


\section{Appendix D: SSG's Strategic Objectives}

The following PowerPoint slides, presented by Rick Plaskett on October 27,2003, outline the objectives for SSG.

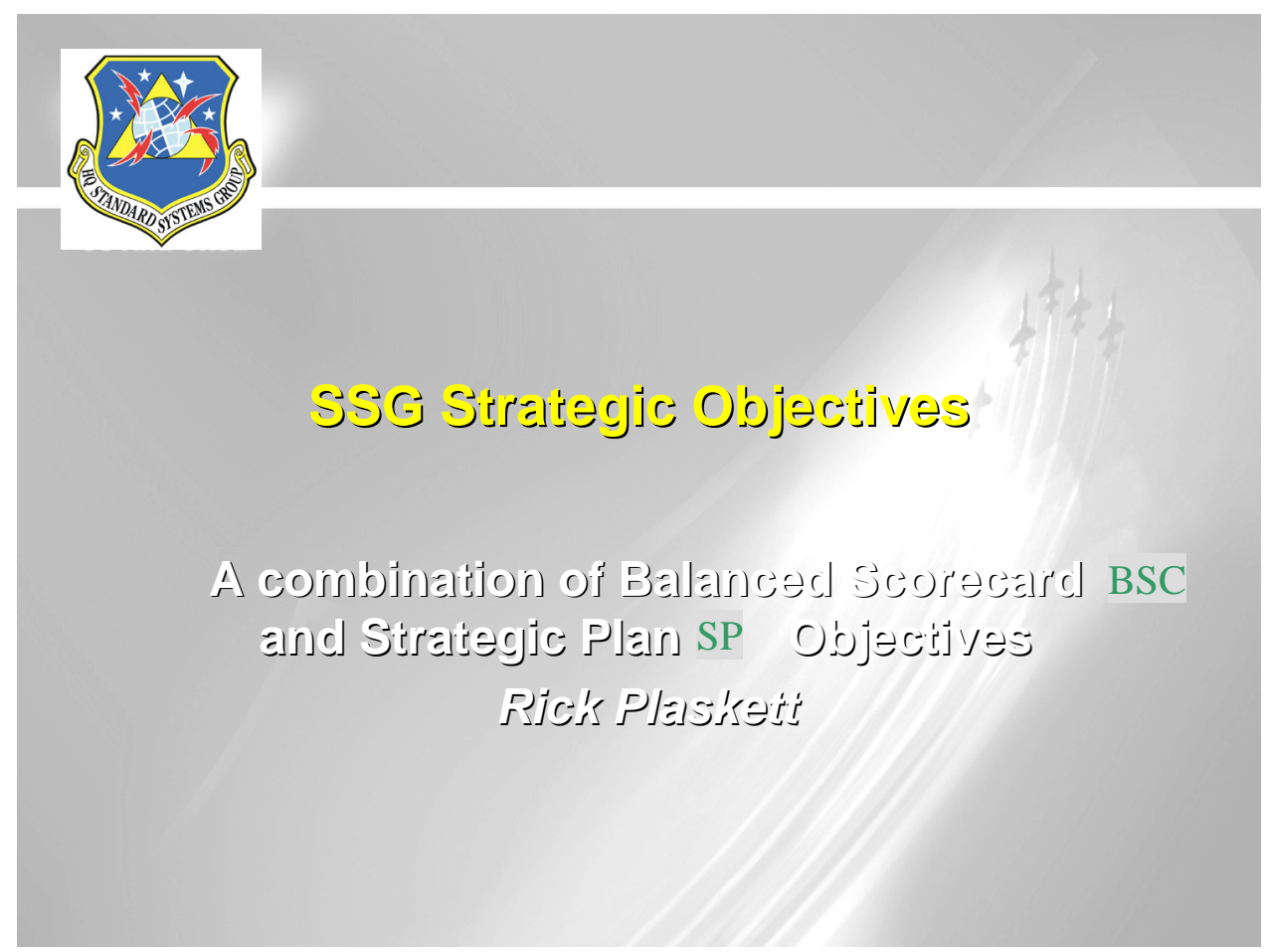




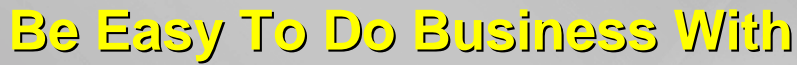

\section{BSC}

○ Avelilebility alncl accessibjlity

- Rellialoly consistent with poljey arucl procedujes

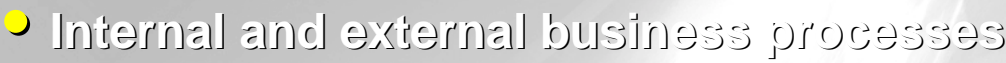

- Sijpole

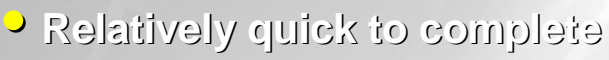

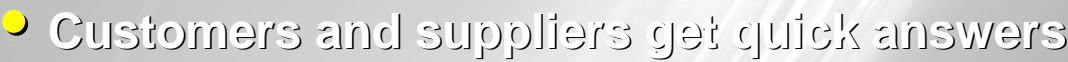
to thejs ofyerjes

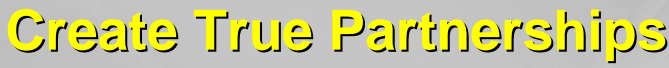

\section{BSC}

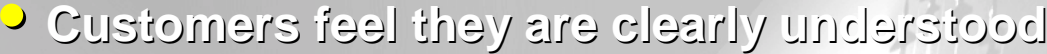
with jespect to regujuensents

- Jnolustiry providers alre jnyolved, jespected conjulbutors to the sojssjor

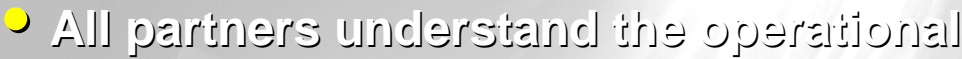

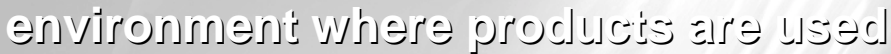

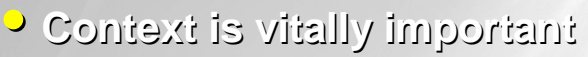

- Delivesy of capalojlity to jucrease effect is c]esired solutios 


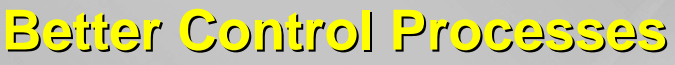

\section{BSC}

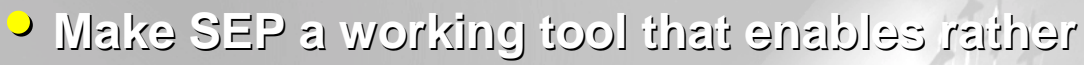
íjgln encusjogrs progjess

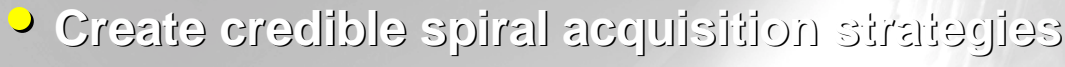

- Progjalss specjifte

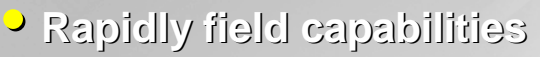

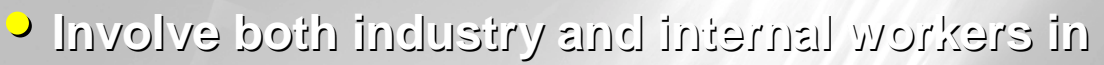
thje stals]e processes

- Use Profornal als ssaljojisg tor]

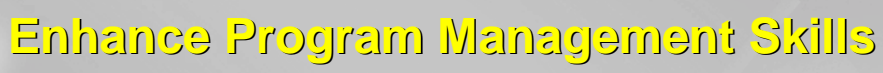

Eย=15อ

\section{BSC}

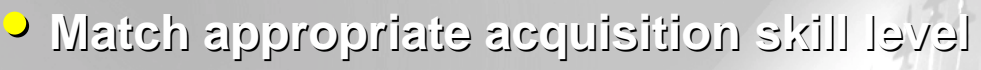
With each APDP posjitor

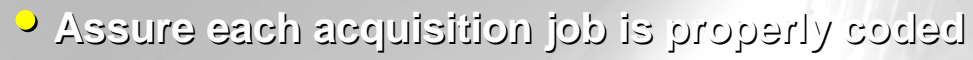

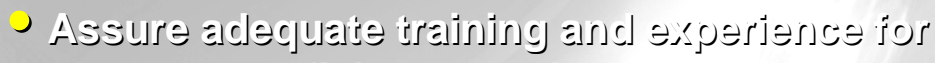
each person filljugg these jo'ss

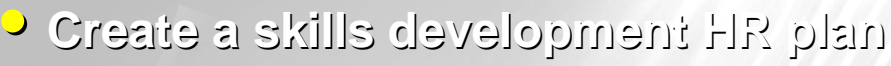

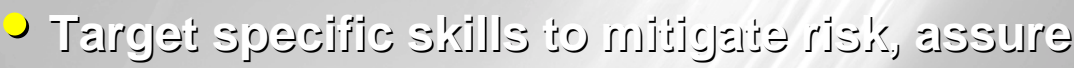

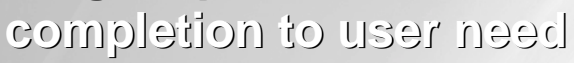




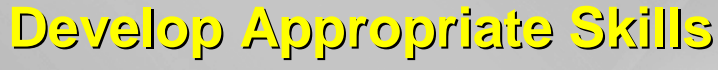

\section{BSC}

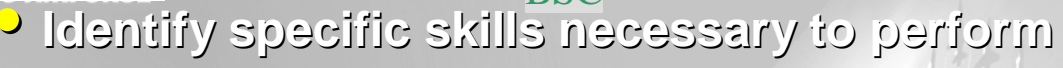
each job at SSG

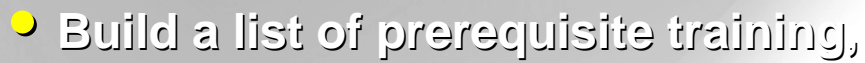

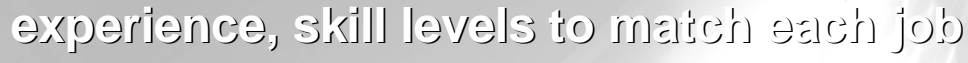

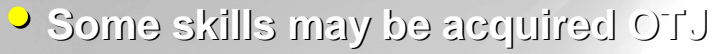

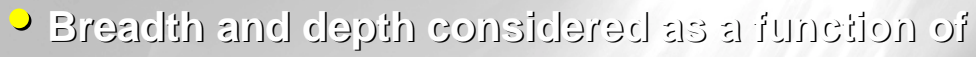
postitios

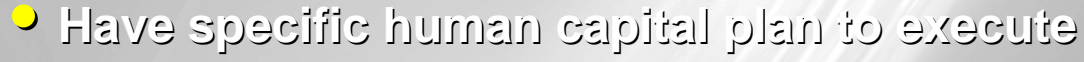
if

- preplesining al necessity

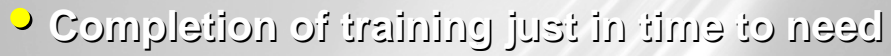

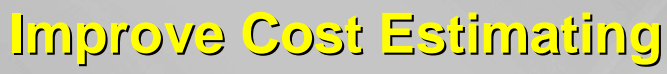

\section{BSC}

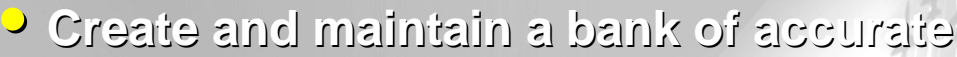

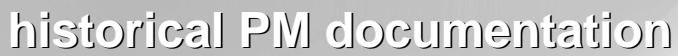

- Scope and complexily estinstites

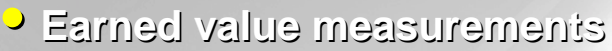

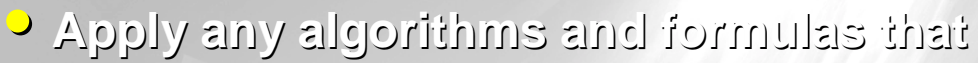

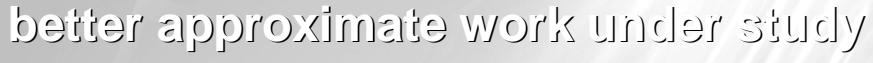

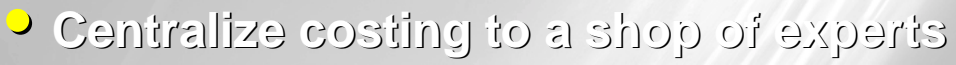

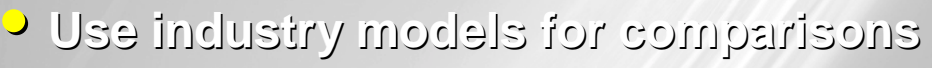




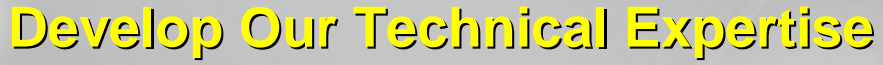

\section{BSC}

- Girow web-based ajchjiecture glsud integralion skillls

- Jolentify cujrent and future jeected tectujust

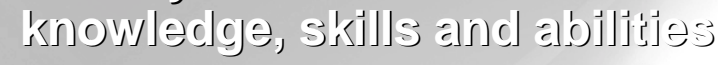

- Use straitegje plals als gujde

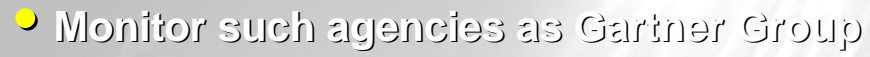

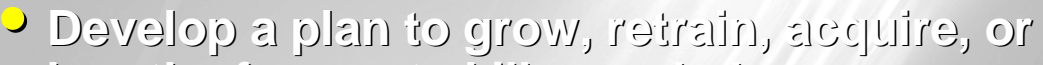
buy the forectast stsuls juegchesl

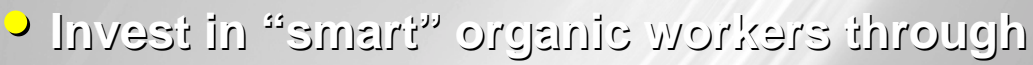

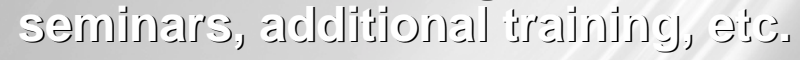

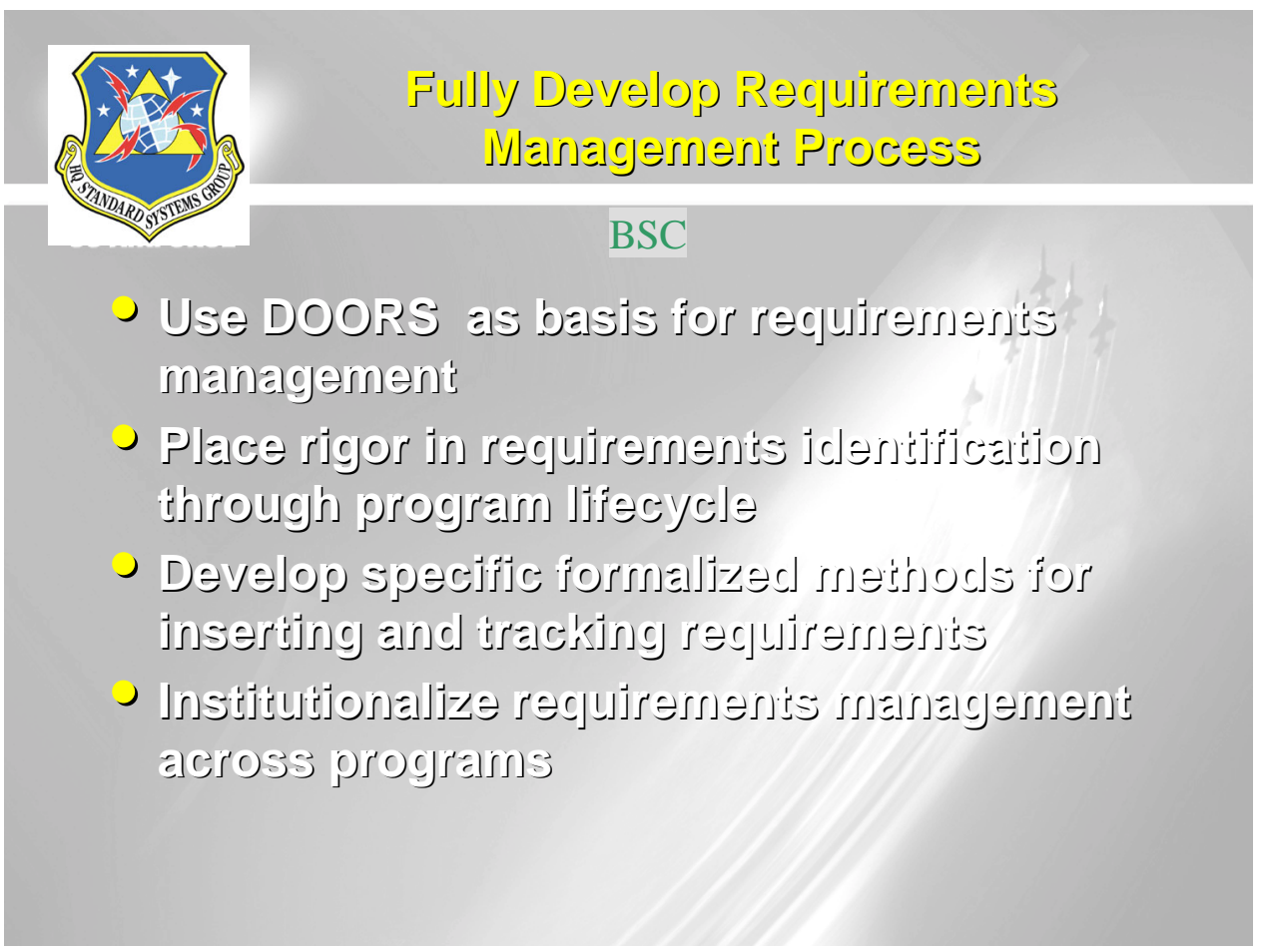




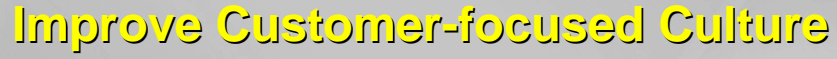

\section{BSC}

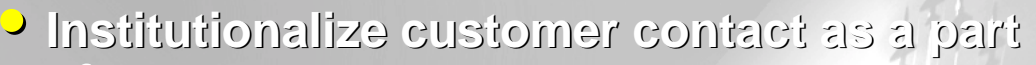
of prograln nalnagentent

- Riegulals feedlogkk sessjons

- Progjrajsa reviense

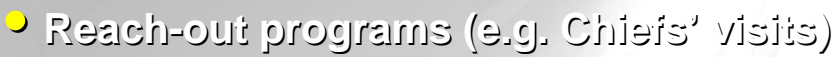

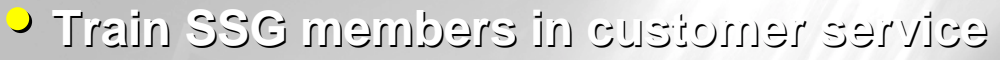

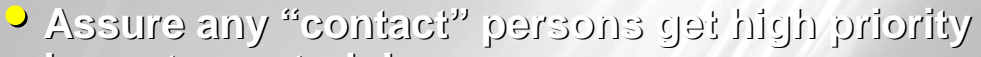

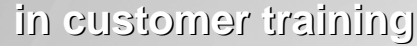

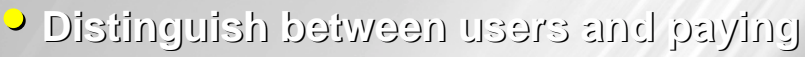
custonsuers

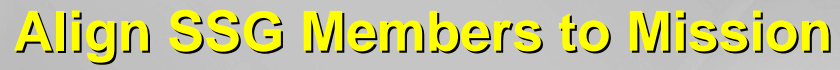

\section{BSC}

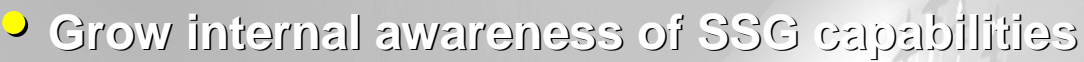
andel ongoing progralns or projects

- Directior's Callas regularly

- Qualrterly newsyetrers

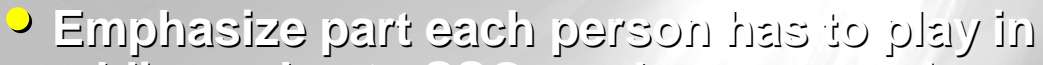

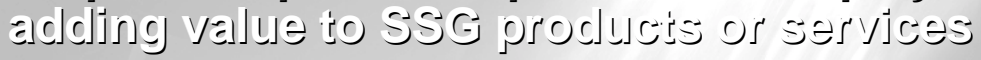

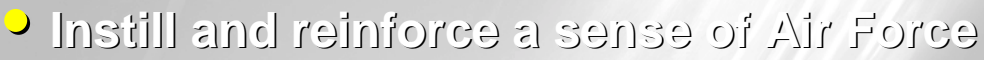
Core Valdues

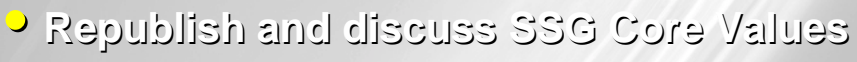




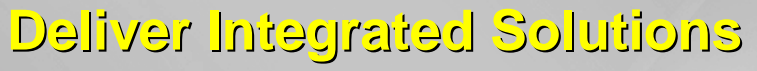

\section{BSC}

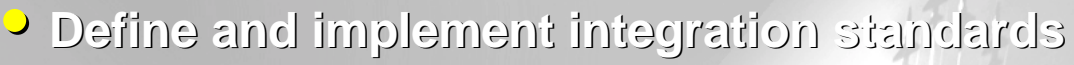

- FolJoy Jead of A F-CJO

- Develop Aju Force Enjterprise Solujurors

- We ssust deljver íse goods

- On thjse

- On cost

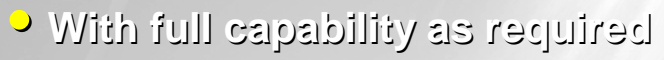

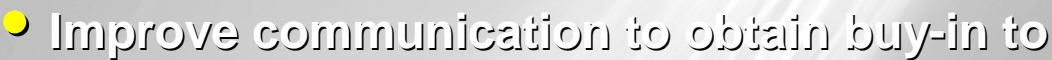

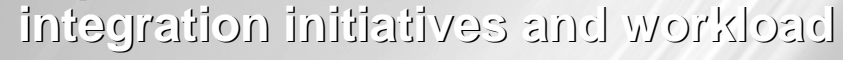

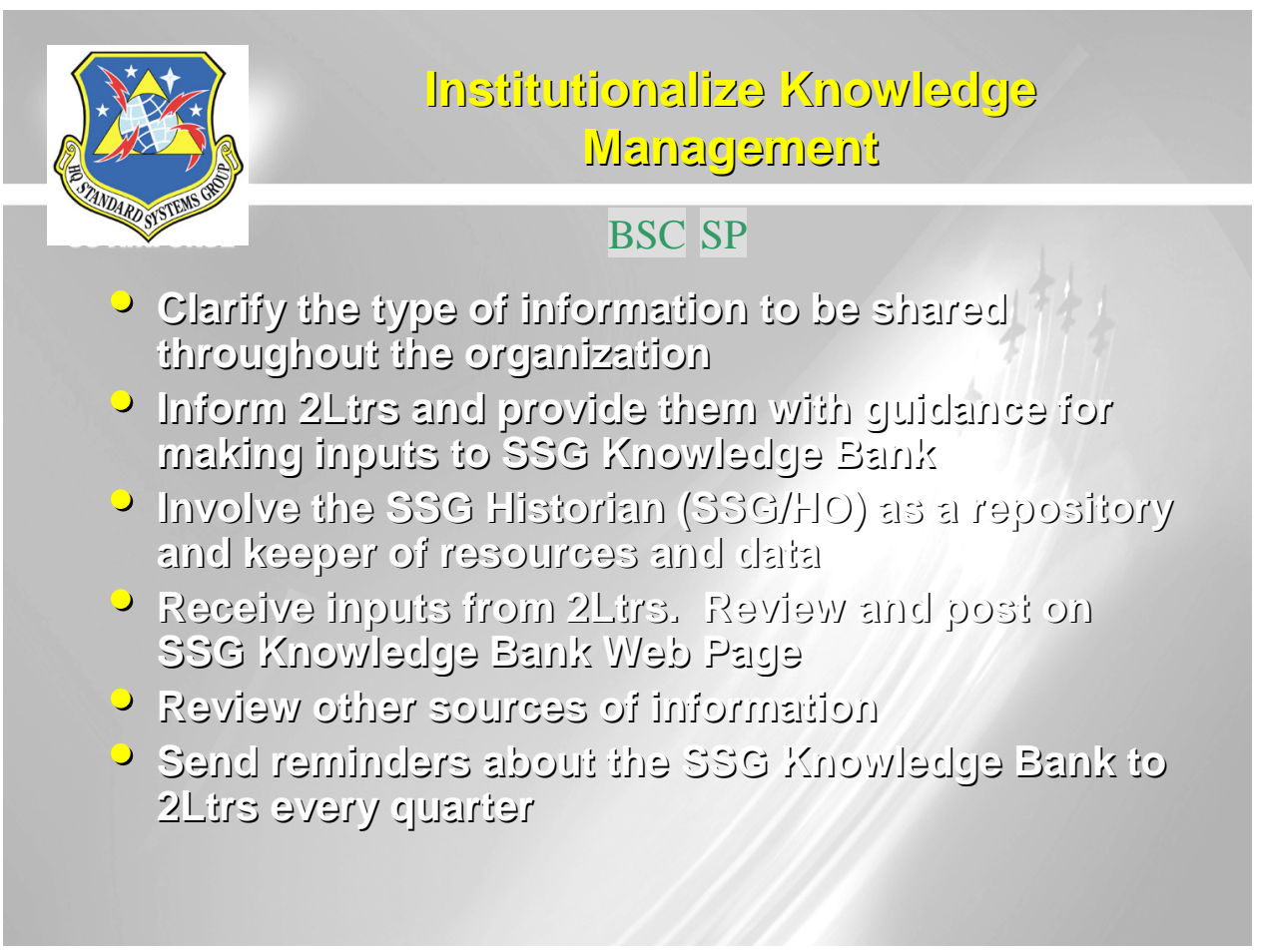




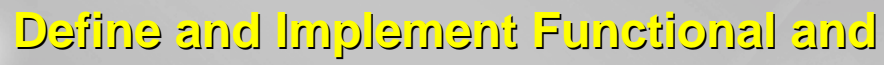

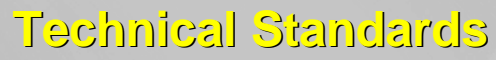

\section{BSC}

Build the standards into the process, into p odlutet for:

- Sectuity

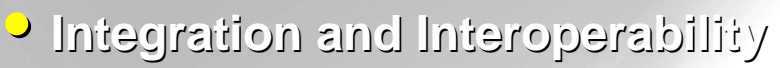

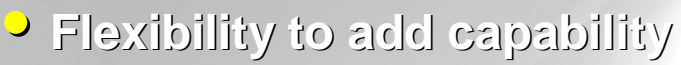

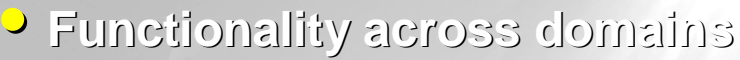

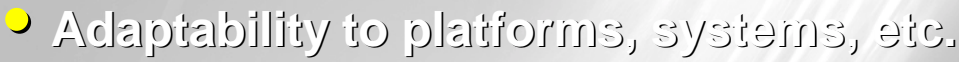

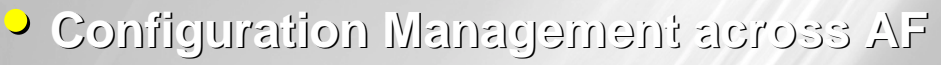

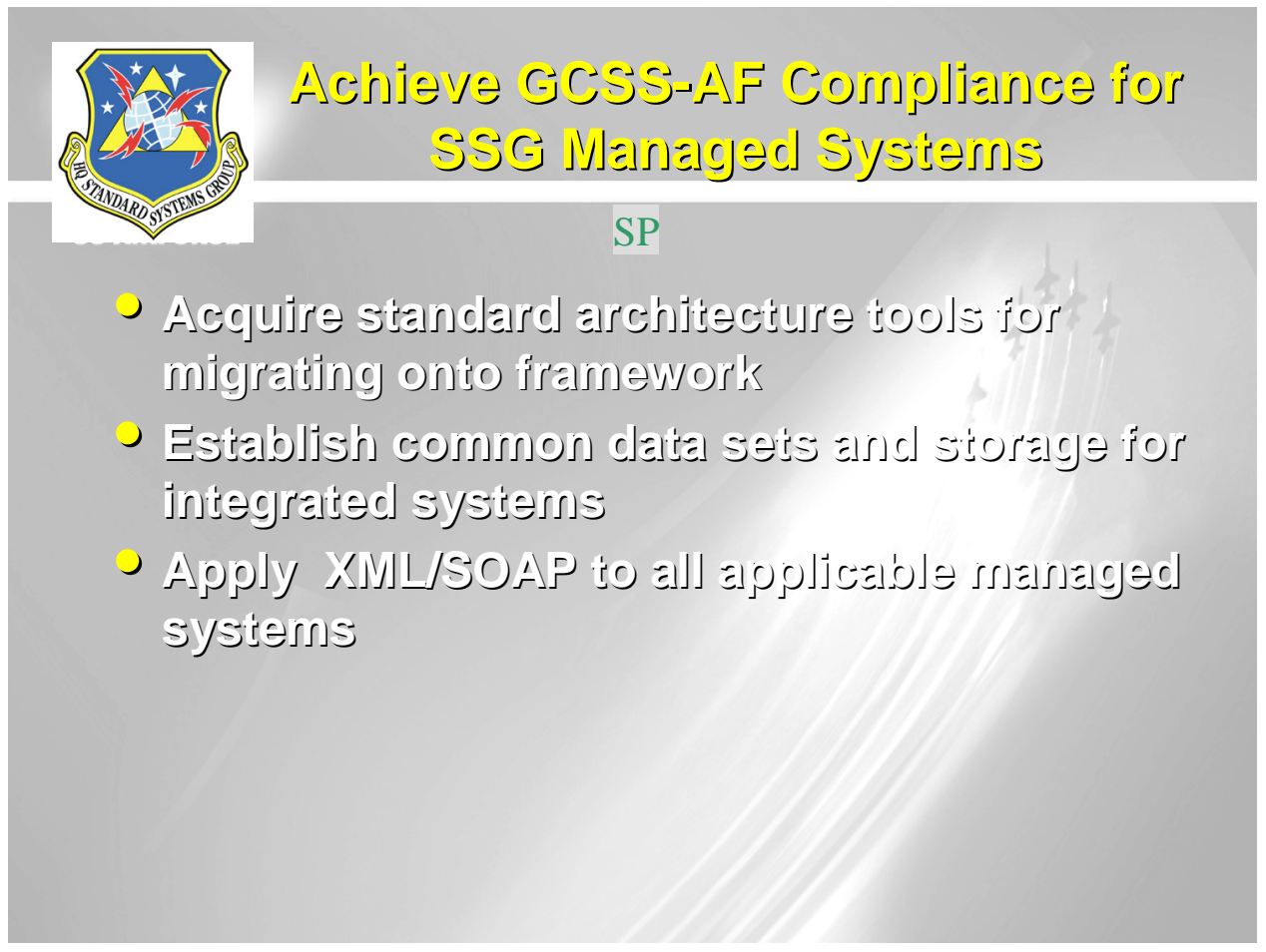




\section{SP}

- Develop systenss engjineering processes íngit tralnsiorns custonser needs, expecterijorss, alsul constralints into product solutions

- Install and institutionalize those processes thjoughout the orgasizgitjoss

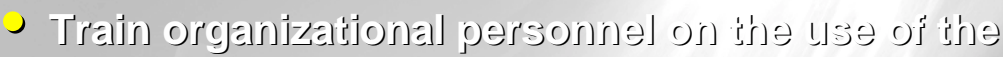

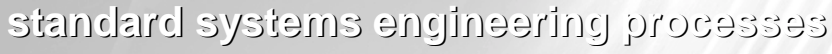

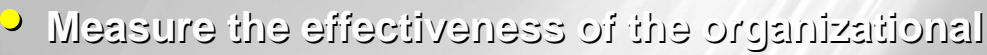
stingatal processes

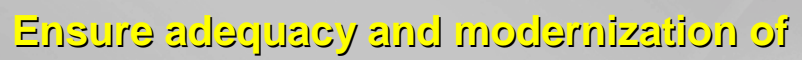

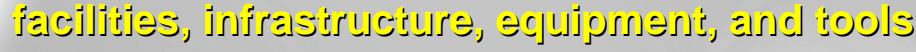

\section{SP}

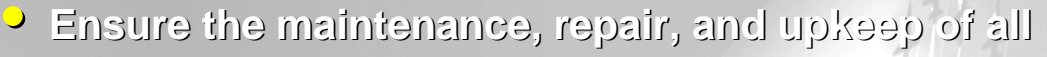

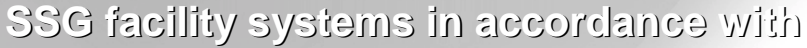
estalolished stalnolarols

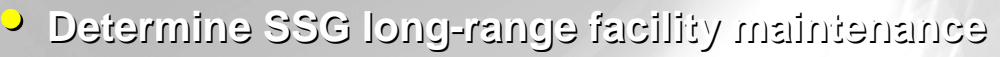
recjujressesuis

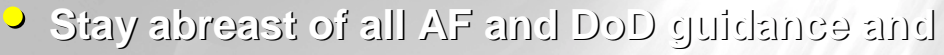

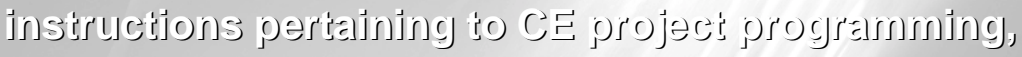

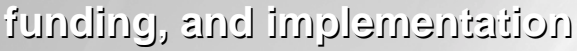

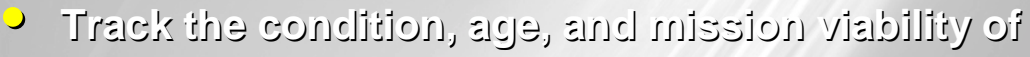

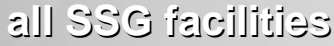



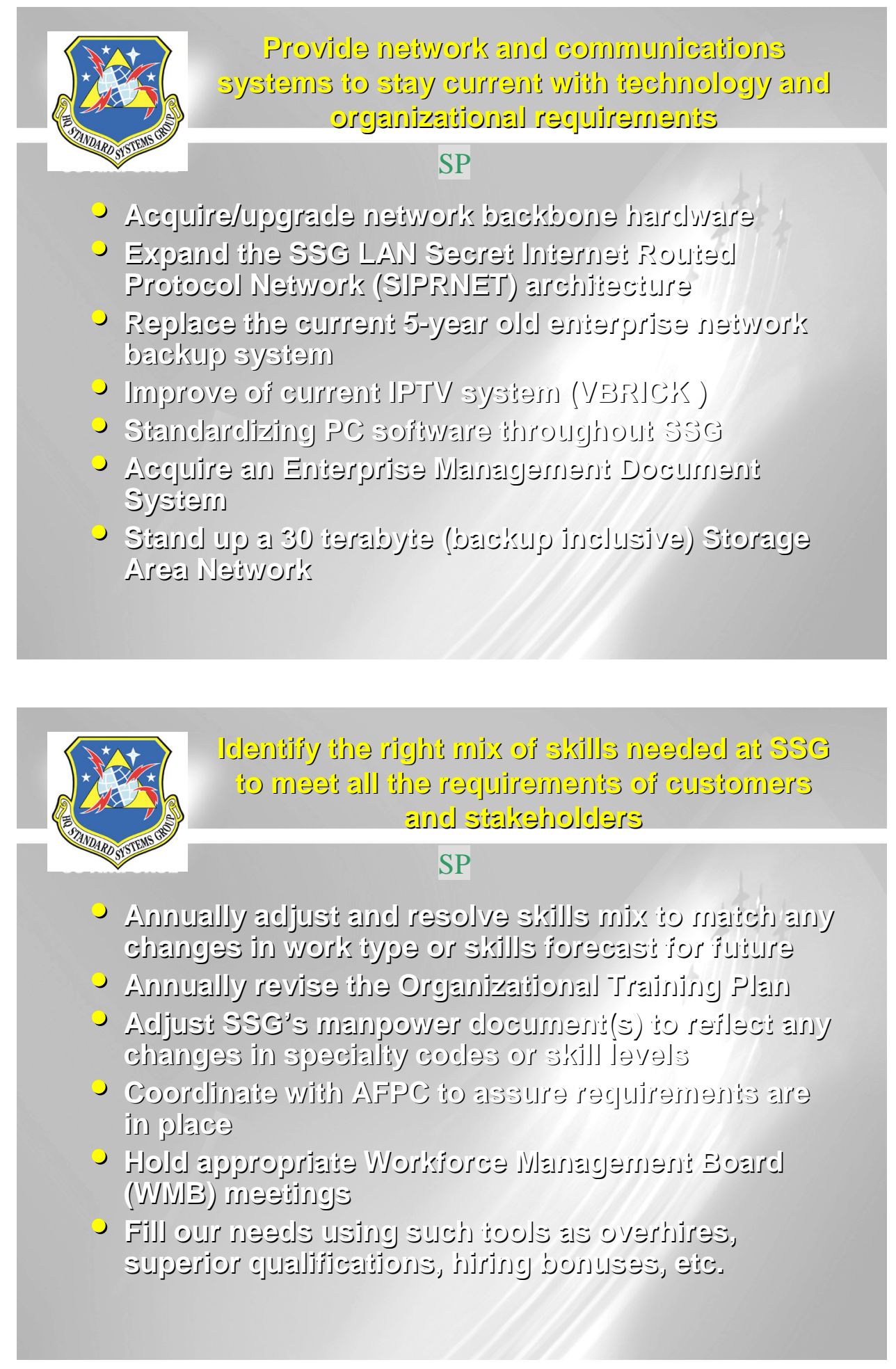

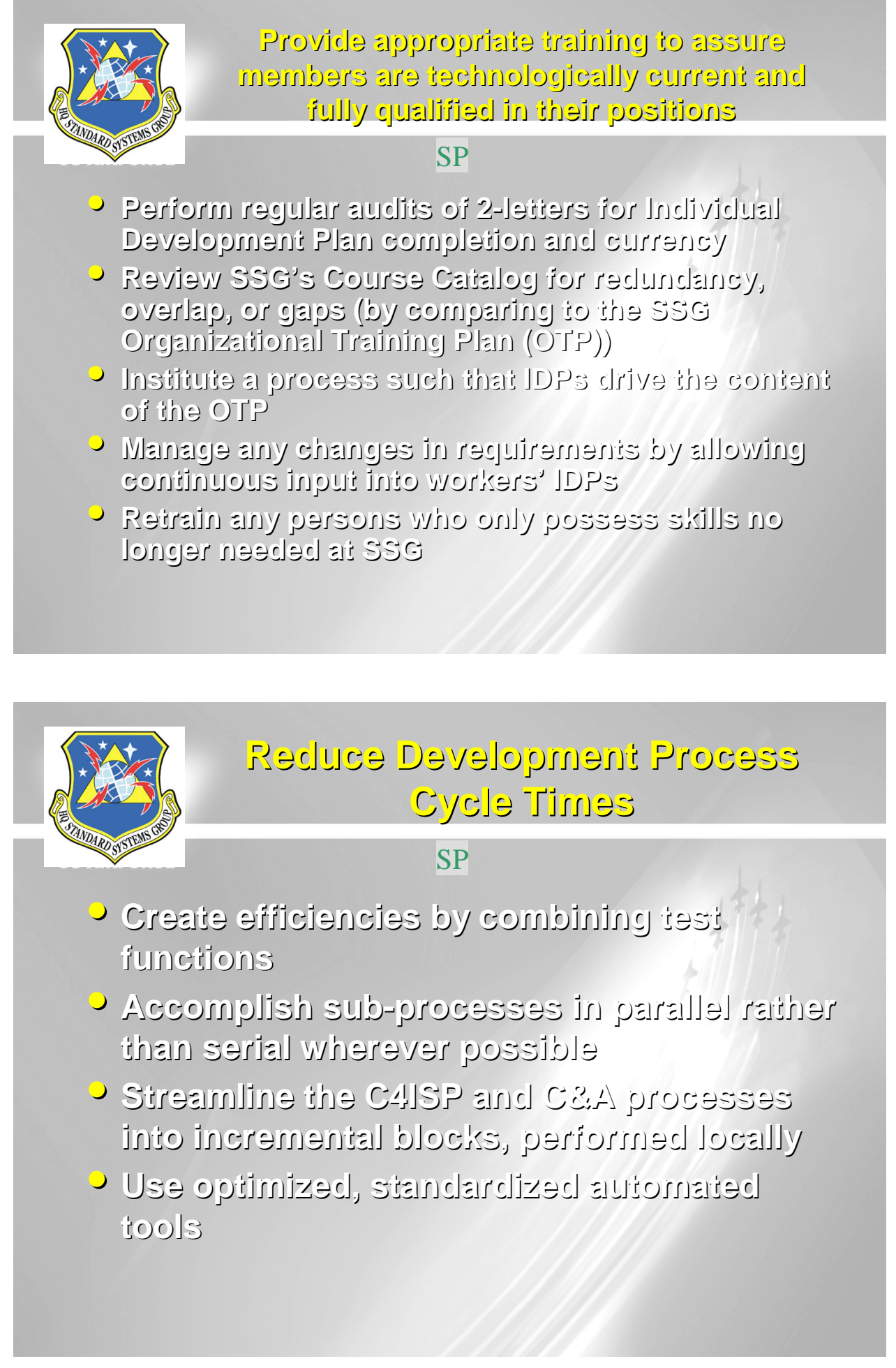


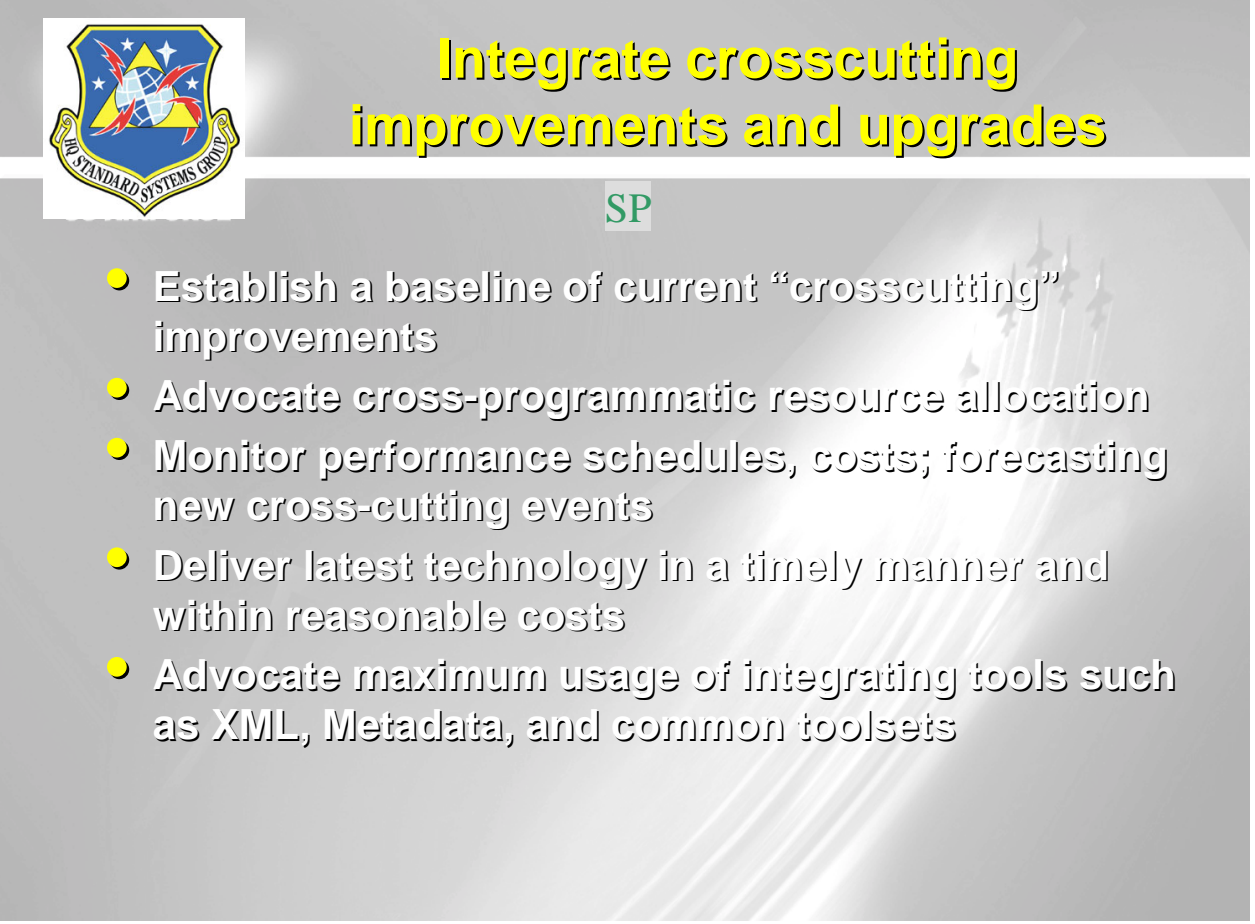




\section{Appendix E: SEl Work Plan}

This work plan was distributed at the workshop on October 27,2003.

\section{FISCAL YEAR 2003-04 WORK PLAN \\ FOR THE \\ Standard Systems Group (SSG) \\ PWS 4-198 \\ Version 1.40}

Howard Stubblefield

Standard Systems Group/XP

Thomas C. Brandt

Program Integration Directorate

Software Engineering Institute

John Foreman

Air Force Chief Engineer

Acquisition Support Program

Software Engineering Institute
Date

Date

Date 


\section{WORK PLAN CHANGE LOG}

This section contains a history of changes made to the Work Plan.

\begin{tabular}{|c|c|c|}
\hline Ver \# & Description of Change & Date \\
\hline 1.0 & Initial draft FY03 work plan & $4 / 15 / 03$ \\
\hline 1.1 & Incorporated changes from jtf, cpg, rcs, and Ken Heitkamp & $5 / 6 / 03$ \\
\hline 1.2 & $\begin{array}{l}\text { Changed signatory to Howard Stubblefield, revised task } 2.2 \text { (Technology Adoption Planning } \\
\text { Workshop), revised task } 2.8 \text { (COTS-Based Systems), added task } 2.9 \text { (Enterprise Architecture), } \\
\text { revised the cost estimates to reflect FY04 overhead rates }\end{array}$ & $6 / 17 / 03$ \\
\hline 1.35 & $\begin{array}{l}\text { - Formatting changes in the task table. } \\
\text { - Edits to most of the task descriptions. } \\
\text { - Rewrote } 2.5\end{array}$ & 30 July 03 \\
\hline 1.38 & $\begin{array}{l}\text { - Changed Tech lead, changed account exec. } \\
\text { - Changed Account exec title to "Business Manager". } \\
\text { - Added background section (section 2) to explain the project history - all section \#s } 2 \text { and } \\
\text { higher are now } 3 \text { and higher }\end{array}$ & \\
\hline 1.40 & $\begin{array}{l}\text { - Miscellaneous layout and formatting changes } \\
\text { - Added Executive CMMI intro course to the CMMI section } \\
\text { - Incorporated results of the Sept } 03 \text { TIM w/Gunter people }\end{array}$ & Oct 03 \\
\hline
\end{tabular}

\section{The information listed below must be completed:}

Name of Organization: $\quad$ Standard Systems Group

Point of Contact: $\quad$ Howard Stubblefield

Street Address: $\quad 490$ E. Moore Drive

Bldg 892

City, State, Zip Code: Maxwell AFB-Gunter Annex,

AL 36114

Phone \#:

$334-416-4041$

Fax \#:

$334-416-5505$

E-mail address: $\quad$ Bloise.Stubblefield@Gunter.AF.mil 


\section{PWS 4-198 \\ STANDARD SYSTEMS GROUP \\ WORK PLAN}

VERSION 1.40

CDRL A002

Customer:

Standard Systems Group

Maxwell AFB-Gunter Annex, AL 36114

SEI Business Manager: Lisa Masciantonio

SEI Technical Lead: Jan Vargas

SEI Chief Engineer: John Foreman

Period of Performance: 20 Sep 03 through 30 Sep 04

\section{Introduction}

This Work Plan outlines the work that members of the Software Engineering Institute (SEI) will perform under PWS 4-198 for the Standard Systems Group (SSG) during the period 20 Sep 03 through 30 Sep 04.

The intent of the SEI support detailed in this Work Plan is to:

- help SSG understand and use pertinent software engineering technologies and processes;

- $\quad$ assist SSG to improve its software acquisition practices; and

- assist $S S G$ in various transformation efforts.

This Work Plan may be revised to reflect new agreements between the SSG and the SEI. Changes to this Work Plan will require the approval of the authorized persons from the SSG and the SEI and will be documented in the Work Plan Change Log on page 2.

Additional background information can be found in PWS 4-198.

\section{Background}

In late CY02, the SEI was asked by the new SSG director, Mr. Frank Weber, to perform an "enterprise assessment" of SSG. SSG's goal is to establish itself as a Center of Excellence (CoE) for Air Force combat support Information technology (IT) systems. Given that goal, SSG asked the SEI to provide initial, objective insights on core SSG processes/organizations that are critical to establishing this $\mathrm{CoE}$, to include:

- roles/relationships between the Program Offices and Software Factory;

- Skills mix required to support future AF IT environment, to include best balance of blue suit vs. government civilian vs. contractors considering legacy system requirements, modernization/technology evolution and training requirements/capabilities;

- Core competencies to promote an integrated combat support system domain; and

- Basic organizational strategies.

Initial work culminated in a 17 Jan 03 briefing, which addressed areas of Apparent Strength and Areas of Apparent Concern toward the accomplishment of this goal. 
Further investigation to include interviews and discussions with various Air Force leaders resulted in a more detailed presentation and a closeout of the "discovery phase" on 8 May 03.

The tasking in this work plan is the direct result of the aforementioned assessment out briefs and ongoing discussion/direction from SSG leadership and is meant to be consistent with Mr. Weber's stated goals:

- Make SSG Easy to do business with . . . as deemed by our customers!

- Streamlined organization with agile processes;

- Recognized expertise in exploring and exploiting leading IT technologies;

- Enterprise-wide perspective.

\section{Tasking}

\section{Project Management}

The SEI shall coordinate the planning, implementation, and delivery of the support defined in this Work Plan. The SEI will:

- provide on-going customer interface, coordination, planning and support to ensure services and products are satisfactorily delivered;

- provide experienced SEI members of the technical staff to support the SSG;

- present status and progress briefings/reports to both the SEI and the SSG; and

- track deliverables and progress against plans, and track the expenditure of funds against schedules, milestones, and deliverables.

Refer to section 4 of the PWS for project management reporting deliverables.

Sections 3.2 through 3.10 define suggested tasking for this work plan. These tasks address technology adoption planning, workforce management, techniques for improving sustainment of existing systems, modernizing legacy systems, portfolio management, CMMI adoption planning, COTS-based systems, and enterprise architecture.

\section{Technology Adoption Planning Workshop}

The workshop is specifically focused on producing a working plan for incorporating technologies in the SEI work plan into the SSG transformation activities. The workshop will begin by reviewing the objectives and achievement strategies in the SSG FY03-08 Strategic Plan (Aug 22, 2002) to validate that they are still relevant in the context of recent organizational changes and priority changes. Working with the SSG leadership team, the SEI will collaborate in planning and prioritizing the adoption of the technologies proposed in this FY03-04 work plan. These will be explicitly connected to the SSG strategic objectives in order to provide maximum benefit to SSG in achieving said objectives.

The SEI will work with SSG prior to the workshop to establish the agenda and identify appropriate participants. Attendees at the workshop should include the Executive Director of SSG, his direct reports, and staff members who will be responsible for implementing, monitoring, and controlling the transformation effort.

Deliverable: An output of the workshop will be a prioritized list of SSG's strategic objectives tied to specific tasks in this SEI work plan. In addition to creating the prioritized list of tasks, sequencing (i.e., education/training, consulting, etc.) of the subtasks will be discussed and documented.

\section{People Capability Maturity Model (P-CMM) Gap Analysis and Improvement Plan}


One of the findings from the Enterprise Assessment was that in order for SSG to meet its transformation goals, SSG will need to fill certain skills, abilities, and knowledge gaps in their workforce. Assuming that the Technology Adoption Planning Workshop (section 3.2) confirms the aforementioned need as a priority, SEI recommends launching this effort with a P-CMM gap analysis of SSG's people management capability. The P-CMM gap analysis will involve structured interviews by SEI with SSG process owners (from DP, work environment (facilities) management, security, safety, and IT), managers, and representatives of the workforce. At a workshop, the findings from these interviews will be analyzed and synthesized into recommendations for improvement in the form of an improvement plan. The output of the workshop will show how SSG's processes for workforce management are structured to meet the mission (these are opportunities for leverage) and where the gaps are that could be inhibiting factors in the transformation.

Workshop attendees should include leadership from DP, technical staff, and middle management. SEI will work with SSG to identify these individuals. Also, SEI will require the participation of 2-3 SSG personnel and a member of the DP organization for approximately one week, full time, to contribute to the gap analysis activities and the development of the recommendations and improvement plan. SEI will work with SSG to identify appropriate personnel.

Deliverable: P-CMM Gap Analysis findings, Workshop, Improvement plan

\section{Software Sustainment - Measured Improvement of Sustainment Processes}

Most systems that are SSG's responsibility are in the sustainment phase. This task will define and apply sustainability measures to sustainment projects at SSG, identify and measure causal factors that can be correlated to sustainability measures, and implement/transition a process of metrics-based continuous sustainment process improvement to SSG.

The SEI is currently developing processes and technical practices that focus on improving the performance of sustainment activities. In order to pilot and transition these techniques, an SEI team will perform two sustainability assessments with SSG observers. The output from these assessments will be a sustainability profile consisting of an annotated set of Excel reports. The SEI will then develop training materials and train up to 10 sustainment assessors on-site at SSG. The SEI will accompany an SSG assessment team during the first SSG-lead sustainability assessment.

Deliverable: Sustainability profile reports, On-site training, Coaching/evaluation during SSG assessment

\section{Modernizing Legacy Systems}

A growing need in the emerging Air Force IT environment will be to evolve and modernize legacy systems to incorporate new technologies, function in Web-based environments, achieve horizontal integration and interoperability, and consolidate into Common applications and processes across AF/DoD. The SEI has developed processes and technical practices that focus on system modernization and evolution as well as building new systems using advanced technologies such as commercial components.

This task will enhance and grow SSG's skill sets in modernization, web-based technologies, interoperability, design and architectural alternatives, etc. The SEI will provide training in both Modernizing Legacy Systems and Building Systems from Commercial Components onsite at SSG. The SEI will provide direct support and consultation for design and architecture reviews for two selected programs, which focus on major modernization efforts and new Java-based developments. To transition these techniques to SSG personnel, and stimulate a 
culture of continuous growth and improvement, the SEI will assist/coach an SSG team as it performs a design/architecture review for a legacy system modernization.

Deliverable: On-site training, direct support and consultation for design and architecture reviews, coaching during SSG review

\section{Portfolio Management and Integration}

Portfolio management refers to a process/activity that establishes measures of technical quality and business value for the set of systems under SSG control and then evaluates the set against the measures. Business value measures the number and criticality of the business goals supported and the degree to which these goals represent core competencies of the business. Technical quality measures vary based upon business requirements but may include sustainability, evolvability, usability, performance, availability, security and other system qualities.

This task will establish criteria for measures of technical quality and business value. Then, beginning with a list of key SSG systems, this task will determine appropriate evolution/migration strategies for each (to include evolution towards the GCSS AF Integration Framework (GCSS-AF IF) and work with SSG management to prioritize and assign appropriate resources to these efforts.

Deliverable: Systems evolution assessment, High-level plan for system evolution

Changes still to be made to 3.6 to more clearly indicate how the measures of technical quality and business value get established. And how are they used to determine appropriate evolution/migration strategies.

\section{CMMI Adoption and Implementation Planning}

In 3Q02, an SSG-requested assessment of SSG's Systems Engineering Process (SEP) was conducted. The assessment compared the existing SEP to the CMMI-SE/SW V1.1. The majority of the gaps in coverage that were found resulted from the SEP being Software and SW-CMM oriented. The SEP contains a well written set of processes that can facilitate the transition from the SW-CMM to the CMMI SE/SW V1.1.

If the outcome from Task 3.2 (Technology Adoption Planning Workshop) indicates that CMMI adoption is an appropriate step for SSG, then the SEI can provide assistance in understanding and interpreting the CMMI reference model and in developing processes that are consistent with the practices contained therein. In order to move forward in this area, the SEI will present the Executive CMMI intro course and utilize findings from an Adoption Readiness and Fit Analysis to assess SSG's readiness for adopting and implementing each of the identified CMMI practices and the potential risks associated with each practice. These findings will then be used to build an Improvement Plan, which will lay out specific steps to mitigate high risk areas, and describe steps for implementing the CMMI practices for which SSG is ready.

Deliverable: Executive CMMI intro course, Readiness and Fit Analysis, Improvement Plan for implementing CMMI practices.

\section{COTS-Based Systems}

The SEl is an acknowledged expert in the techniques and practices necessary to develop and evolve software systems which are based on/extensively utilize COTS products, as opposed to building systems completely from scratch. Using COTS products requires new or alternate processes and practices throughout the system life cycle, to include but not limited to business case evaluation, requirements definition, vendor and supplier relationships/management, architecture, product evaluation, risk management, and more. Using COTS products also requires ongoing tradeoffs be made among the system context 
(requirements, cost, schedule, business processes), the system's architecture/design, and the product marketplace.

The SEI will provide SSG with training and workshops addressing the various key aspects of using COTS products, and transition new risk management, and life cycle management processes. The SEI will also provide consulting in technology insertion and adoption, especially in the context of proper approaches/processes for using Enterprise Resource Planning (ERP) systems.

Deliverable: Training and workshops, Consulting, White paper on ERP.

\section{Enterprise Architecture}

The SEI will work with SSG to develop an enterprise architecture that covers business architecture, data architecture, application architecture, and IT architecture to produce a set of guidelines on how to define system architectures. This enterprise architecture will support C4ISP support plan requirements, be implemented using C4ISR architectural views implemented in the Unified Modeling Language (UML), and incorporate the technical constraints of the GCSS AF Integration Framework (GCSS-AF IF). The enterprise architecture will initially be focused on a set or subset of Air Force information systems to be identified by SSG management.

Deliverable: TBD

\section{Standard SEI Products and Services}

This task provides SSG with the normal delivery of standard SEI products and services (i.e., courses, workshops, tutorials, publications, and events). This tasking will be used/negotiated if such a need arises during the period of this work plan. Reporting of any activity under this task will be documented in the Annual Summary Report.

\section{Technical Assistance and Guidance}

This task provides SSG with technical assistance and guidance related to the SEI initiatives and expertise. This work plan includes the flexibility to accommodate any unforeseen support requirements requested by the customer within the defined scope and in accordance with the SEI mission and initiatives. Tasking, deliverables, cost, and schedule for all involved parties will be mutually agreed upon and documented in advance of task execution. Reporting of supported services will be included in the Annual Summary Report.

\section{Knowledge Integration and Transfer}

The SEI will capture knowledge from this engagement, integrate it with lessons learned from other similar work, and help transfer that knowledge for the betterment of the software/systems engineering and acquisition community. This may include but is not limited to, briefings, technical reports, articles, advocacy, and participation in building an acquisition community of practice.

Deliverable: Lessons learned report 


\section{Task Summary}

TASK S UMM ARY

S S G - P W S 4-198

20 SEP 03 THROUGH 30 SEP 04

\begin{tabular}{|c|c|c|c|c|}
\hline $\begin{array}{l}\text { TASK } \\
\text { No. }\end{array}$ & TASK DESCRIPTION & DELIVERABLE(s) & $\begin{array}{c}\text { ESTIMATED } \\
\text { DELIVERY DATE(S) }\end{array}$ & $\begin{array}{c}\text { ESTIMATED } \\
\text { COST }\end{array}$ \\
\hline 3.1 & Project Management & Management and Technical Reports & Various per PWS \#4-198 & $\$ 78,100$ \\
\hline 3.2 & $\begin{array}{l}\text { Technology Adoption Planning } \\
\text { Workshop }\end{array}$ & Technology adoption plan & $\begin{array}{l}\text { Anytime after the work plan is } \\
\text { signed ( } \& \text { depending on } \\
\text { availability of key SSG } \\
\text { personnel) }\end{array}$ & $\$ 58,400$ \\
\hline 3.3 & $\begin{array}{l}\text { P-CMM Gap Analysis and } \\
\text { Improvement Plan }\end{array}$ & $\begin{array}{l}\text { Gap analysis findings } \\
\text { Workshop } \\
\text { Improvement plan }\end{array}$ & TBD & $\$ 48,700$ \\
\hline 3.4 & Software Sustainment & $\begin{array}{l}\text { Sustainability profile reports } \\
\text { On-site training } \\
\text { Coaching/evaluation during SSG } \\
\text { assessment }\end{array}$ & $\begin{array}{l}\text { TBD (1 month and } 3 \text { months } \\
\text { after task start date ) } \\
\text { TBD ( } 5 \text { months after task start } \\
\text { date) } \\
\text { TBD (6 months after task start } \\
\text { date) }\end{array}$ & $\$ 67,000$ \\
\hline 3.5 & Modernizing Legacy Systems & $\begin{array}{l}\text { On-site training } \\
\text { Techniques, guidance in and direct } \\
\text { support for architecture and design } \\
\text { reviews } \\
\text { Coaching/evaluation during SSG } \\
\text { review }\end{array}$ & $\begin{array}{l}\text { TBD ( } 3 \text { months after task start } \\
\text { date) } \\
\text { As needed } \\
\text { TBD }\end{array}$ & $\$ 75,000$ \\
\hline 3.6 & $\begin{array}{l}\text { Portfolio Management and } \\
\text { Integration }\end{array}$ & $\begin{array}{l}\text { Systems evolution assessment } \\
\text { High-level plan for system evolution }\end{array}$ & $\begin{array}{l}\text { As needed } \\
\text { As needed }\end{array}$ & $\$ 15,500$ \\
\hline 3.7 & CMMI Adoption Planning & $\begin{array}{l}\text { Executive CMMI intro course } \\
\text { Readiness and Fit findings } \\
\text { Improvement plan }\end{array}$ & $\mathrm{TBD}$ & $\$ 38,600$ \\
\hline 3.8 & COTS-Based Systems & Training and workshops & TBD & $\$ 75,000$ \\
\hline
\end{tabular}




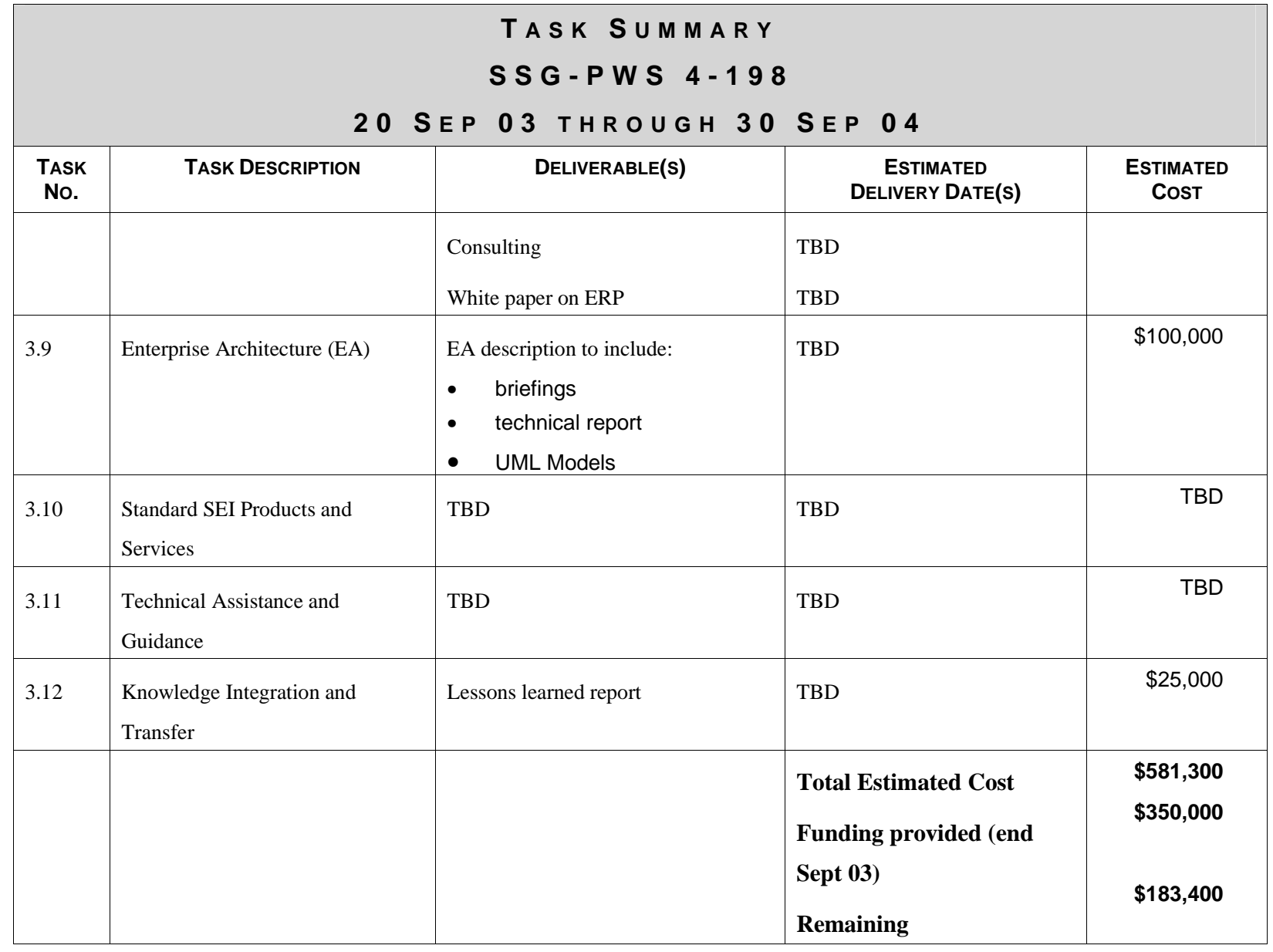

Note: Estimated costs listed above include staff and travel costs. Costs are estimates only. The actual cost will depend on the actual staff resources that are used and travel that is completed. Only actual resources expended, plus actual travel costs will be charged. The estimated delivery dates listed above assume the availability of the needed participants from SSG and a Work Plan start date of no later than $20 \mathrm{Sep} 03$. Adjustments may be required, based on actual start date and mutual availability of SSG and SEI staff. 


\section{Appendix F: People Capability Maturity Model (P-CMM)}

Gian Wemyss gave the following PowerPoint presentation at the workshop on October 27, 2003.

CarnegieMellon

Software Engineering Institute

Pittsburgh, PA 15213-3890

People Capability Maturity Mode ${ }^{\circledR}$ $\left(\right.$ People $\mathrm{CMM}^{\circledR}$ ) version 2

Gian Wemyss

Senior Member of the Technical Staff

Capability Maturity Model Team

Sponsored by the U.S. Department of De (C) 2002 by Carnegie Mellon University

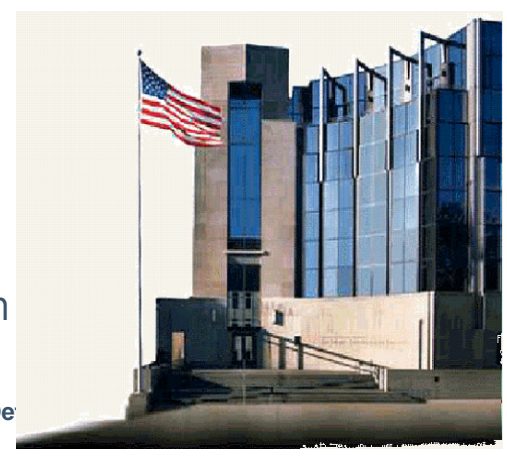

page 1 


\section{Improving Organizations}

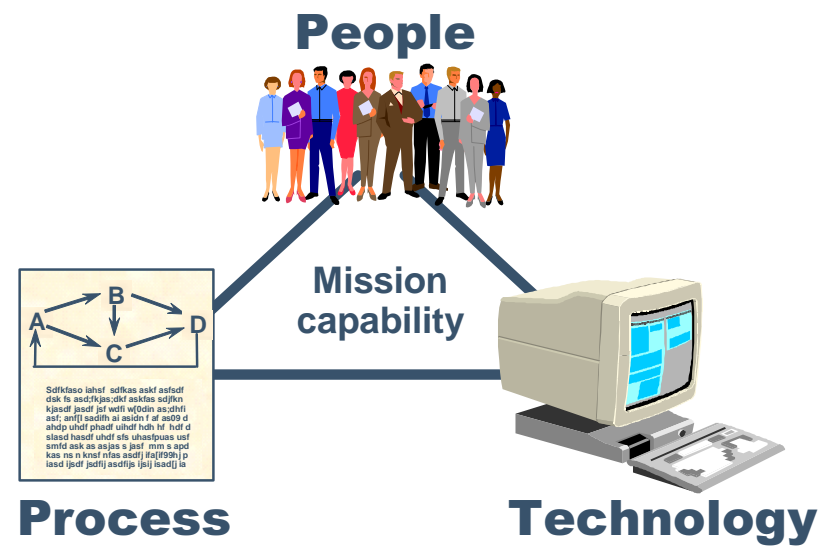

CarnegieMellon

Software Engineering Institute

\section{What Is the People CMM ?}

An organizational change roadmap based on state-of-the-art workforce practices to help organizations:

- Develop the workforce required to execute organization strategy

- Characterize maturity of workforce practices

- Set priorities for improving workforce capability

- Integrate improvements in process and workforce

originally developed with support from the U.S. Army and the Office

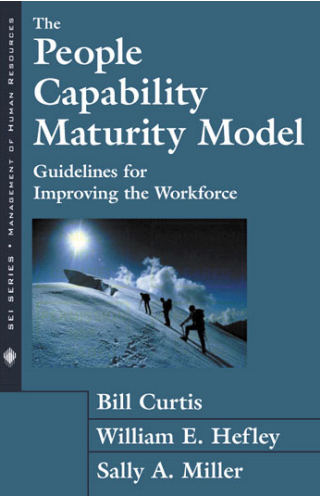
of the Secretary of Defense 


\section{Founding Advisory Board}

Miriam Browning
Ed Cotter
Barry Frew
Paul Garber
Paul Gehrmann
Glenn Gienko
Marlene Griffin-Bunnell
Watts Humphrey
James Jackson
Cindy Kendall
Belkis Loeng-Hong
Sally Mathews
Jeff McHenry
Ron Radice
Roger Sobkowiak
Ed Thompson

\author{
U.S. Army \\ Digital Equipment Corporation \\ Naval Postgraduate School \\ Citicorp \\ International Business Machines \\ Motorola \\ Eli Lilly \& Co. \\ Software Engineering Institute \\ Texas Instruments \\ Office of the Secretary of Defense \\ Defense Information Systems Agency \\ General Services Administration \\ Microsoft \\ Software Technology Transition \\ Software People Concepts \\ Advanced Research Projects Agency
}

CarnegieMellon

Software Engineering Institute

People CMM Foundations

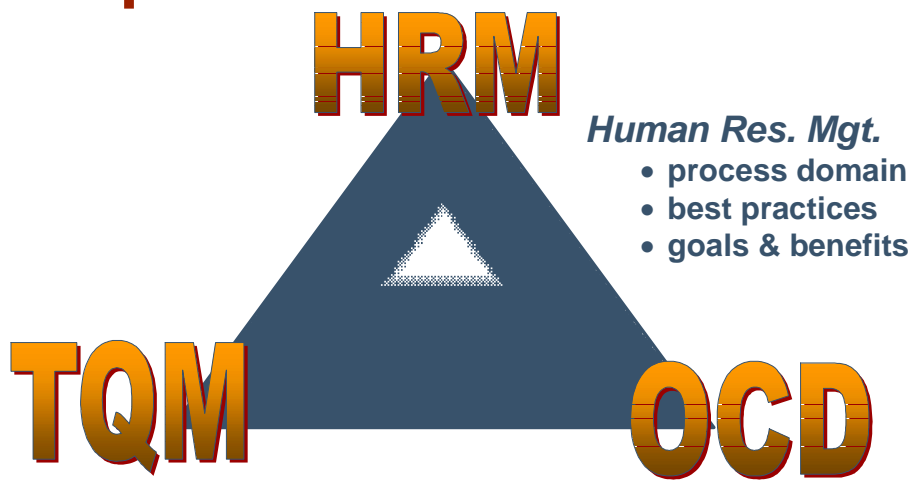

Total Quality Mgt.

- process \& performance

- quantitative management

- continuous improvement
Org. Change \& Devel.

- culture \& maturity

- assess \& improve

- change management 


\section{People CMM-Based Improvement}

- Improvement in Workforc Capability

- The model helps us understand "what" to do.

- "How" is up to the organization.

- The model is a roadmap.

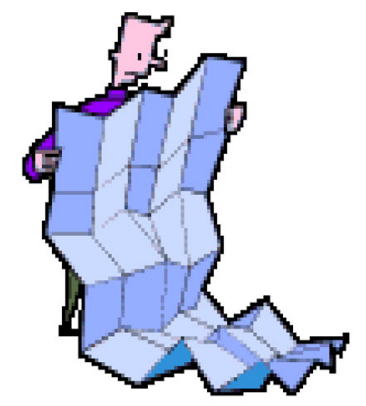

CarnegieMellon Software Engineering Institute

\section{Why Adopt People CMM?}

1) Become 'Employer of Choice'

2) Enhance organization performance

3) Manage:

- intellectual assets

- knowledge capital

4) Measure HR's contribution to the business

- provides common measurement framework

- allows benchmarking against best practices 


\section{Why People CMM for SSG?}

- Enhance Project Management Skills Base.

- Develop Your Technical Expertise.

- Communication and Coordination of the SSG strategic plan.

- Mitigate the loss of institutional knowledge (employees eligible for retirement, opportunities from other organizations, outplacement).

- Understand what investment to make in "smart" organic workers.

- Establish a Culture of Human Capital Management.

(9) 2002 by Carnegie Mallon University

\section{People $\mathrm{CMM}^{\circledR}$ Architecture}

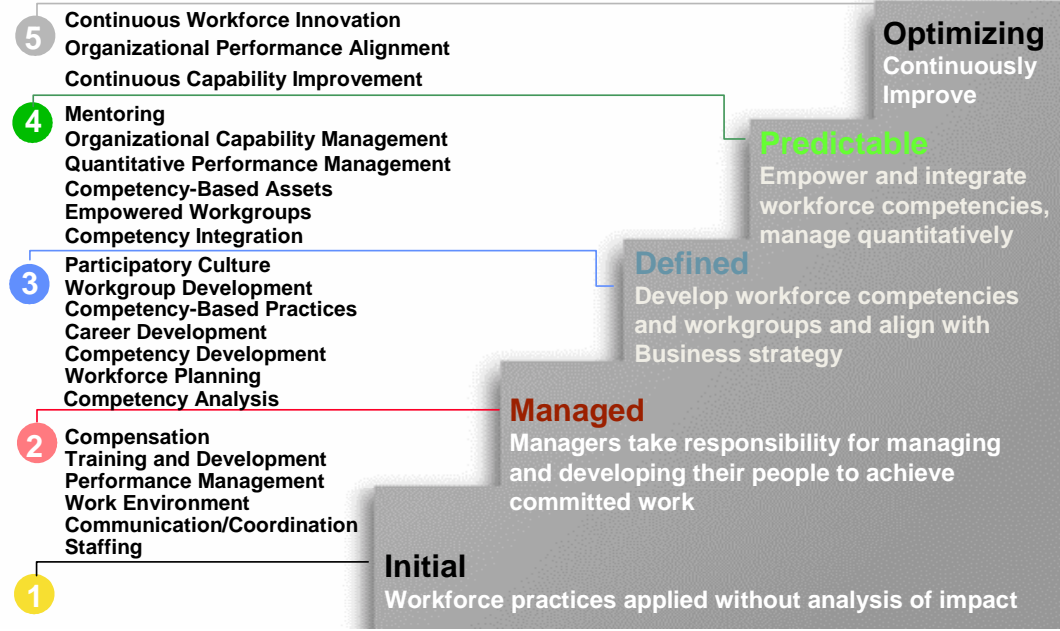

(c) 2002 by Carnegie Mellon University 


\section{Staffing Process Example}
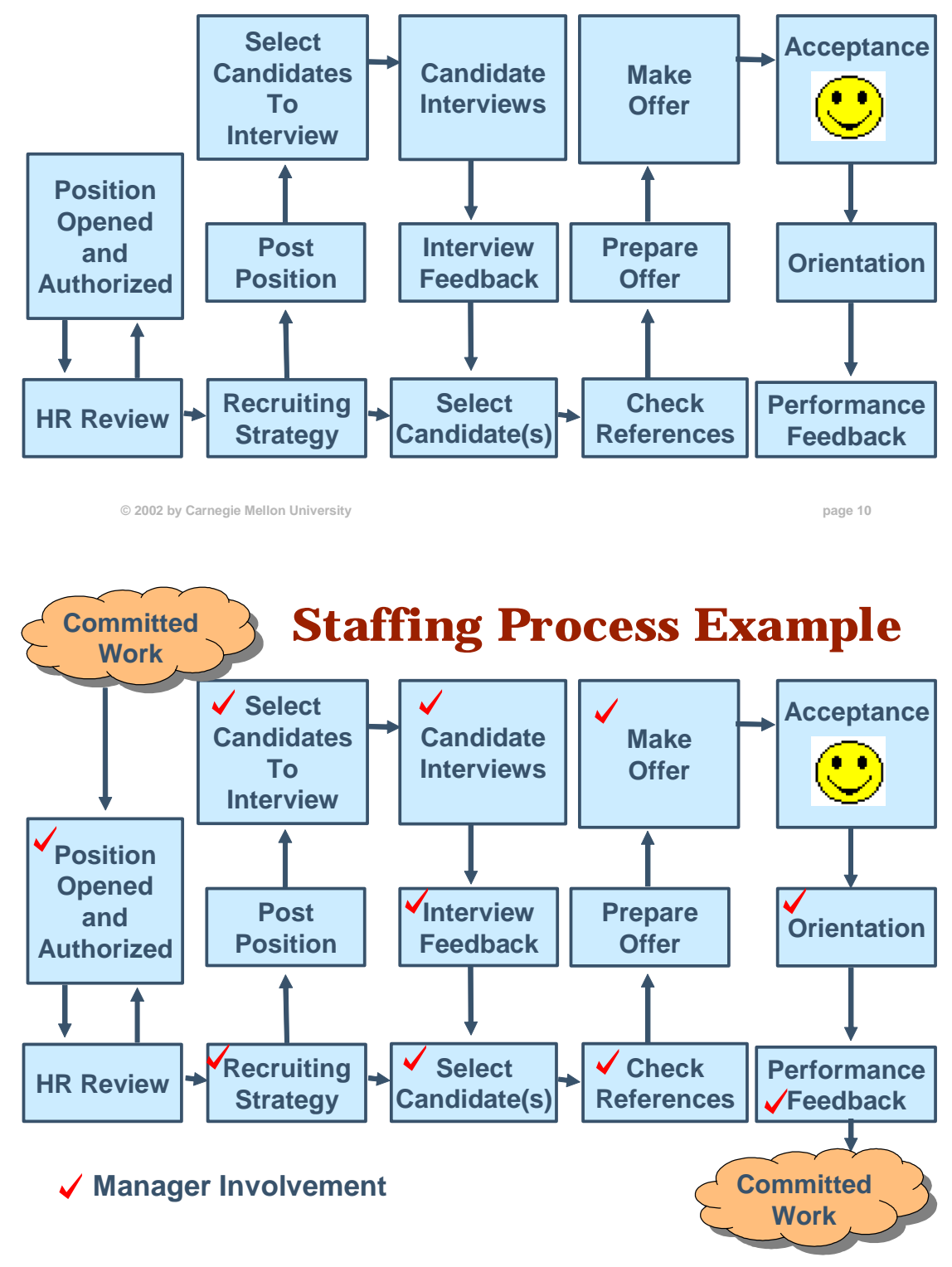


\section{All the solutions have to fit}

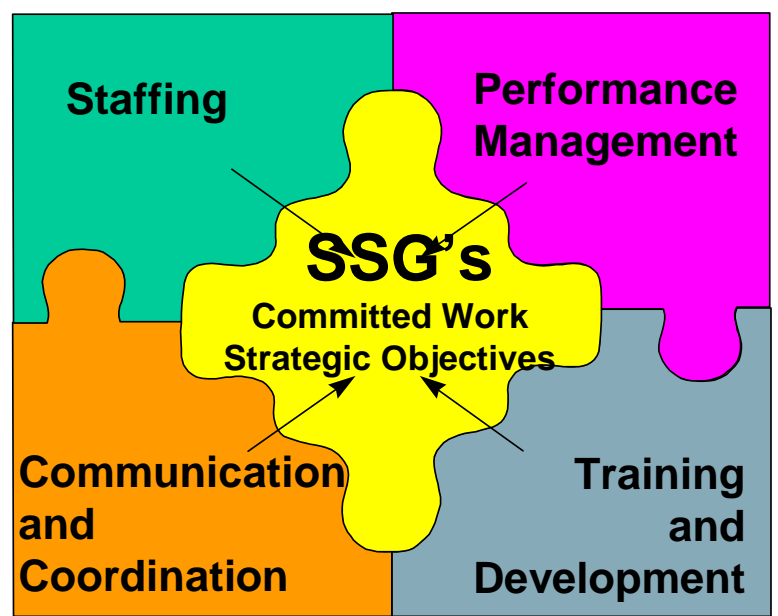

CarnegieMellon

Software Engineering Institute

\section{Questions}
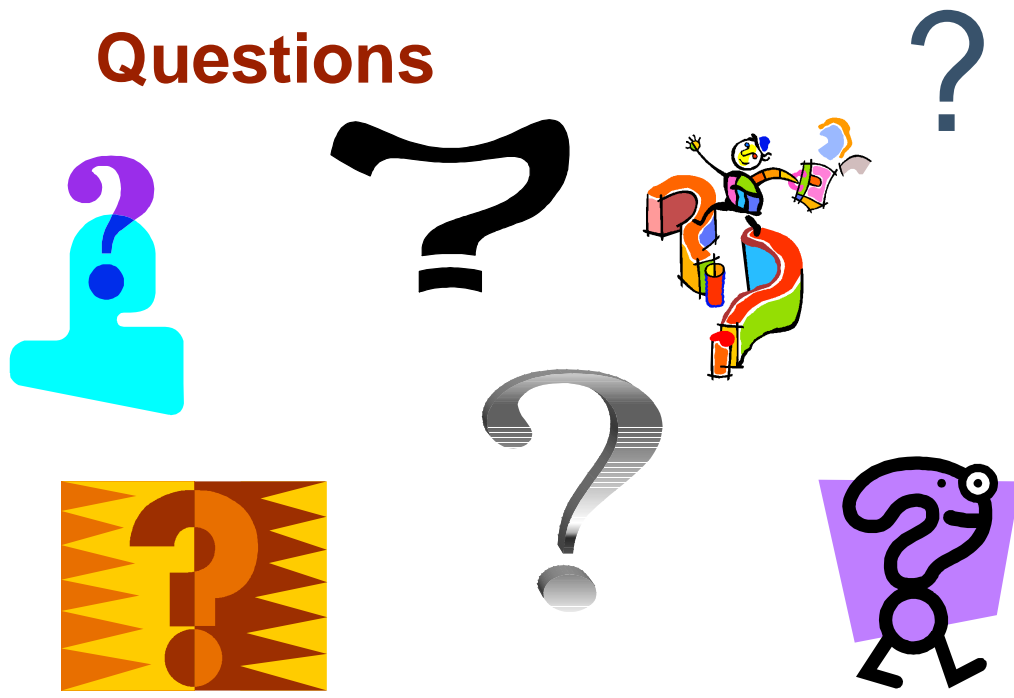


\section{Appendix G: Enterprise Architecture}

Grady Campbell gave the following PowerPoint presentation on October 27, 2003.

CarnegieMellon

Software Engineering Institute

Pittsburgh, PA 15213-3890

\section{Enterprise Architecture}

Grady Campbell

(Robert Seacord)

Sponsored by the U.S. Department of Defense (C) 2003 by Carnegie Mellon University

page 1 
CarnegieMellon

Software Engineering Institute

\section{Enterprise Architecture}

A coherent view of the mission and capabilities of an enterprise and an integrated business/technology strategy for achieving the organization's goals

The set of rules that guide all system development, modernization, and system integration efforts, aligned with enterprise strategic business goals.

- Description of supported business processes

- Description of common services

- Description of legacy migration path

- Prescribed technologies and usage guidelines

- Guidelines for development of system architectures

- Patterns (blueprints) for implementation of applications that use the common services and prescribed technologies

CarnegieMellon

Software Engineering Institute

\section{A Simplified Model of Enterprise Architecture}

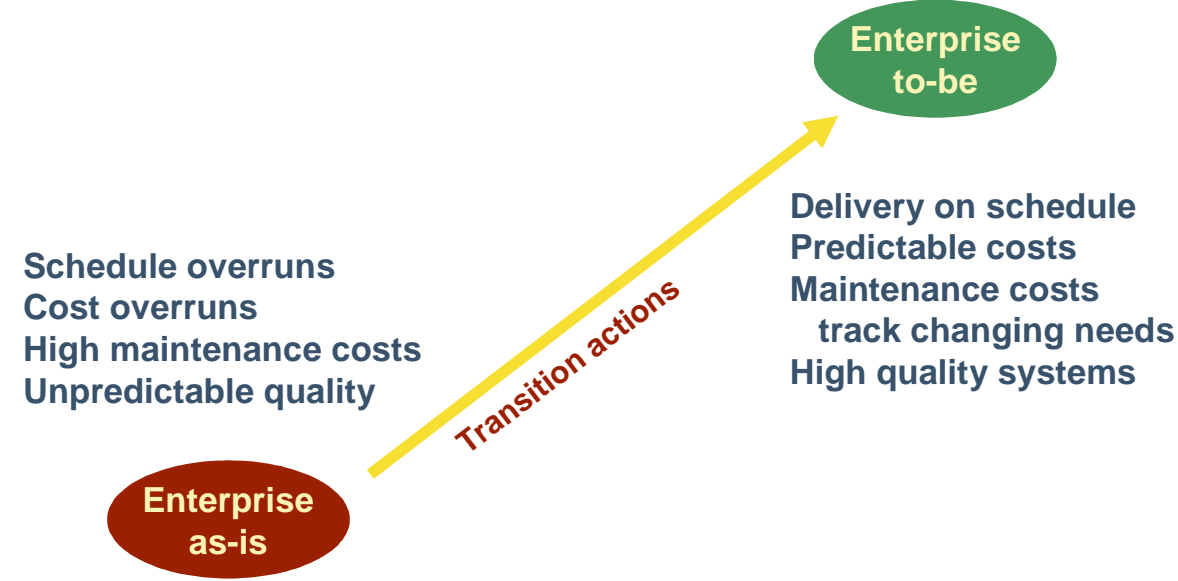


Carnegie Mellon

Software Engineering Institute

\section{Realistic Model for Enterprise Architecture}

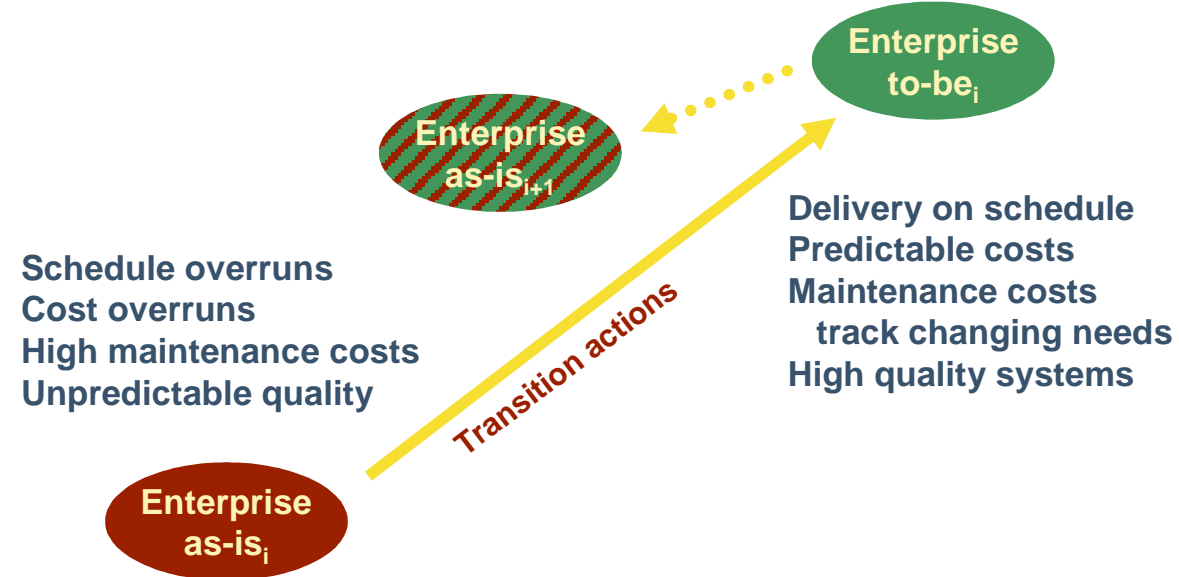

CarnegieMellon

Software Engineering Institute

\section{Enterprise Architecture Elements}

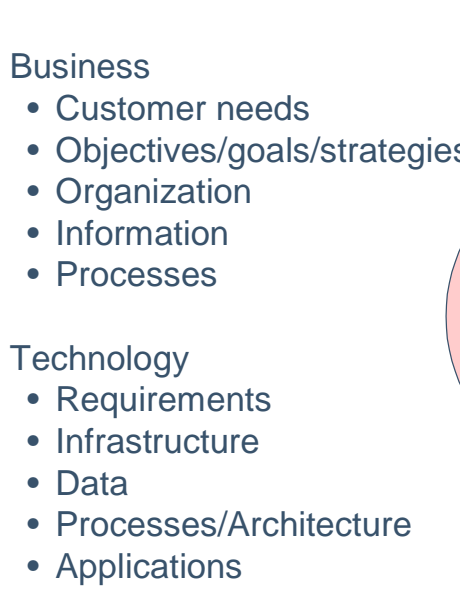

(๑) 2003 by Carnegie Mellon University

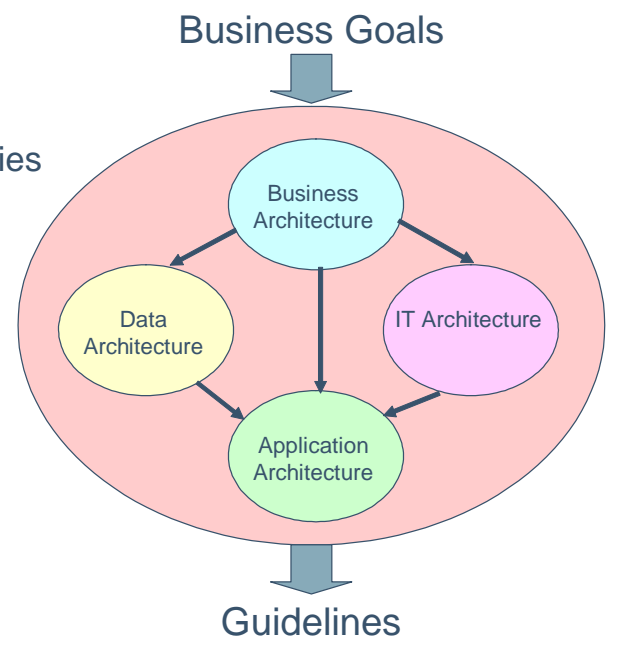

page 5 
CarnegieMellon

Software Engineering Institute

\section{Business Architecture}

Business goals and core competencies

Business processes

Organizational structure

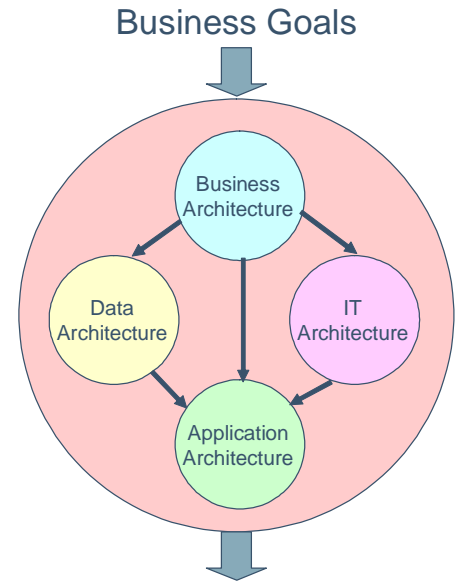

Guidelines

\section{Data Architecture}

Enterprise business information/data needs, supported by:

- Database distribution

- Data mining

- Data protocols for integration and exchange

- Data integrity and security

- Data usage

- Data migration (optional)

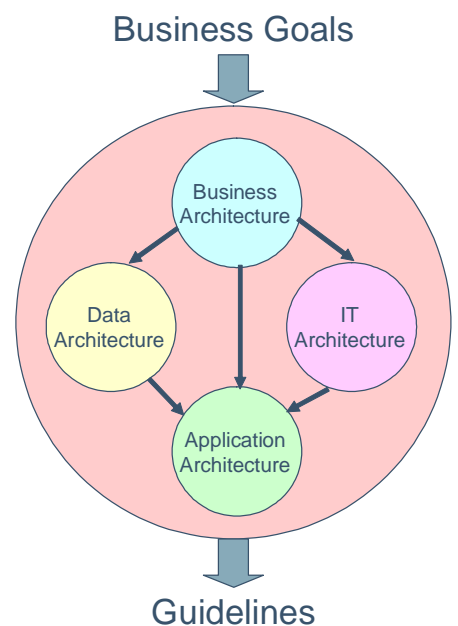

page 7 
CarnegieMellon

Software Engineering Institute

\section{Information Technology Architecture}

Hardware and software, the technological base for the enterprise (e.g., GCSS-AF)

- Server configurations

- Client configurations

- Network configuration

- Middleware

- Devices (storage, printing, etc.)

- Development environments

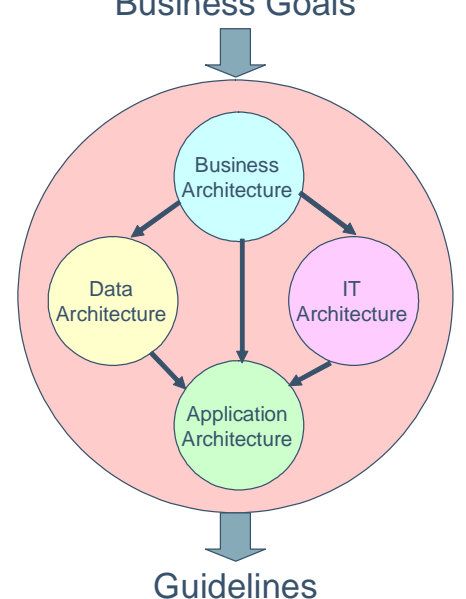

단 2003 by Carnegie Mellon University

CarnegieMellon

Software Engineering Institute

\section{Application Architecture}

Blueprints for the construction of applications, based on the IT technologies and business data to support business processes.

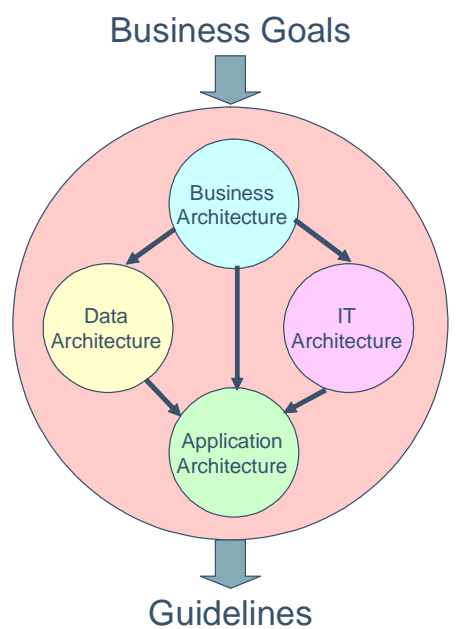

Guidelines 


\section{Appendix H: Software Sustainment and Modernizing Legacy Systems}

Dan Plakosh gave the following PowerPoint presentation on October 27, 2003.

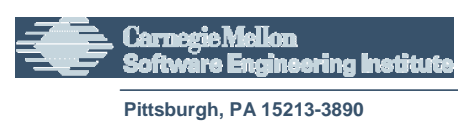

\section{Software Sustainment}

Sponsored by the U.S. Department of Defense

() 2003 by Carnegie Mellon University

page 1 


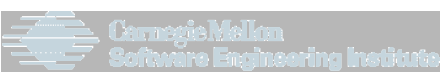

\section{Software Sustainment ${ }^{\star}$}

There will always be old software

The term "software sustainment" is not well-defined. It has some use within DoD and limited use in academia and industry.

JAC/SEI Definition (from Challenge Problems) ${ }^{1}$

"implies integrated logistic support, which includes all aspects of acquisition after initial system delivery including, e.g., maintenance, evolution, upgrades, warranties, and depot management"

DoD definition ${ }^{2}$

"involves a full spectrum of support, ranging from acquisition and outsourcing, to in-house development and modification (with little maintenance) of software"

*Generally refers to activities and techniques used to maintain software after it has been developed

'Software Engineering Thrusts and Challenge Problems

${ }^{2}$ Lt. Col. Joe Jarzombek, U.S. Air Force ESIP Director, Realities of Software Sustainment vs. Maintenance CrossTalk, May 1997

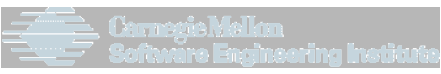

\section{Top DoD Software Sustainment Issues ${ }^{1}$}

\section{Staffing: Software engineering staff instability or shortages}

Computer Resources and System / Software Engineering Environment (S/SEE) Capability: Obsolete and/or saturated computer hardware; adequacy and long-term viability of the support / test environment, programming language, etc.

Training: Lack of appropriate and timely training

Documentation: Inadequate or outdated system/software documentation

Guidance: Lack of policy, guidance, and methods for SIWS acquisition and support

${ }^{1}$ AF ClO directed study "Weapon System Software Sustainment Study", Apr 2001

SIWS- Software Intensive Weapon Systems 


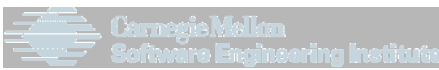

Software Evolution and Maintenance

Why is this important?

Software Lifetime and Maintenance Cost

- Average lifetime of software is about 10 years $^{1}$

- Most of the lifecycle costs for software occur after initial system delivery ${ }^{2}$

- Maintenance now represents over $70 \%$ of the total cost

'T. Tamai and Y. Torimitsu, "Software Lifetime and its Evolution Process over Generations", Proceedings of 1992
Conference on Software Maintenance, Nov. 1992.
2R. Grady, Software Metrics: Establishing a Company-Wide Program, Prentice-Hall, 1987.

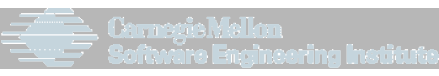

\section{Software Maintenance Statistics 1}

It is estimated that US Corporations spend over $\$ 30$ billion annually on software maintenance, and in the 1990's, $95 \%$ of lifecycle cost would go to maintenance. ${ }^{1}$

\begin{tabular}{|l|c|c|}
\hline \multicolumn{1}{|c|}{ Survey } & Year & Maintenance (\%) \\
\hline Canning & 1972 & 60 \\
\hline Boehm & 1973 & $40-80$ \\
\hline deRose/Nyman & 1976 & $60-70$ \\
\hline Mills & 1976 & 75 \\
\hline Zeikowitz & 1979 & 67 \\
\hline Cashman and Holt & 1979 & $60-80$ \\
\hline
\end{tabular}
Maintenance Costs as a \%of Total Software Lifecycle
Costs

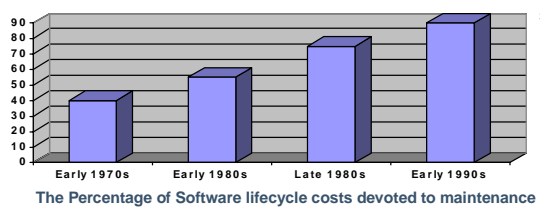

${ }^{1}$ Gartner Group

${ }^{2}$ Arthur, L. J. Software Evolution: The Software Maintenance Challenge. John Wiley \& Sons, New York

3988. J. Maintaining The Competitive Edge DATAMATION 61-6. 1990

(C) 2003 by Carnegie Mellon University 


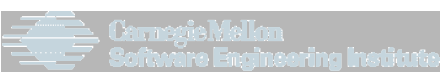

\section{Software Maintenance Statistics ${ }_{2}$}

Over $75 \%$ of maintenance costs are for providing enhancements in the form of adaptive and perfective maintenance.

\begin{tabular}{|l|c|c|c|c|}
\hline $\begin{array}{c}\text { Maintenance } \\
\text { Category }\end{array}$ & $\begin{array}{c}\text { Lientz \& } \\
\text { Swanson } \\
1980\end{array}$ & $\begin{array}{c}\text { Ball } \\
1987\end{array}$ & $\begin{array}{c}\text { Deklava } \\
1990\end{array}$ & $\begin{array}{c}\text { Abran } \\
1990\end{array}$ \\
\hline Corrective & $22 \%$ & $17 \%$ & $16 \%$ & $21 \%$ \\
\hline Non-Corrective & $78 \%$ & $83 \%$ & $84 \%$ & $79 \%$ \\
\hline
\end{tabular}

$\%$ effort spent on Corrective and Non-Corrective maintenance

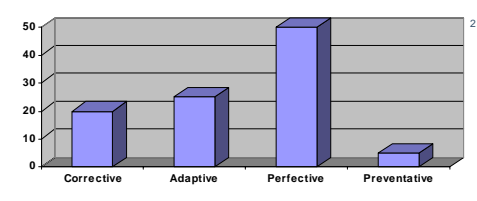

Distribution of maintenance by categories

'Leintz \& Swanson 1980 Lientz B. P. \& Swanson E. B. Software Maintenance Management. Addison-Wesley Publishing Company. Reading ${ }^{2}$ Martin J. and McClure C. Software Maintenance: The Problems and Its Solutions. Englewood Cliff, NJ: Prentice Hall

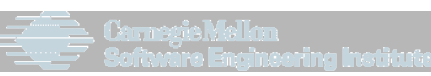

\section{Software Maintenance Statistics ${ }_{3}$}

Software maintenance consumes the biggest part of the budget devoted to software

\begin{tabular}{|l|c|c|c|}
\hline & Avg. & Information system & Real time software \\
\hline Development & $\mathrm{n}$ & $\mathrm{n}$ & $\mathrm{n}$ \\
\hline Maintenance & $5 \times \mathrm{n}$ & $3 \times \mathrm{n}$ & $7 \times \mathrm{n}$ \\
\hline Corrective Maintenance & $7,5 \times \mathrm{n}$ & $5 \times \mathrm{n}$ & $12 \times \mathrm{n}$ \\
\hline Adaptive Maintenance & $5 \times \mathrm{n}$ & $2 \times \mathrm{n}$ & $5 \times \mathrm{n}$ \\
\hline Perfective Maintenance & $4 \times \mathrm{n}$ & $3 \times \mathrm{n}$ & $5 \times \mathrm{n}$ \\
\hline Evolutive Maintenance & $3 \times \mathrm{n}$ & $2 \times \mathrm{n}$ & $7 \times \mathrm{n}$ \\
\hline
\end{tabular}

Cost of developing vs. maintaining 


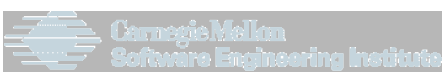

\title{
Some Reasons for Software Decay
}

\author{
Brittle architectures \\ Requirements changes \\ Inadequate documentation \\ Loss of staff \\ Technological change \\ - operating system \\ - language \\ - changes in supporting software \\ - methods and paradigms (e.g., structured to object oriented) \\ - tools \\ (ㅇ 2003 by Carnegie Mellon University
}

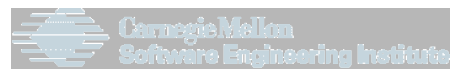

\section{Building Software for Sustainment}

General guidelines (that everybody knows, but few practice):

- Build it right the first time

- Move to the left

- Develop a robust architecture

- Design for change

- Have strong separation of concerns

- Document the knowledge and rationale for design and changes

- Have a disciplined process, methods, and tools 


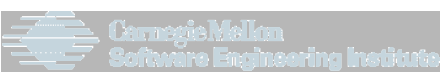

\section{Software Sustainment - How can} we help?

\begin{tabular}{|c|c|}
\hline Area & Activity \\
\hline $\begin{array}{l}\text { Pre Software Development - } \\
\text { Acquisition Phase }\end{array}$ & $\begin{array}{l}\text { Provide RFP language (sections } \\
\text { L\&M) and evaluation criteria that can } \\
\text { help increase the sustainability of the } \\
\text { software to be developed }\end{array}$ \\
\hline $\begin{array}{l}\text { Software Development } \\
\text { Phase - Prior to transition to } \\
\text { sustainment }\end{array}$ & $\begin{array}{l}\text { Develop policies and processes that } \\
\text { will help increase the sustainability of } \\
\text { the software once it is transitioned. }\end{array}$ \\
\hline During Sustainment & $\begin{array}{l}\text { - Develop policies and processes that } \\
\text { will help keep the system } \\
\text { sustainable through out its lifecycle. } \\
\text { - Apply some of our research work in } \\
\text { sustainment and transition, if } \\
\text { suitable }\end{array}$ \\
\hline
\end{tabular}

\section{Modernizing Legacy Systems}




\section{Modernizing Legacy Systems,}

A Legacy System can be defined as "any system that significantly resists modification and evolution." [Brodie 95]

They can cause several problems

- Usually run on obsolete hardware that is slow and expensive to maintain.

- Software maintenance can also be expensive, because documentation and understanding of system details is often lacking and tracing faults is costly and time consuming.

- A lack of clean interfaces makes integrating with other systems difficult.

- Often are difficult, if not impossible, to extend.

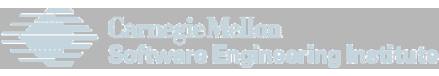

\section{Modernizing Legacy Systems}

Modernization involves extensive changes, but conserves a significant portion of the existing system.

For example:

\begin{tabular}{|l|l|}
\hline \multicolumn{1}{|c|}{ Modernize From } & \multicolumn{1}{c|}{ To } \\
\hline $\begin{array}{l}\text { Batch sequential } \\
\text { architecture }\end{array}$ & $\begin{array}{l}\text { B2B/component- } \\
\text { based architecture }\end{array}$ \\
\hline $\begin{array}{l}\text { Hierarchical/network } \\
\text { structure database }\end{array}$ & Relational structure \\
\hline Mainframe platform & J2EE-based platform \\
\hline COBOL/Fortran & Java \\
\hline
\end{tabular}




\section{Software Evolution}

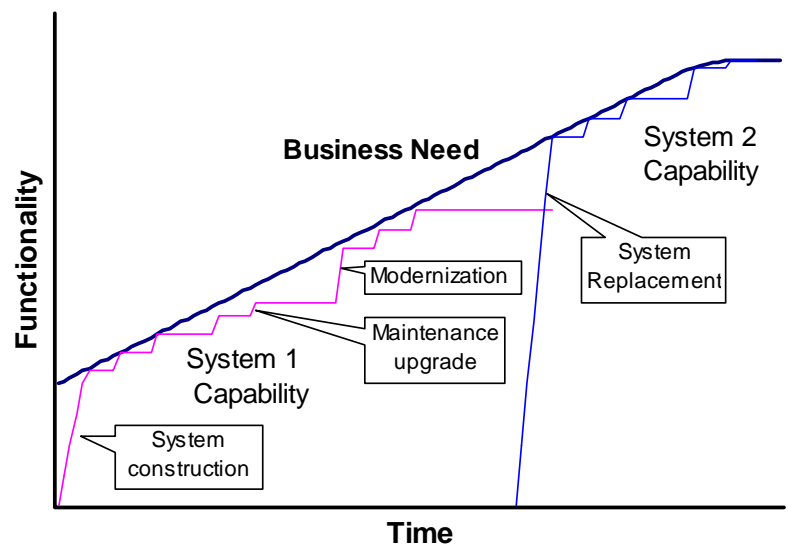

\section{Chresishallin}

\section{Legacy Crisis 1}

The amount of legacy code is immense and growing.

- 250 billion lines of source code being maintained

[Sommerville 00].
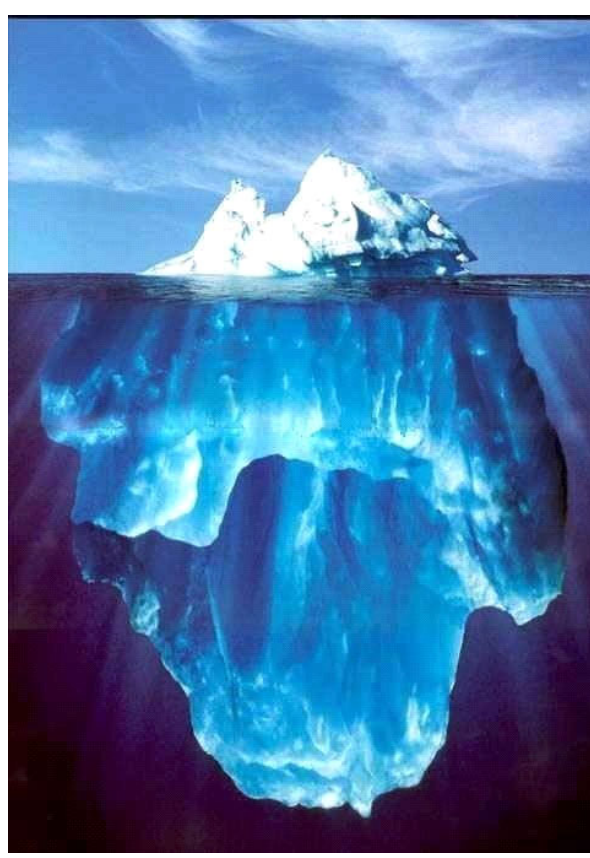


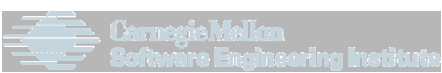

\section{Legacy Crisis 2}

Information systems expand with time

- The average Fortune 100 company [Müller 94]

- maintains 35 million lines of code

- adds $10 \%$ per year in updates, enhancements, and other maintenance.

- code doubles in size every seven years

Cumulative code changes over many years often lead to less maintainable code.

Increased complexity means that the system becomes increasingly brittle.

\section{Modernization Challenges}

Legacy system size and complexity

Conflicting stakeholder priorities

Software technology and engineering processes

Achieving business objectives 


\section{Modernizing Legacy Systems - How can we help?}

- Provide training and coaching with respect to modernizing legacy systems

- Address the Legacy Modernization Challenges

- Establish good modernization strategies

- Direct support and consultation

- Design and architecture reviews

- Determine technical quality and business value of candidate software

- Development and execution of tailored modernization strategies 


\section{Appendix I: Capability Maturity Model - Integrated (CMMI)}

Kristi Keeler gave the following PowerPoint presentation on October 27, 2003.

Pittsburgh, PA 15213-3890

Arlington, VA. 22203
$\mathrm{CMMI}^{\circledR}$ - The Next Step in
Process Improvement

SSG Presentation 10-27-2003

Kristi Keeler

SM SCAMPI, SCAMPI Lead Appraiser, and SEl are service marks of Carnegie Mellon University.

(®) CMMI, Capability Maturity Model, and CMM are registered in the U.S. Patent and Trademark Office by Carnegie Mellon

University.

Sponsored by the U.S. Department of Defense

๑) 2003 by Carnegie Mellon University 
Carnegie Mellon

Software Engineering Institute

\section{This Presentation}

Provides an overview of CMMI

The Past—where we've been and what has influenced us

The Present-where we are

The Future—where we are going and how you can help

\section{The Past}

era of "manufacturing in quality"

The premise of "manufacturing in quality"

- Implies a focus on processes as well as on products

- Is a long-established premise in manufacturing

- Is based on Total Quality Management principles as taught by Shewhart, Juran, Deming, and Humphrey

"It costs a lot of money to build bad products."

Augustine's $12^{\text {th }}$ Law

"The quality of a system is highly influenced by the quality of the process used to acquire, develop, and maintain it."

Phillip Crosby "Quality is Free: The Art of Making Quality Certain" 
CarnegieMellon

Software Engineering Institute

Quality Management Maturity Grid

\begin{tabular}{|c|c|c|c|c|c|}
\hline $\begin{array}{l}\text { Management } \\
\text { Categories }\end{array}$ & $\begin{array}{l}\text { Stage 1: } \\
\text { Uncertainty }\end{array}$ & $\begin{array}{l}\text { Stage 2: } \\
\text { Awakening }\end{array}$ & $\begin{array}{l}\text { Stage 3: } \\
\text { Enlightenment }\end{array}$ & $\begin{array}{l}\text { Stage 4: } \\
\text { Wisdom }\end{array}$ & $\begin{array}{l}\text { Stage 5: } \\
\text { Certainty }\end{array}$ \\
\hline $\begin{array}{l}\text { Cost of } \\
\text { quality as \% } \\
\text { of sales }\end{array}$ & $\begin{array}{l}\text { Reported: } \\
\text { unknown } \\
\text { Actual: 20\% }\end{array}$ & $\begin{array}{l}\text { Reported: } \\
5 \% \\
\text { Actual: } 18 \%\end{array}$ & $\begin{array}{l}\text { Reported: } 8 \% \\
\text { Actual: } 12 \%\end{array}$ & $\begin{array}{l}\text { Reported: } \\
6.5 \% \\
\text { Actual: } 8 \%\end{array}$ & $\begin{array}{l}\text { Reported: } \\
2.5 \% \\
\text { Actual: } 2.5 \%\end{array}$ \\
\hline $\begin{array}{l}\text { Summation } \\
\text { of company } \\
\text { quality } \\
\text { posture }\end{array}$ & $\begin{array}{l}\text { "We don't } \\
\text { know why } \\
\text { we have } \\
\text { quality } \\
\text { problems." }\end{array}$ & $\begin{array}{l}\text { "Must we } \\
\text { always have } \\
\text { quality } \\
\text { problems?" }\end{array}$ & $\begin{array}{l}\text { "We are } \\
\text { identifying and } \\
\text { resolving our } \\
\text { quality } \\
\text { problems." }\end{array}$ & $\begin{array}{l}\text { "We } \\
\text { routinely } \\
\text { prevent } \\
\text { defects } \\
\text { from } \\
\text { occurring." }\end{array}$ & $\begin{array}{l}\text { "We know } \\
\text { why we don't } \\
\text { have quality } \\
\text { problems." }\end{array}$ \\
\hline
\end{tabular}

Crosby, P. Quality is Free: The Art of Making Quality Certain. New York: McGrawHill, 1979.

(9) 2003 by Carnegie Mellon University

CarnegieMellon

Software Engineering Institute

The Present

era of "engineering in quality"

$\mathrm{CMMs}^{\circledR}$ focus on

- Process and product quality

- Business results

- Engineering in quality

CMMs continue to be adopted and used

Companies in key markets are adopting CMMs

- Defense

- Aerospace

- Automotive

- Entertainment

- Telecommunications

- Finance 
CarnegieMellon

Software Engineering Institute

\section{Multiple Process Models}

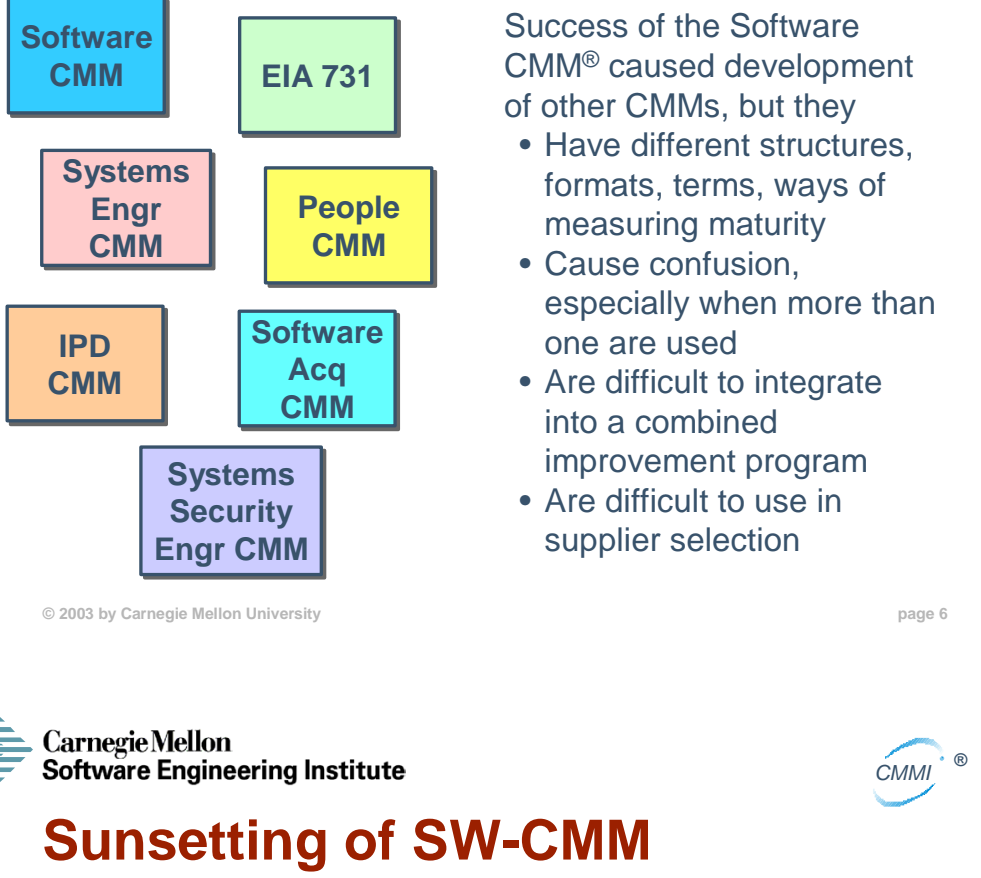

Introduction to SW-CMM training course

- Last public offering from SEISM is December 2003

- Continued availability from transition partners

CBA-IPI Assessments and SCE Evaluations

- Last Lead Assessor (LA) training is December 2003

- Last Lead Evaluator (LE) training is October 2003

- LA and LE authorizations expire December 31, 2005; Las and Les must upgrade to SCAMPISM to continue providing SEI-Authorized appraisal services

For more information, see the Sunset FAQ at http://www.sei.cmu.edu/cmmi/adoption/sunset-faq.html 
The Future era of "innovating in quality"

We face unprecedented engineering challenges.

Customer demand quality products faster and cheaper.

Management expects higher productivity.

Engineering fields continually evolve and merge.

Organizations are dynamic; there is much more partnering.

Our knowledge and experience must be shared.

The future is now!

$\mathrm{CMMI}$ is our knowledge infrastructure

() 2003 by Carnegie Mellon University

\section{CMMI Is Integration and Improvement}

CMMI supports process integration and product improvement.

CMMI integrates multiple disciplines into one processimprovement framework that eliminates inconsistencies and reduces duplication.

CMMI provides a framework for introducing new disciplines as needs arise and therefore reduces the cost of implementing model-based improvement.

$\mathrm{CMMI}$ is designed to minimize the impact on legacy process improvement efforts and investment. 
CarnegieMellon

Software Engineering Institute

CMMI Models

Source Models

- Capability Maturity Model ${ }^{\circledR}$

for Software V2, draft C

(SW-CMM V2C)

- EIA 731, System

Engineering Capability

Model (SECM)

- Integrated Product

Development Capability

Maturity Model, draft

V0.98 (IPD-CMM)

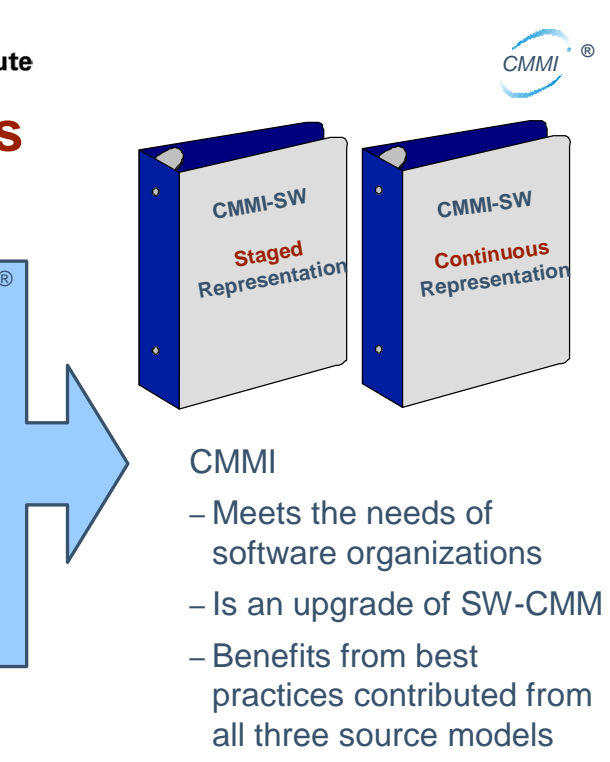

๑) 2003 by Carnegie Mellon University

\section{Improving on the Software CMM}

CMMI Models improve on SW-CMM Version 2.0 Draft C:

- Incorporate additional years of learning

- More explicitly link best practices to business objectives

- Expand the scope of and visibility into the product life cycle and engineering activities

- Add more best practices, (e.g., measurement, risk management, product integration, decision analysis and resolution, and supplier management)

- Capture more robust high-maturity practices

- Address additional generic practices needed for institutionalization

- More fully comply with relevant ISO standards 
CarnegieMellon

Software Engineering Institute

One Model, Two Representations
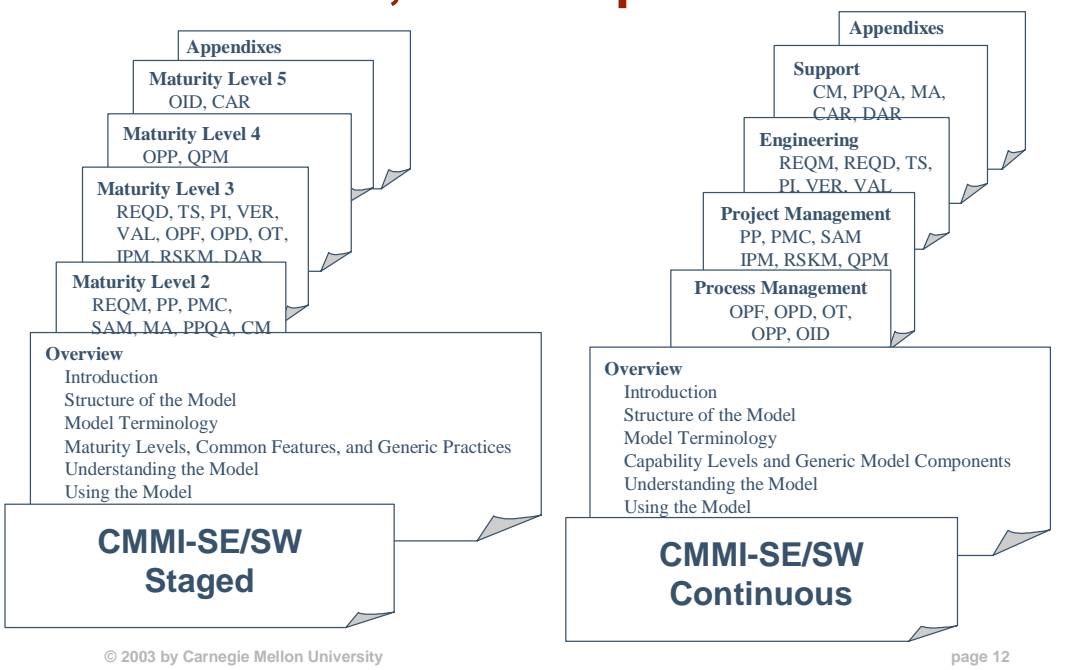

() 2003 by Carnegie Mellon University

CarnegieMellon

Software Engineering Institute

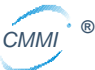

\section{Understanding CMMI Representations}

A representation allows an organization to pursue different improvement objectives and presents model components differently. The content is nearly identical in both representations.

\section{So why both?}

- The representation of each source model was different

- Software CMM-Staged

- SE-CMM, SECM-Continuous

- Ease adoption by legacy communities.

- Both representations provide inherent benefits. 
CarnegieMellon

Software Engineering Institute

Advantages of Each Representation

\begin{tabular}{|l|l|}
\hline Continuous Representation & Staged Representation \\
\hline $\begin{array}{l}\text { Provides maximum flexibility for } \\
\text { order of process improvement }\end{array}$ & $\begin{array}{l}\text { Predefined and proven path with } \\
\text { case study and ROI data }\end{array}$ \\
\hline $\begin{array}{l}\text { High visibility of improvement within } \\
\text { process areas }\end{array}$ & $\begin{array}{l}\text { Focuses on organizational } \\
\text { improvement }\end{array}$ \\
\hline Easy upgrade from EIA 731 & Easy upgrade from SW-CMM \\
\hline Easy comparison to ISO 15504 & $\begin{array}{l}\text { Provides familiar benchmarking } \\
\text { capability }\end{array}$ \\
\hline $\begin{array}{l}\text { Improvement of process areas can } \\
\text { occur at different rates }\end{array}$ & $\begin{array}{l}\text { Overall results summarized in a } \\
\text { maturity level }\end{array}$ \\
\hline
\end{tabular}

\section{CMMI in a Nutshell}

A CMMI model provides a structured view of process improvement across an organization.

CMMI can help

- set process improvement goals and priorities

- provide guidance for quality processes

- provide a yardstick for appraising current practices 
CarnegieMellon

Software Engineering Institute

CMMI Today

Stable Version 1.1 CMMI Product Suite was released January 2002

CMMI models will not change until 2005 at earliest (per CMMI Steering Group direction)

Many defense, aerospace, and commercial organizations are upgrading to $\mathrm{CMMI}$

One appraisal method, SCAMPI, covers

- internal process improvement

- supplier source selection

- contract process monitoring Early Adopters

Currently there are 30+ early adopters.

Are you an early adopter? Send email to $\underline{\mathrm{cmmi}}-$ comments@sei.cmu.edu to be listed.

See Early Adopter list at http://www.sei.cmu.edu/cmmi/a doption/early-adopters.html

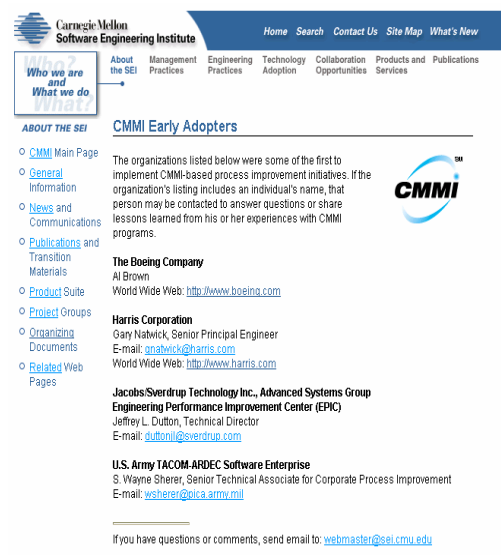

page 17 
CarnegieMellon

Software Engineering Institute

Discoveries in Use

Ease of upgrade to CMMI reported by:

- Multiple SW-CMM level 5 organizations that upgraded and maintained their maturity level

- Multiple organizations that upgraded from EIA 731 systems engineering assessments

- Numerous European companies in group discussion of CMMI adoption at recent SEl-Europe quarterly meeting

Appraisal times reflect excellent learning curves

- Australian group reported $40 \%$ reduction in appraisal time as learning occurred over five appraisals

Mappings and gap analyses confirm evolutionary expansion from predecessor models

- Government and contractors agree on CMMl's improved engineering coverage in contract monitoring

- ISO/CMMI compatibility appears favorable

\section{Where We're Going}

Adoption activities

- Transition Partner data

- Workshops, technical notes, and book publication

- Interpretive Guidance project

Appraisal enhancement activities

- SCAMPI appraisal data

- CMMI appraisals conducted worldwide

- SCAMPI enhancements

Training activities

- CMMI training data

- Training course upgrades 


\section{Adoption-What's Happening Now}

Events related to CMMI adoption:

- Quarterly transition workshops

- Annual NDIA/SEI CMMI User Workshop Interpretive Guidance project

Technical notes and special reports:

- CMMI and Product Line Practices

- CMMI and Earned Value Management

- Interpreting CMMI for Operational Organizations

- Interpreting CMMI for Service Organizations (in progress)

- CMMI Mappings

- Specific interests (e.g., safety, security) Publication of SEI Series Book with Addison-Wesley

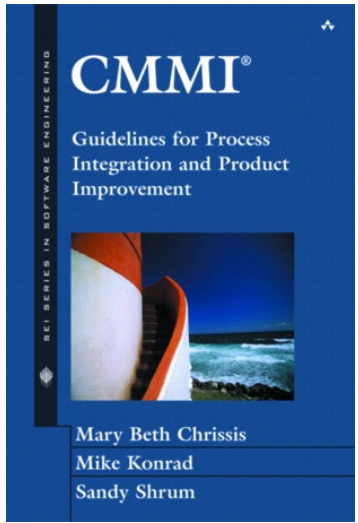

page 20

\section{In Summary}

In today's fast-paced, competitive business environment, approaches used in the past such as "manufacturing in quality" and present, "engineering in quality" are not enough. The future is innovation.

CMMl helps organizations to ...

- Improve delivery of performance, cost, and schedule

- Integrate stakeholders into project activities

- Provide competitive world-class products and services

- Implement an integrated enterprise business and engineering perspective

- Use common, integrated, and improving processes for systems and software

Upgrade to CMMI now... and lead the way to the future of process improvement. 
CarnegieMellon

Software Engineering Institute

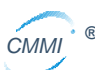

\section{For More Information...}

For more information about CMMI, see http://www.sei.cmu.edu/cmmi/

You can find more presentations like this on the SEI Web site at http://jo.sei.cmu.edu/pub/english.cgi/0/323123.

Or, contact

SEl Customer Relations

Phone: 412 / 268-5800

Email: customer-relations@sei.cmu.edu 


\section{Appendix J: COTS-Based Systems}

John Foreman gave the following PowerPoint presentation on October 27, 2003.

CarnegieMellon

Software Engineering Institute

Pittsburgh, PA 15213-3890

\section{COTS-Based Systems}

Sponsored by the U.S. Department of Defense (C) 2003 by Carnegie Mellon University

\section{Carnegie Mellon}

Software Engineering Institute

\section{COTS: Attraction and Motivation}

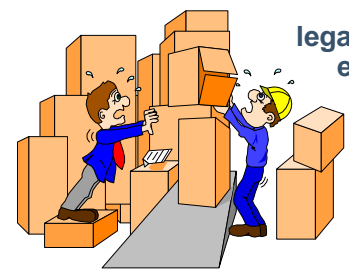

- Clinger Cohen/ITMRA

- Technology insertion
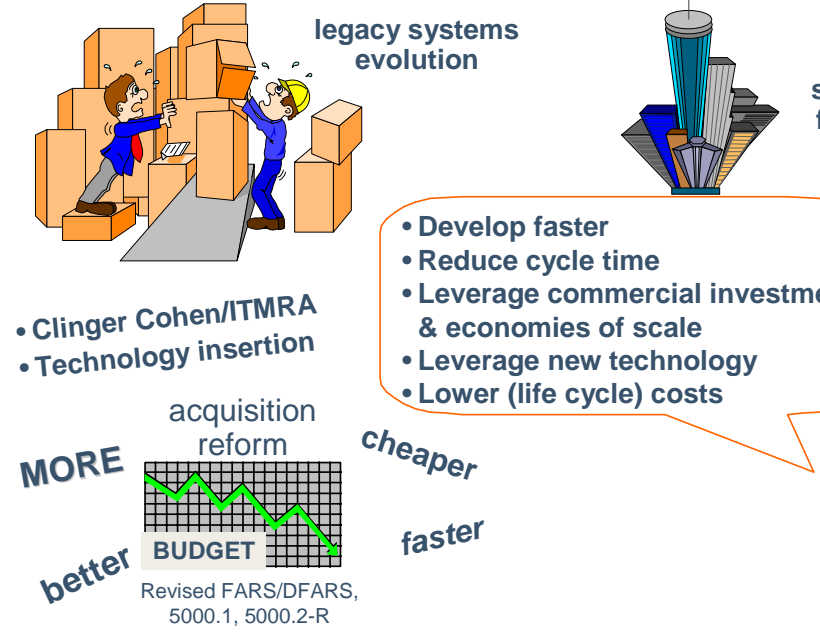

demands

for new

systems and

functionality

- Develop faster

- Reduce cycle time

- Leverage commercial investment

\& economies of scale

- Leverage new technology

- Lower (life cycle) costs

cheaper

faster 


\section{COTS Challenges}
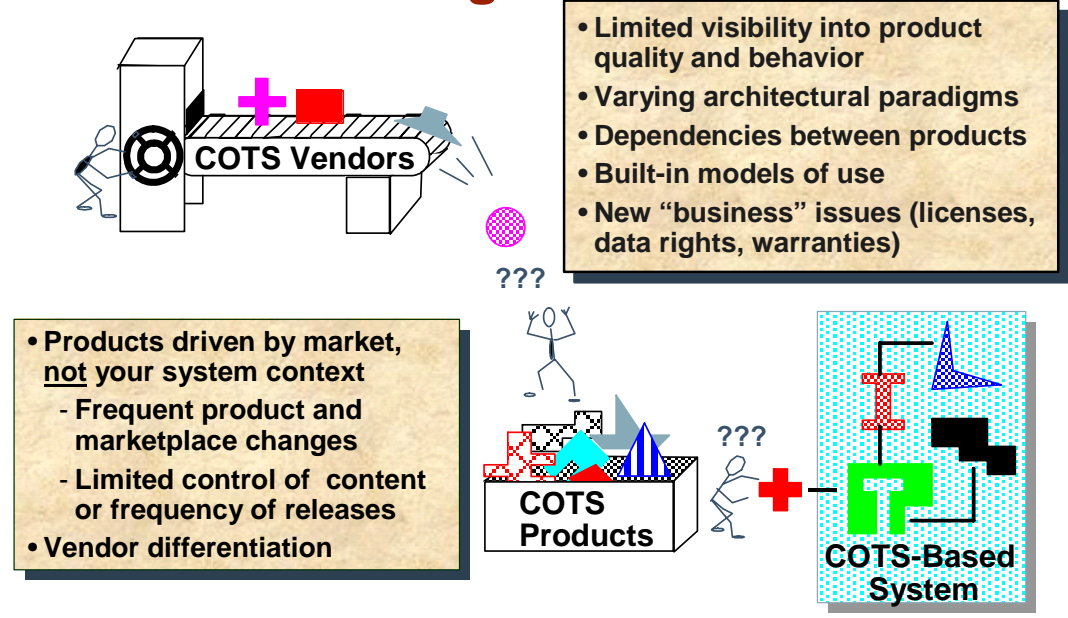

() 2003 by Carnegie Mellon University

CarnegieMellon

Software Engineering Institute

\section{Fundamental Change}

Traditional Approach (Waterfall Development)
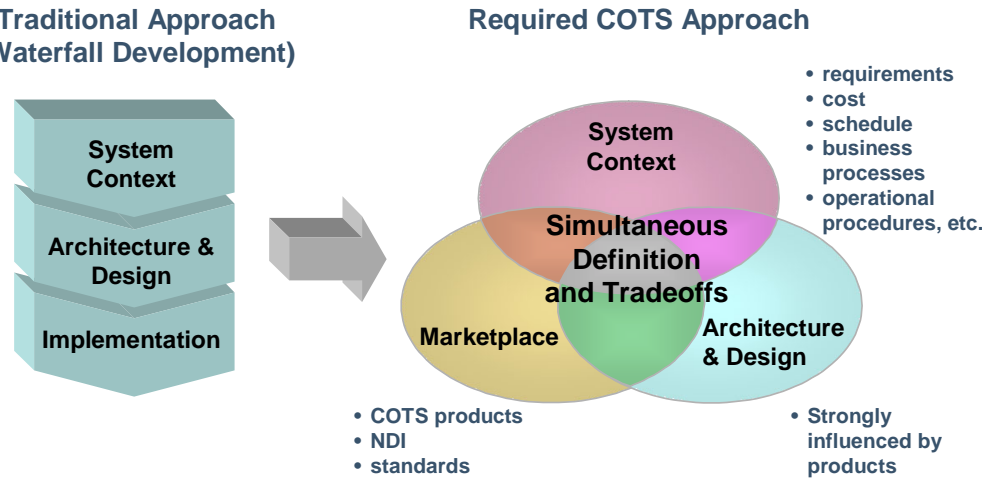

Build from Scratch

Buy, Integrate, Continuously Refresh 
Cyclic Nature of COTS-Based Systems

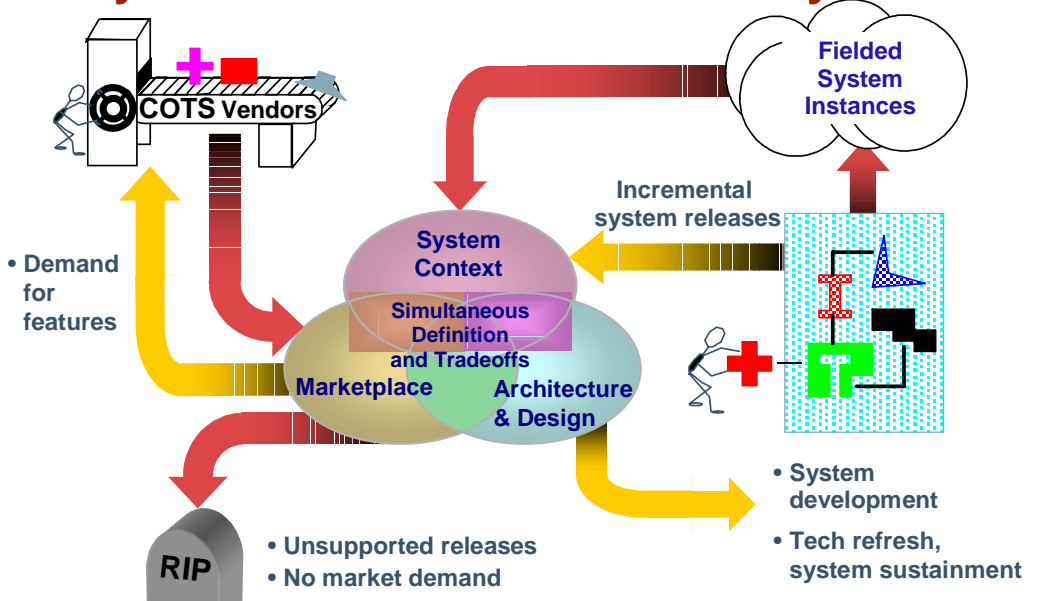

(๑) 2003 by Carnegie Mellon University

CarnegieMellon

Software Engineering Institute

\section{CBS are Radically Different}

\section{Mil Spec}

- Requirements driven

- Spec Focus

- Rigid requirements

- Unique architecture

- Owner controls evolution

- Stable design

- Ignore evolution

- Cost emphasis

- Make custom hardware

- Develop software

- Obsolescence

-Waterfall-style development

\section{COTS}

- Market driven

- Business plan focus

- Flexible requirements

- Open system architecture

- Market controls evolution

- Constant changes

- Design for evolution (tech refresh)

- TOC emphasis

- Buy from catalog

- License software

- Earlier obsolescence

- Spiral development

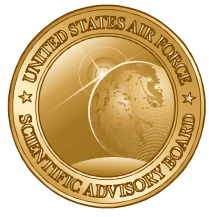

page 6 


\section{CBS Implications for You}

New requirements processes - more flexible

New concerns over existing end-user processes - Acquisition and development processes as well as Business/end user processes must yield to the realities of commercial practice

More use of spiral/iterative/incremental approaches

Different view of system sustainment/CM

New questions about COTS products and reliability/safety, performance/real-time security/survivability

New skill sets required

CarnegieMellon

Software Engineering Institute

\section{CBS Capabilities and Products}

-COTS Product Evaluation Techniques

- Determining the right product in the right context

-Design and Engineering Practices

- Techniques for analysis of alternatives, design, integration, and sustainment

- COTS Based Process Framework

- Develop / Institutionalize new management and development processes to build, field, and support CBS

-Risk Identification and Mitigation - Identify and propose mitigations for common System CBS risks and known failure modes - COTS Usage Risk Evaluation (CURE)

-Information Dissemination - Technical publications, Courses/tutorials

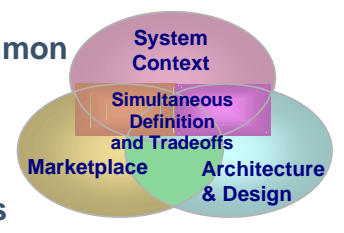




\section{Why is COTS Product Evaluation}

\section{Hard?}

COTS product evaluation is the examination of individual COTS products for the purpose of determining the products' fitness for use in a particular context.

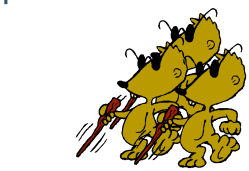

Less than perfect system understanding

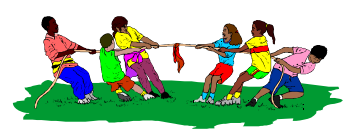

Conflicting interests

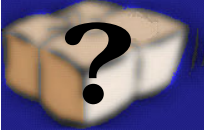

Black box products and vendors

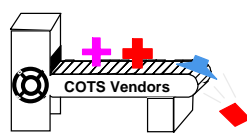

Rapid rate of change of COTS products

CarnegieMellon

Software Engineering Institute

\section{Design and Engineering Practices}

Techniques that facilitate analysis of alternatives, design, integration, sustainment, and evolution of COTS Based Systems:

- Developing "just-in-time" competency

- Component ensemble evaluation that focus on project risk rather than product features

- Capturing, representing and sharing component integration knowledge

- Legacy system modernization 

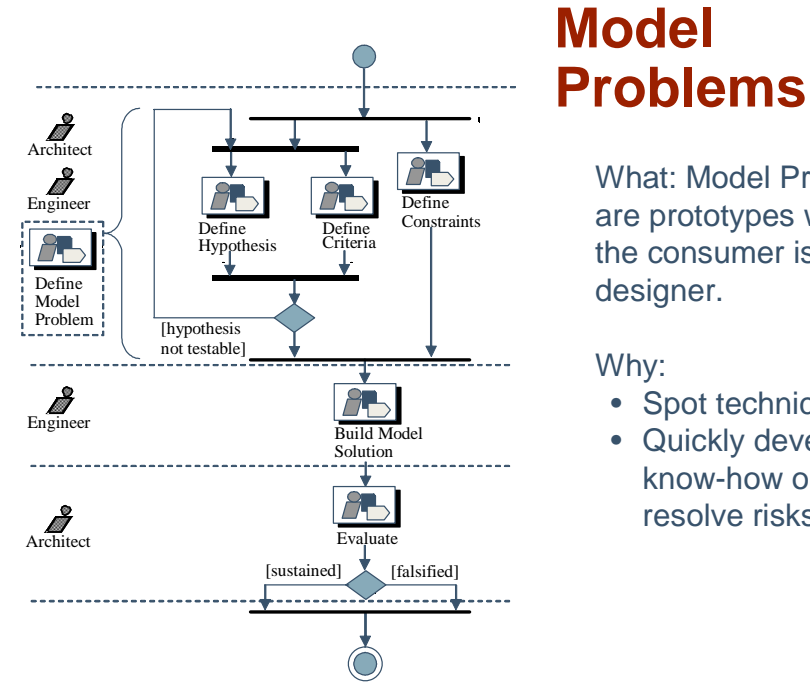

What: Model Problems are prototypes where the consumer is the designer.

Why:

- Spot technical risks

- Quickly develop know-how on how to resolve risks

CarnegieMellon

Software Engineering Institute

\section{Evolutionary Process for Integrating COTS-Based Systems (EPIC)}

EPIC operationalizes software engineering best practice and COTS lessons learned to build, field, and support COTS-based systems

- Negotiation-driven, disciplined, spiral approach

- Objectives, activities, and artifacts at a sufficient level of detail to facilitate needed culture change (using RUP for basic management and engineering processes and artifacts) 


\section{COTS Based Process Framework}

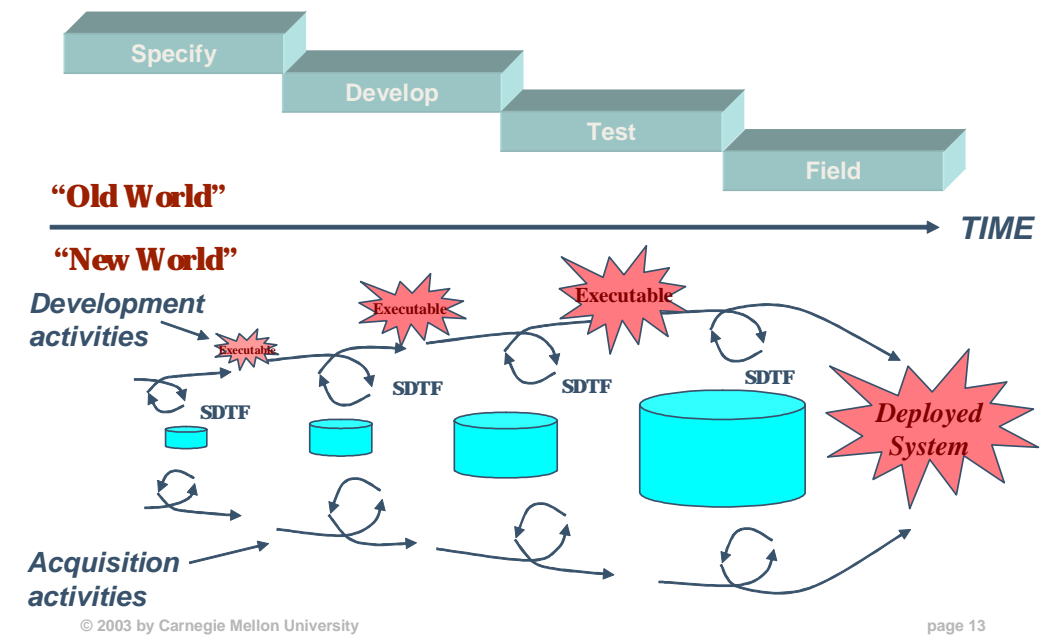

Carnegie Mellon

Software Engineering Institute

\section{EPIC Concepts}

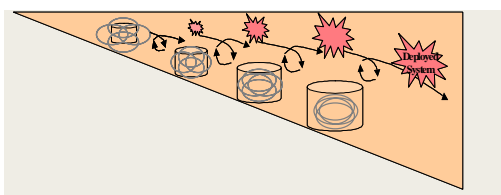

Knowledge grows incrementally

- Risk-based spiral development

- Frequent, evolving executable representations show understanding

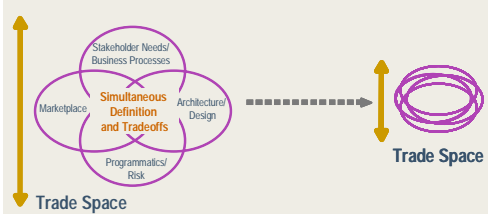

Decisions converge iteratively

- Trades are negotiation-driven

- Requirements formed based on knowledge of market/architecture

- Continuous awareness of changes to end-user business processes

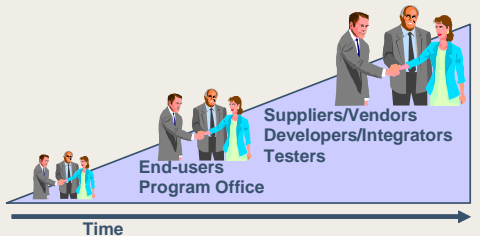

Stakeholder buy-in increases

- Stakeholder needs mature

- Quick resolution to mismatches

- Business processes change to leverage available products

- End users committed to solution 


\section{Phases Bounded by Anchor Points}

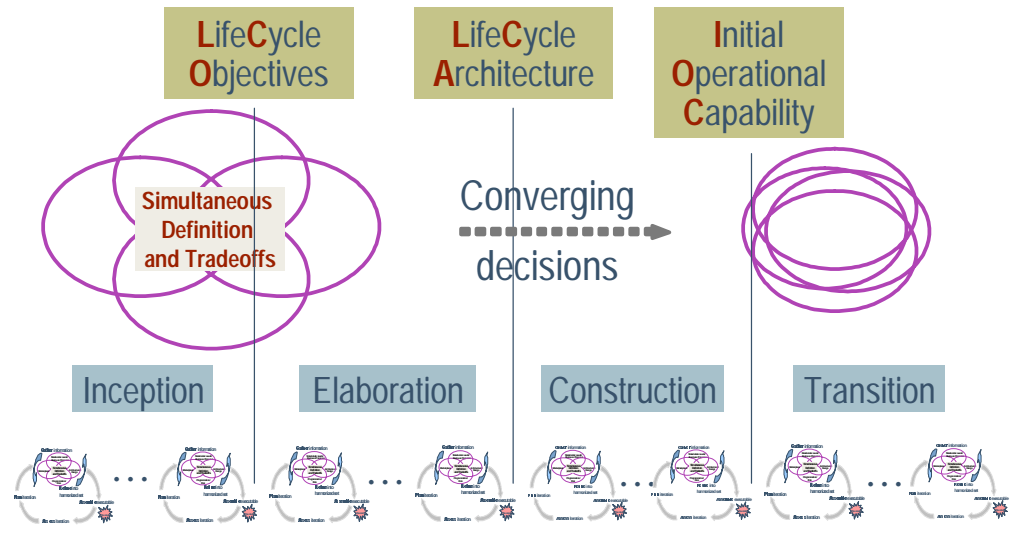

Multiple iterations (Plan, (Gather, Refine), Assemble, Assess) per phase

(ㅇ) 2003 by Carnegie Mellon University

CarnegieMellon

Software Engineering Institute

\section{COTS Usage Risk Evaluation (CURE)}

-What: Early identification of COTS-based risks within a program to raise management awareness

-Who: Focus is comprehensive:

- integrators and developers

- acquirers and managers

- Result: Report on risks and mitigations

- Preferred: out-brief delivered to program management

- Optional: written report
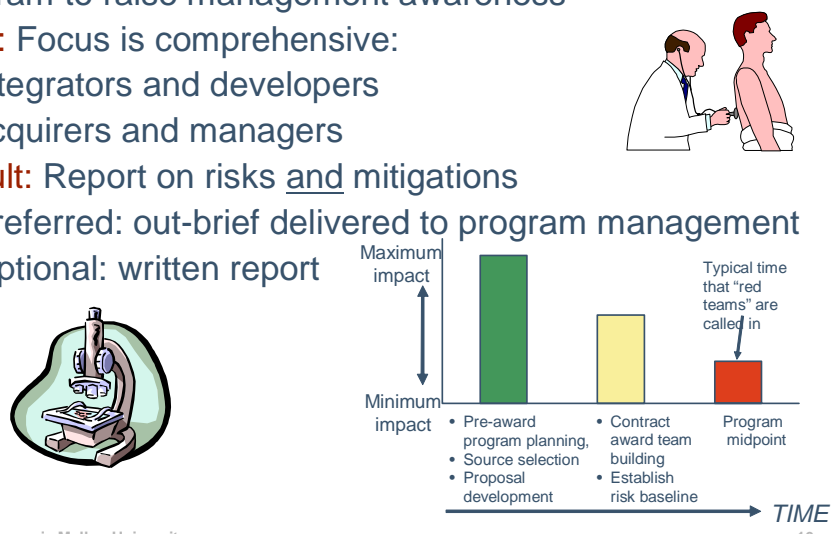


\section{COTS-Based Systems Courses}

\begin{tabular}{|c|c|}
\hline Audience & Offerings \\
\hline $\begin{array}{l}\text { - Executives (govt and industry) } \\
\text { - OSD policy makers } \\
\text { - PEOs, DACs, CIOs, CFOs }\end{array}$ & $\begin{array}{l}\text { - COTS-Based Systems (CBS) for } \\
\text { Executives }(2.5 \mathrm{hrs}) \\
\text { - Open Systems for Executives ( } 4.5 \mathrm{hrs})\end{array}$ \\
\hline $\begin{array}{l}\text { - Program managers (PMs) } \\
\text { - Functional managers } \\
\text { - Financial/budget personnel ... }\end{array}$ & $\begin{array}{l}\text { - CBS for PMs (4-5 hrs) } \\
\text { - CBS for PMs - on CDROM } \\
\text { - CBS for PMs w/ extended } \\
\text { discussion ( } 8 \text { hrs) } \\
\text { - CBS Workshop for PMs ( } 8 \text { hrs) }\end{array}$ \\
\hline $\begin{array}{l}\text { - Technical staff - engineers, } \\
\text { system integrators, proposal } \\
\text { evaluators, contracts personnel }\end{array}$ & $\begin{array}{l}\text { - COTS Product Evaluation (abridged -3 } \\
\text { hours, full - } 2 \text { days) } \\
\text { - Building Systems from Commercial } \\
\text { Components (abridged - } 4 \text { hrs, } 2 \text { Days) } \\
\text { - Modernizing Legacy Systems (8 hrs) } \\
\text { - CBS for Practitioners - } 2 \text { Days }\end{array}$ \\
\hline
\end{tabular}




\section{Appendix K: The Mind Maps}

The mind maps in this appendix were created on October 27, 2003 as outputs from mapping SEI technologies to various SSG strategic objectives. 


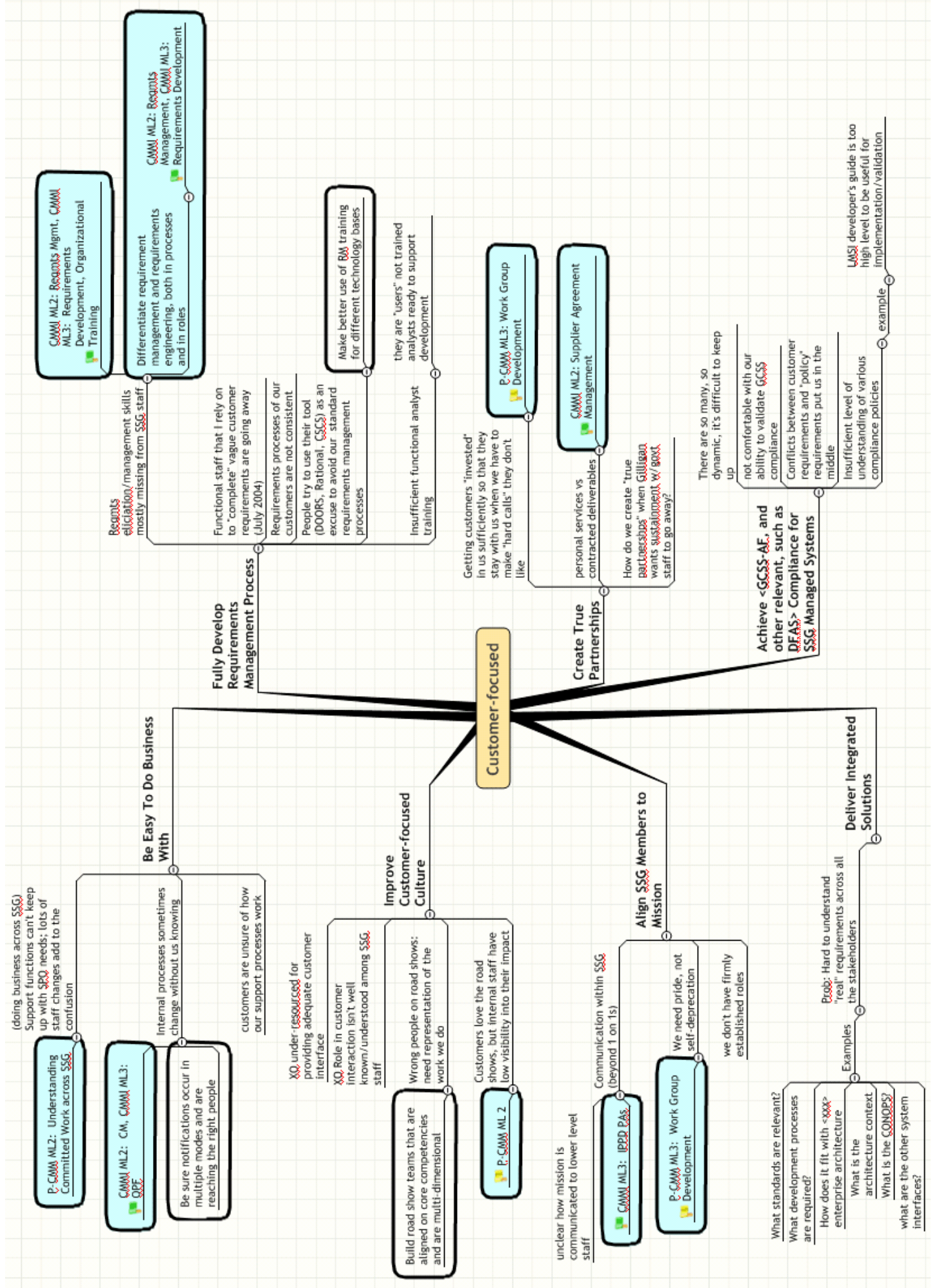

Figure 2: Map of SEI Technologies Against SSG (Cluster Focused on Customer Issues) 


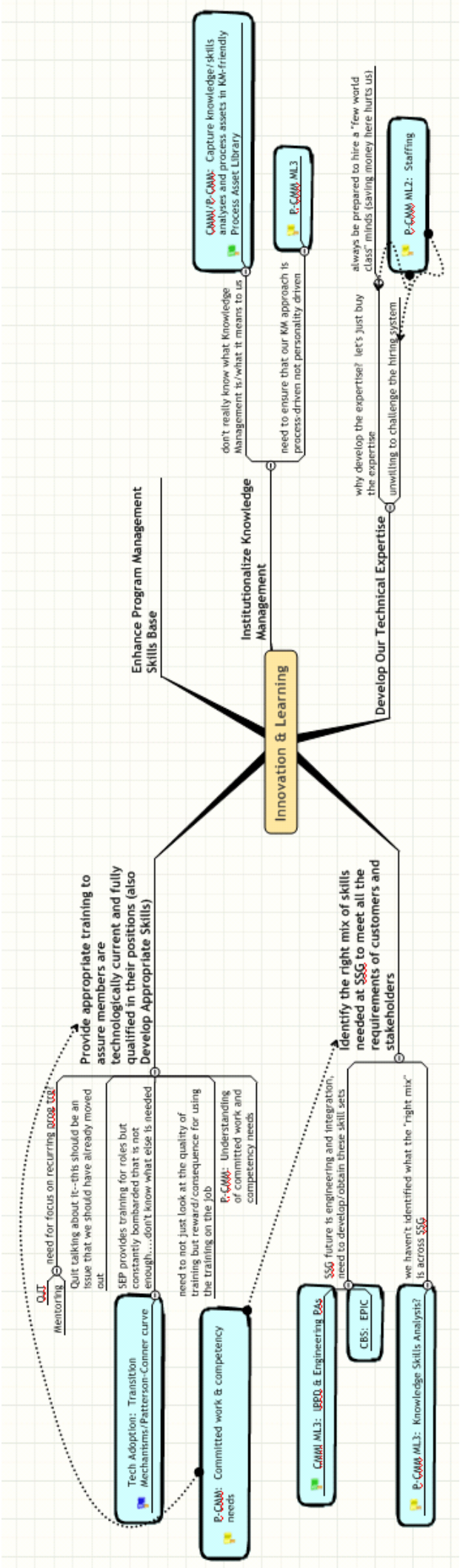

Figure 3: Map of SEI Technologies Against SSG (Cluster Focused on Innovation and Learning Issues) 


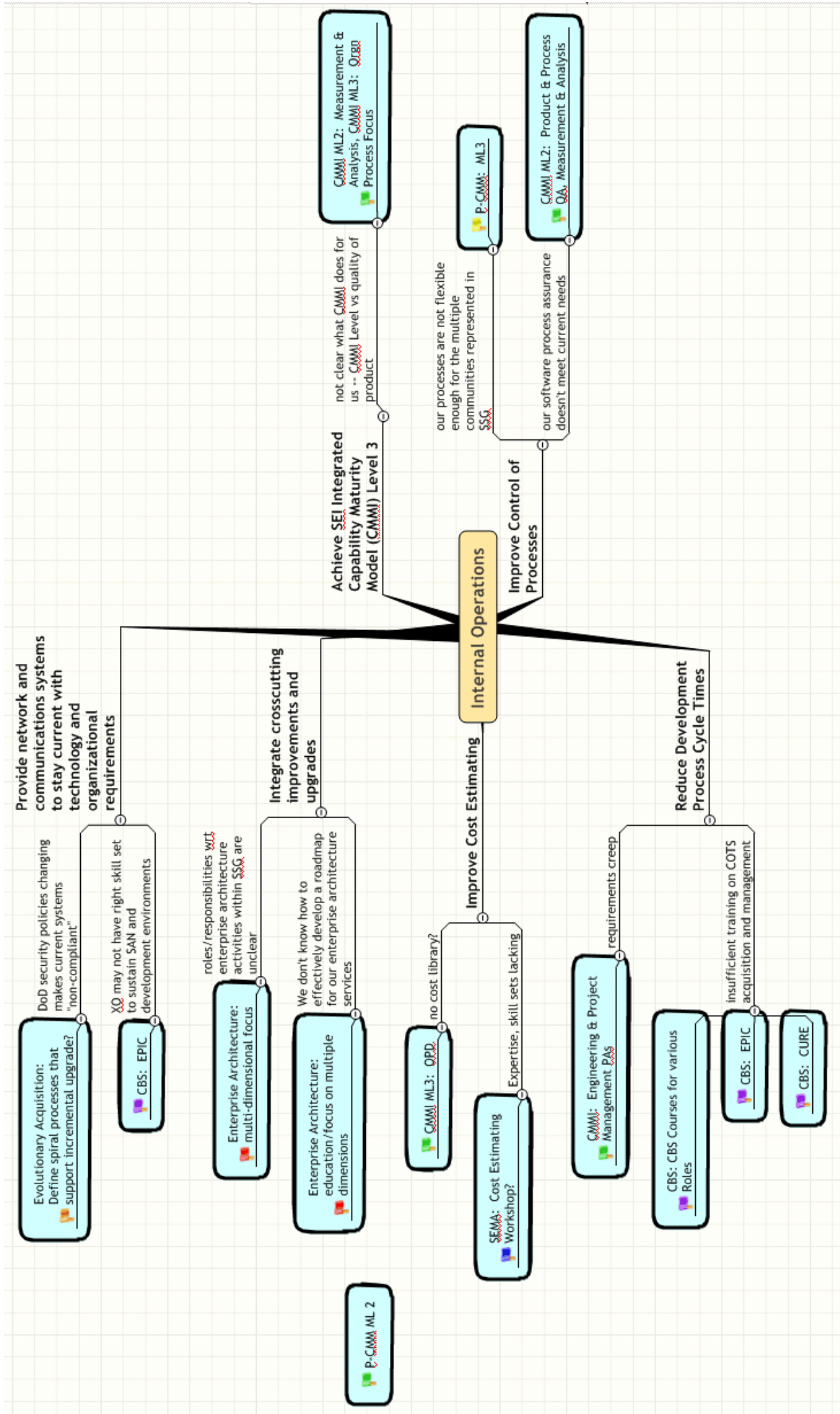

Figure 4: Map of SEI Technologies Against SSG (Cluster Focused on Internal Operations Issues 


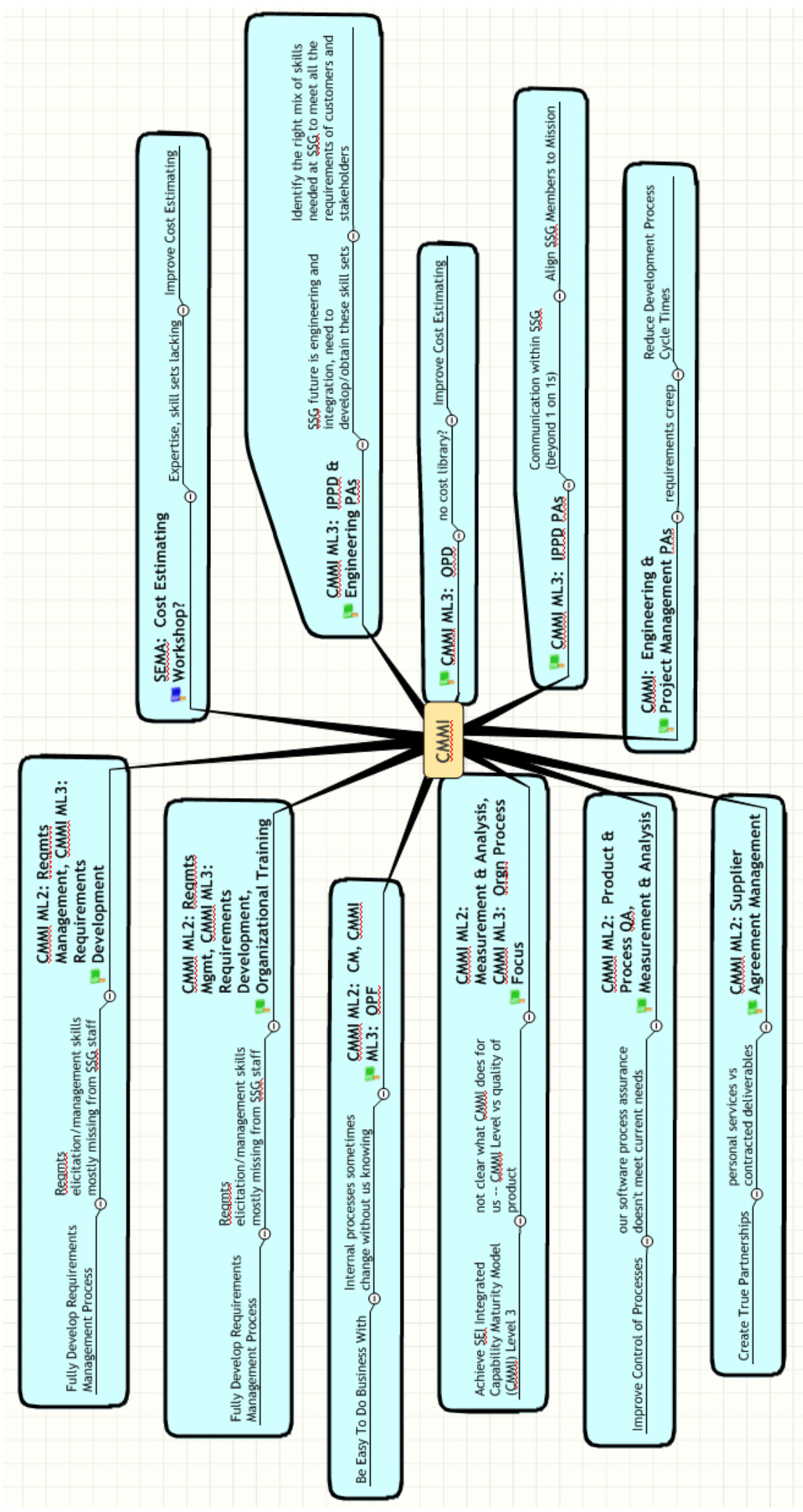

Figure 5: Map of SSG Issues to CMMI Content 


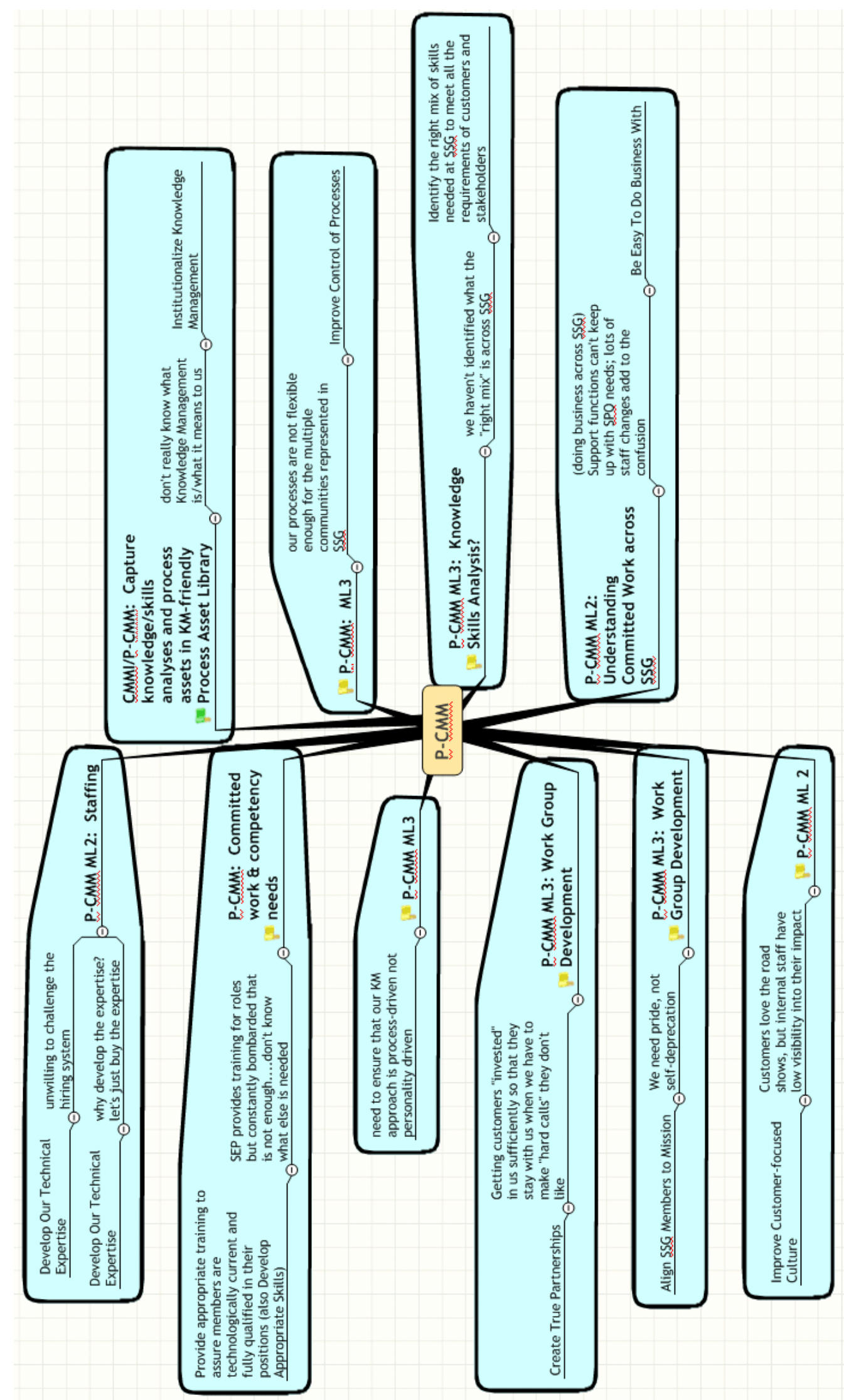

Figure 6: Map of SSG Issues Against P-CMM Content 


\section{Appendix L: COTS-Based Systems Enablers and Barriers}

The list of COTS-Based Systems Enablers and Barriers was created as workshop output on Tuesday, October 28, 2003.

CBS Barriers \& Enablers - Engineering \& Integration

\section{CBS Barriers}

1. Individual skills/skill sets

Erosion of talent when we can't "offload" benched team members

2. Lack of palpable experience, success with integration

3. Current processes/procedures are "engrained" in workforce / unwillingness to change

4. Competing org (MSG) appears to be "better positioned" to do this.

(Not necessarily better equipped.)

5. Undefined, detailed standard configurations for AF.

No one accountable to adopt standards

Insufficient motivation to comply

6. Customers are "finding" and dictating "solutions"

CBS Enablers

SEI can train/mentor on CBS intelligence

1. Change in AF personnel system

Training and workforce reshaping

Shift focus to external sources

2. Partnering with proven winners in industry

Locally fielded solutions

Do "pilot" programs small scale

3. OSD "enterprise integration toolkit"

"First fielding" of 20\% EPIC solution pilots

Decision-makers must control at least some resources 
4. (+1) Use current resident expertise to explore new possibilities and look forward Improve working relationship with HQ AFMC

Hire an ERP advisor to SSG/ED

5. Define what "standards" are - many kinds

Focus on results and capability of STDs

\section{Gap Analysis}

- Gap Analysis: what you have, what is available, what you need

- $\quad$ Staffing

- Communication/coordination

- Work environment

- * Performance management: implementation by managers \& DAG/DP, Pilot = MI

- * Training/development: mapping training to needs (\#'s)

- Compensation 


\section{Appendix M: People Capability Maturity Model Enablers and Barriers}

This outline of enablers and barriers was output of the P-CMM pilot planning session (part of the workshop held on Tuesday, October 28, 2003).

1. Goal:

- $\quad$ processes \& practices for Level 2

- $\quad$ process areas piloted and ready for organizational implementation by $12 / 04$

2. Picture of success:

- SSG workforce mgmt practices support transformation objectives and speed transformation of organization to be Center of Excellence for AF combat support IT

3. Success Criteria:

- Practices implemented by $75 \%$ of 2 -ltr orgs. at SSG

- Customers recognize increased/new capabilities of SSG and select SSG for work

4. Tasks (Next 3 months):

- Gap analysis of SSG workforce practices against P-CMM

- Recommendations for improvement

- Coordination points for Booz-Allen human capital plan

- Implementation plan for P-CMM improvement

5. Tie to Balanced Scorecard:

- Innovation/learning
a. Maintain/add technologically current skills
b. Enhance PM skills base
c. Develop technological expertise
d. ID right mix of skills needed @ SSG 
e. Knowledge mgmt

- Internal ops

a. Communication \& coordination

b. Adequacy \& modernization of infrastructure

- Customer focus

a. Align SSG members to mission

b. Be easy to do business with 


\section{Appendix N: Capability Maturity Model- Integrated Enablers and Barriers}

This outline of enablers and barriers to the success of Configuration Maturity ModelIntegrated was output of the workshop held on Tuesday, October 28, 2003.

\section{CMMI Barriers to Success}

1. Lack of knowledge in writing clear, firm requirements.

2. Responsibility for training? Who 'owns' this?

3. Need independent determination of requirements quality (clear, complete, etc.) prior to design.

4. Lack of commitment to process, contract. Tool does not replace process and training.

5. Unrealistic expectations from customer.

6. No customer or funding for enterprise architecture and integration requirements.

7. Willing to perform at risk and accept unrealistic requirements.

8. Inadequate capture of baseline and senior management tracking of changes (impact of changes on program success).

9. Government and contractor disagreement or misunderstanding of roles and responsibilities.

\section{Enablers of Success}

1. SEP

2. DOORS (and its integration with Mercury Test Director), Rational, Performa.

3. EN for non-functional requirements (e.g.: GCSS, DFAS, sizing, etc.)

4. Staff responsiveness.

5. Combined Test Force (CTF) and the move of testing to requirements phase. 


\section{Pilot Ideas}

1. Develop requirements facilitation function with domain knowledge, contract understanding, and experience. This should be an SSG level, corporate shared resource. (AQ, ST)

2. Identify lead projects and teams from each SPO. (not to exceed 6 months, 3 to 4 projects/teams) . $=>$ Revised REQM process. (IL, FN, ST, AQ)

3. Implement/improve Earned Value Management processes with senior management level tracking of significant deviations $(5 \%),=>$ SEMA. (XP)

4. Restart recurring program review for senior staff that includes functional staff. (XP)

\section{CMMI Pilot Planning Session}

1. Pilot Goal:

- Establish and charter a requirements facilitation team and supporting processes.

- Document requirements management and requirements engineering processes beginning with customer view, covering complete life cycle of requirements. Introduce tools and processes to customer.

- Develop a shared view of the requirements (an educated customer).

2. Deliverables:

- Customer education process.

- Requirements communication plan.

- Requirements management documentation.

- Requirements engineering documentation.

- Capture pilot lessons.

3. Picture of success:

- "Better" requirements documentation and customer has a better understanding of requirements.

- Requirements are "right." 
- Definition of "better" requirements, "right" (According to Customer, According to SSG)

4. Success Criteria:

- No DRs tied to requirements (based upon root cause analysis of the DR).

- Positive CSAR (Customer Satisfaction Assessment Report).

5. Next 3 months:

- Gap analysis discussion.

- Form IPT (SSG, Customer, SEI).

- Develop charter template.

6. Tie to Balance Scorecard:

- Customer Focus: Easy to do business with (customer satisfaction).

- Center of choice (cheaper).

7. LOE Estimate for next 3 months, each member of IPT:

- 25 FTE for pilot project, gap analysis.

Notes:

IPT Members:

- Contracting/AQ

- $\mathrm{FM}$

- FN (program manager) - system view of requirements

- SEPG

- $\mathrm{EN}$ (non functional requirements)

- ST (software requirements)/IL (COTS) 
- Customer/functional representation (DFAS)

- $\mathrm{XP}$ (tools)

- SEI

The process must be iterative, tied to spiral development and release processes.

Leverage the current SEP, tools, meetings, historical data. 